\title{
Pharmacochemical Aspects of the Evolution from Erythromycin to Neomacrolides, Ketolides and Neoketolides
}

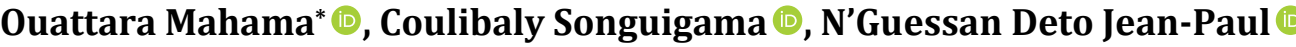 \\ Department of Therapeutic Chemistry and Organic Chemistry, UFR Pharmaceutical and Biological Sciences, FHB University, \\ Abidjan, Côte d'Ivoire \\ Email: *mahama.ouattara@univ-fhb.edu.ci
}

How to cite this paper: Mahama, O., Songuigama, C. and Jean-Paul, N.D. (2020) Pharmacochemical Aspects of the Evolution from Erythromycin to Neomacrolides, Ketolides and Neoketolides. Open Journal of Medicinal Chemistry, 10, 57-112. https://doi.org/10.4236/ojmc.2020.103005

Received: June 24, 2020

Accepted: August 2, 2020

Published: August 5, 2020

Copyright (c) 2020 by author(s) and Scientific Research Publishing Inc. This work is licensed under the Creative Commons Attribution International License (CC BY 4.0).

http://creativecommons.org/licenses/by/4.0/

\begin{abstract}
Antibiotic macrolides are experiencing renewed interest in anti-infective therapy since the advent of ketolides. This therapeutic class was introduced in order to broaden the narrow antibacterial spectrum of macrolides and to cope with the emergence of germs resistant to Erythromycin A and its hemisynthetic derivatives or neomacrolides (Clarithromycin, Roxithromycin, Azithromycin, Dirithromycin). From a pharmacochemical point of view, ketolides were first of all obtained by operating chemical modulations on Erythromycin A to obtain the neomacrolides, then, by replacing the neutral sugar ( $L$-cladinose) in $C 3$ by a ketone function coupled with the creation of an oxazolidinone like heterocycle in $C 11$ and $C 12$ in place of the hydroxyls present in these positions (Telithromycin, Cethromycin, Solithromycin). These modulations have enabled the improvement of the chemical stability of ketolides in gastric acid medium and increase their affinity for the ribosomal target, hence the broadening of their spectrum of action towards Gram positive germs including strains resistant to other macrolides and to neomacrolides. Therefore, the objective of this systematic review is to report the various pharmacochemical aspects undertaken since 1952 in the macrolide series based on the structure of Erythromycin A. These aspects will focus on the pharmacomodulations that have led, year after year, to the optimization of stability, the improvement of the pharmacodynamic and pharmacokinetic profile and that have allowed the development of neomacrolides, ketolides and neoketolides, which are today essential in the management of severe bronchopulmonary infections.
\end{abstract}

\section{Keywords}

Pharmacochemistry, Erythromycin, Neomacrolide, Ketolide, Neoketolide, Structure-Activity Relationships 


\section{Introduction}

The history of antibiotic macrolides began in 1952 with the discovery of Erythromycin, which has been shown to be active on penicillinase-producing strains of Staphylococcus aureus [1] [2] [3] [4]. This discovery improved the therapeutic management of staphylococcal infections. However, Erythromycin very quickly presented drawbacks of use such as its degradation in gastric acid medium which leads to its digestive intolerance, its low oral bioavailability and its pronounced bitter taste making it difficult to formulate paediatric forms [1] [2] [5] [6]. These various drawbacks led to a decline in the use of Erythromycin until the advent of the legionellosis epidemic in 1980 [1]. Indeed, Erythromycin has shown better efficacy on the germ responsible for this infection compared to the antibiotic beta-lactams. The renewed interest in erythromycin has led to pharmacomodulation studies around its structure in order to overcome its drawbacks of use [1] [6]. These studies have led to the development of hemisynthesis macrolides or neomacrolides such as Clarithromycin, Roxithromycin, Dirithromycin and Azithromycin which have shown better stability in leaving gastric acid medium, better oral bioavailability or even widening of the antibacterial action spectrum. Thus, the advent of neomacrolides has made macrolides one of the effective antibiotics both in the hospital and in outpatients. Moreover, they are reputed to have non-antibacterial activities, in particular immunomodulatory and anti-inflammatory properties [7] [8]. Such properties are used in particular in the symptomatic treatment of pain caused by inflammatory cytokines released at the sites of infection [7] [8]. However, in the fight against emergence of new resistant bacterial strains [2] [9] [10], Erythromycin A and neomacrolides have proved to be ineffective. In this perspective, pharmacochemical research aimed at obtaining new and more effective macrolides has been continuously carried out and has led to the development of new analogues of erythromycin.

The first modulations consisted in introducing on the structure of Erythromycin analogues in particular of tyrosine in the form of side links of the alkyl-aryl like to imitate the carbohydrate chain of macrolides with 16-membered ring. The second modulations, which are more important and which we will focus on, have led to new macrolides: the class of antibiotic ketolides. The unique and complex structural characteristics, the conformational flexibility and the stereochemical complexity of the lactonic macrocycle of macrolides offer multiple possibilities of structural variation for rational pharmacochemical approaches [11] [12] [13].

The objective of this literature review is to retrace the various pharmacochemical aspects undertaken around the chemical scaffold of Erythromycin A which have led to neomacrolides and then ketolides. Specifically, it will highlight the various structural elements responsible for the activities and limits of use of Erythromycin A, as well as the various chemical modifications undertaken to overcome these limits. The impact of each chemical modulation on digestive tolerance, pharmacodynamic profile, and pharmacokinetic parameters and on the 
spectrum of antibacterial action will be discussed in this review from the perspective of the pharmacochemist.

\section{Erythromycin}

\subsection{General Information}

Erythromycin is a naturally occurring antibiotic obtained by extraction from the fermentation of bacteria of the genus Streptomyces erythreus, currently reclassified as Saccharopolyspora erythraea [1] [2] [3]. It is a mixture of several co-metabolites (A, B, C, D) of which the derivative A, largely predominant (Figure 1), constitutes the primary final product of biosynthesis, while its analogues $\mathrm{D}, \mathrm{C}$ and $\mathrm{B}$, in minor quantities can be considered as bioactive synthetic intermediates from which Erythromycin A is obtained [14]. This would explain the fact that Erythromycin A is the most widespread and most used product in therapy. It is the leader in antibiotic macrolides. From the point of view of its chemical constitution, it has in its structure a 14-membered ring macrocycle called erythronolide, carrying a neutral sugar in position 3 ( $L$-cladinose) and an amino sugar in position 5 ( $D$-desosamine). To this, we identify in position 9 a ketone function and the presence on the lactone macrocycle of an ethyl group, of several methyl groups and of alcohol functions (Figure 1) [1] [2] [5] [6] [9] [15].

Furthermore, X-ray crystallographic and nuclear magnetic resonance studies of Erythromycin A have shown that the polar hydroxyl groups are on one side of the molecule while the other side is made up of aliphatic groups. This exact configuration would favour the crossing of the bacterial wall and the attachment of Erythromycin to its biological target, in this case the bacterial ribosome [2]. Indeed, several studies have shown that erythronolide would mainly adopt in solution, a deployed conformation called "folded-out" very similar in the crystal structure of many macrolides [16] [17] [18]. This conformation of the lactonic macrocycle would be relatively stable. However, a certain conformational flexibility of the whole molecule has been demonstrated with a free rotation of the sugars $L$-cladinose and $D$-desosamine as well as the other substituents around the erythronolide. These conformational specificities are thought to be at the origin

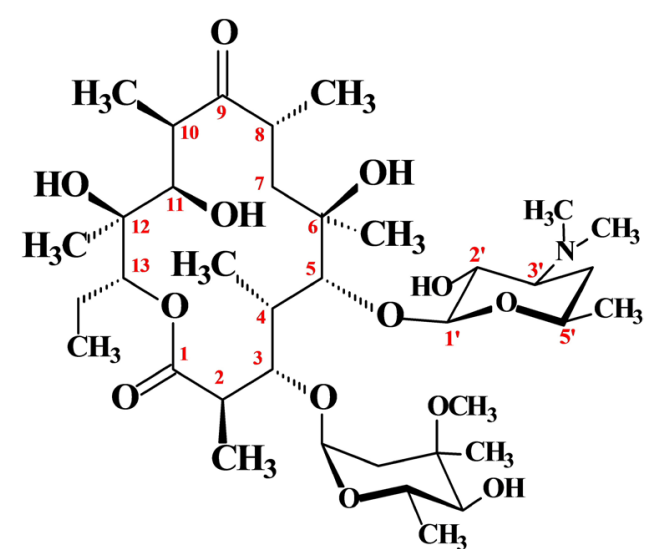

Figure 1. Chemical structure of Erythromycin A. 
of the interactions of Erythromycin with the bacterial ribosomal target but also of the major undesirable effects observed [16] [17] [18].

Erythromycin deploys its antibacterial activity by inhibiting protein synthesis by binding to the $50 \mathrm{~s}$ subunit of the bacterial ribosome. The Erythromycin binding site is at the entrance to the peptide release tunnel, near the base of the cavity that contains the peptidyl transferase center where its synthesis took place. Such tunnel consists of the domains I to V of the $23 \mathrm{~S}$ RNA, of the globular parts of the proteins L22 and L4 and of the $\beta$ chain of L22. The major Erythromycin binding site is located between the central loop of domain $\mathrm{V}$ associated with the peptidyl transferase center and the loop 35 of domain II which are very close in spatial configuration [19] [20]. As for the resistance acquired to macrolides, it would manifest itself according to three mechanisms: modification of the target, inactivation of the antibiotic and resistance by efflux of the antibiotic. Resistance by modification of the target is due to methylation of adenine in the 23S RNA of the 50S ribosomal subunit [21]-[28]. The bacterial resistance by efflux of the antibiotic constitutes the most frequent mechanism at the origin of the induction of cross resistance to 14 and 15-membered ring macrolides. Efflux resistance is based on the acquisition of mef (A) genes carried by a transposon and of plasmid msr (A) genes [19]-[28].

\subsection{Limits of Use of Erythromycin A}

Erythromycin A is responsible for numerous undesirable effects which are more or less closely correlated with its conformational structure and its physicochemical properties. In addition, it has many limits of use, namely its bitter taste and its insolubility in water, making paediatric preparations difficult [1] [6] [14] [29] [30]. Erythromycin A also has a relatively narrow spectrum of antibacterial action, oriented mainly towards Gram-positive organisms and a short half-life requiring repeated administration leading to poor adherence to treatment [1] [6]. In addition, Erythromycin is responsible for digestive intolerance because of its instability in gastric acid medium. This gastric instability would lead to the formation of two degradation products, in particular a hemiketal (8,9-anhydro-erythromycin 6,9-hemiketal) and a spiroketal (anhydroerythromycin 6,9; 9,12-spiroketal) which are bacteriologically inactive. These products are formed following an acetalization reaction in an acid medium between the ketone function in position $C 9$ and the hydroxyl groups in $C 6$ and $C 12$ of Erythromycin A. The reaction would also be favoured thanks to the participation of hydrogen in position $C 8$ of Erythromycin A. The cyclization of Erythromycin into a 9,12-spiroketal derivative would be favoured in aqueous solution by the adoption by the molecule of a conformation in which the hydrogen in position $C 11$ would approach the hydrogens of the methyl group in position $C 12$ of the erythronolide [16] [17] [29] [30] [31]. The hemiketal derivative would interfere with the receptors for the motilin (intestinal hormone) that cause digestive disorders in Erythromycin [30] [31]. 
Another factor limiting the use of Erythromycin is its potent inhibition of cytochrome P450. This inhibition occurs as a result of an enzyme interaction between the erythromycin desosamine and cytochrome P450. This would express by a decrease in the metabolism of the associated drugs, thus leading to a risk of increased drug toxicity [32] [33] [34]. In order to remedy the factors limiting the use of Erythromycin A, structure-activity relationship studies (SAR) have been undertaken. These enable to identify the structural elements essential for maintaining antibacterial activity as well as the sites of inactivation, therefore those that can be modulated to obtain more effective Erythromycin A derivatives.

\subsection{Study of Structure-Activity Relationships}

SAR studies undertaken around Erythromycin have identified the functional elements essential for maintaining antibacterial activity (Figure 2). Thus, the integrity of the lactonic macrocycle is essential for the appearance of activity. As well as the presence of the methyl groups in position 4, 6, 8 and 12 in their alpha conformation as well as the methyl groups in position 2 and 10 in their beta conformation. The hydroxyl groups in position $6,11,12$ in their beta conformation have also proved to be essential for antibacterial activity. Furthermore, these SAR studies have shown that the removal of desosamine in position $C 5$ would cause a total loss of activity, unlike $L$-cladinose which would have no impact on the induction of antibacterial activity. In addition, the presence of ethyl in its alpha conformation would be essential for protection against the opening of the cyclic ester function, thus maintaining the integrity of the aglycone [35] [36] [37] [38]. The various SAR studies have also enabled to identify the structural elements which constitute the inactivation sites (weak region) of Erythromycin A. These inactivation sites thus offer a formidable opportunity for their pharmacomodulation to obtain effective congeners of Erythromycin A. It is the ketone function in position $C 9$, hydroxyl groups in $C 6$ and $C 12$ and hydrogen in position $C 8$ in its beta conformation. These entities are responsible for the acetalization reaction which leads to the hemiketal and spiroketal derivatives

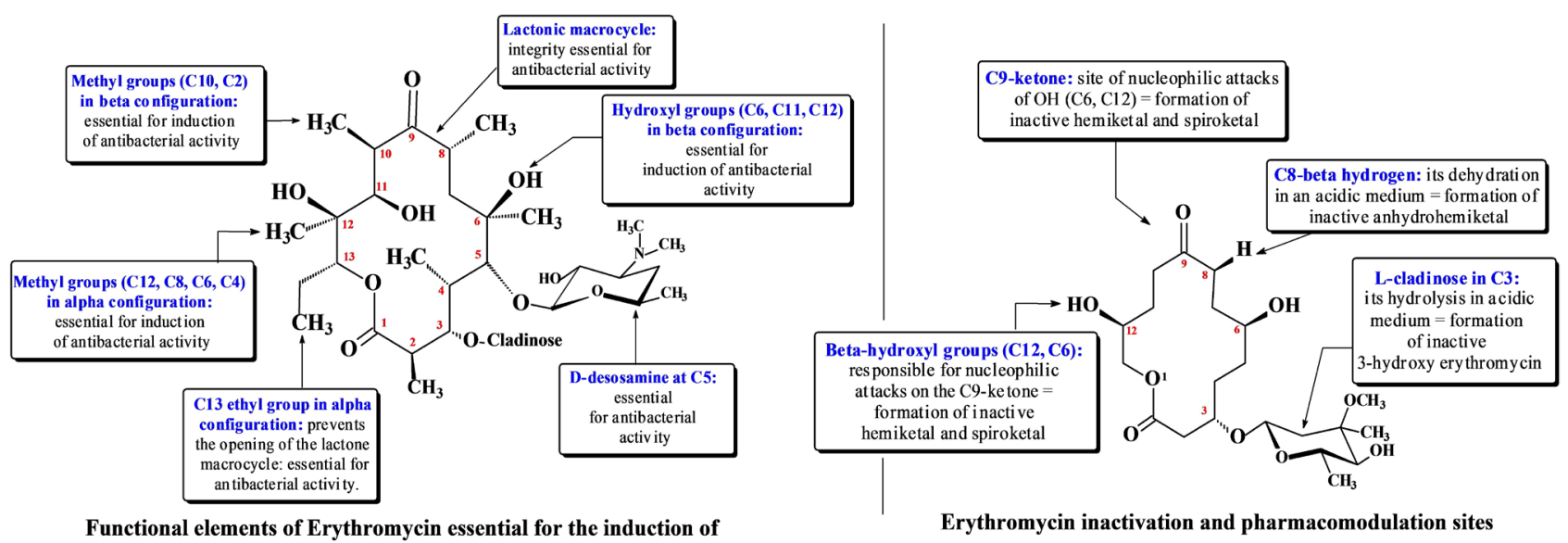

Figure 2. Structure-activity relationships in structure of Erythromycin A. 
responsible for the digestive intolerance of Erythromycin A (Figure 2). Another weak point of Erythromycin A is the presence of $L$-cladinose in position 3. Indeed, in gastric acid medium, the hydrolysis of the latter occurs to form an inactive 3-hydroxy erythromycin A derivative; which would inevitably favour the appearance of drug-resistant germs (Figure 2) [29]-[32].

\section{Pharmacochemical Evolution of Erythromycin A to Neomacrolides}

In order to obtain more effective hemisynthesis derivatives or neomacrolides of Erythromycin A, various chemical variations were made at its pharmacomodulable sites. These include chemical variations at the sites carried by carbons $C 3$, $C 6, C 8, C 9, C 11$ and $C 12$.

These different pharmacomodulations have led to neomacrolides having higher pharmacokinetic performance, better digestive tolerance and/or a broader antibacterial spectrum compared to Erythromycin A [39]-[41]. The neomacrolides are classified according to the size of the 14- or 15-membered rings macrocycle. Thus the 14-membered ring derivatives are composed of Clarithromycin, Roxithromycin, Erythromycylamine, Dirithromycin and Flurithromycin. Only one 15-membered neomacrolide is currently used in therapy, it is Azithromycin. The different pharmacomodulations undertaken around the chemical structure of Erythromycin A can be summarized in one esterification and salification, chemical modulation of the $C 6$ hydroxyl function, halogenation of $C 8$ and chemical modulation of the ketone function in $C 9$.

\subsection{Esterification and Salification of Erythromycin A}

In order to mask the bitter taste of Erythromycin A, the hydroxyl in position $C 2$ 'of $D$-desosamine (Figure 3 ) has been esterified [42] [43]. The Erythromycin esters obtained have shown better stability in an acid medium, but still require repeated administration [42] [43] [44] [45]. Indeed, pharmacokinetic evaluations of Erythromycin stearate and Erythromycin ethyl succinate administered orally have shown that their absorption is influenced by meals [46]. In addition, stearate, ethyl succinate, estolate, propionate and acistrate of Erythromycin A
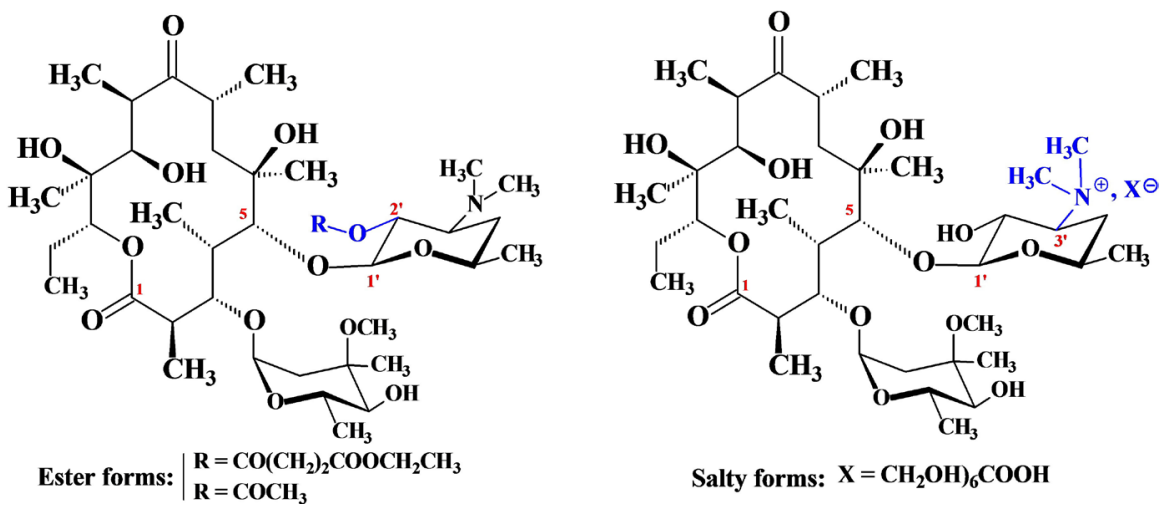

Figure 3. Esters and salty forms of Erythromycin A. 
have enabled preparing intramuscular injectable forms (Figure 3) [46] [47]. In order to obtain formulations for intravenous use, various salts of Erythromycin A have been prepared. The salification concerned the dimethylamine group at $C 3$ 'of $D$-desosamine. The salts for therapeutic use obtained were in particular salts of glucoheptonate and (Figure 3) [48] [49]. A stoichiometric mixture of Erythromycin base with one of these salts is able to obtain an intravenous formulation. However, these salts have the drawback of having inconsistent pharmacokinetics and of causing venous irritations like the phlebitis [46] [47].

\subsection{Chemicals Modulations at $C 6$ and C8: Clarithromycin and Flurithromycin}

The hydroxyl at $C 6$ involved in gastric acid medium in the hemi acetalization reaction with the ketone function at $C 9$, was blocked by $O$-methylation thus leading to O6-methyl erythromycin A or Clarithromycin (Figure 4) [50] [51] [52] [53]. This new molecule has shown an activity greater than or equal to that of Erythromycin A against respiratory pathogens with an increased antibacterial activity against Haemophilus influenzae, due to its active metabolite 14-hydroxyclarithromycin which acts in synergy with the parent molecule [54] [55] [56]. In addition, Clarithromycin is more stable in an acid environment and therefore has fewer gastrointestinal side effects [51]-[56]. However, the presence of hydroxyl at position $C 12$ and the ketone function at position $C 9$ lead to a degradation of Clarithromycin in an acid medium, to pseudo-Clarithromycin which is inactive [54] [55] [56]. The hydrogen at $\beta$ at the $C 8$ position involved in the degradation of Erythromycin A in gastric acid medium has been replaced by a halogen atom, in this case fluorine. This fluorine atom minimizes the metabolism of the molecule [50] [57] [58]. This strategy made it possible to obtain Flurithromycin (Figure 4). Flurithromycin has the advantage of being more stable in an acid environment. Indeed, the dehydration in $C 8$ of Erythromycin A in anhydrohemiketal is prevented by the addition of the fluorine atom. Thus, the enolization of the ketone in $C 9$ is annihilated. This improved stability is characterized by a prolonged half-life time at the origin of its once-daily administration. Flurithromycin exhibited two to four times the antibacterial activity of

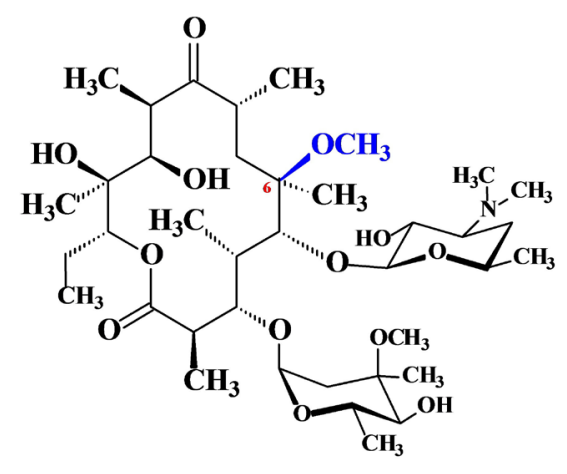

Clarithromycin

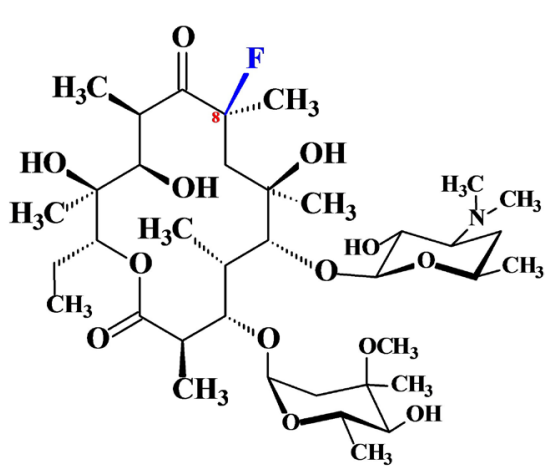

Flurithromycin

Figure 4. Chemicals structures of $C 6$ - and C8-modified neomacrolides. 
Erythromycin A due to its inhibitory effects on the formation of the bacterial ribosome 30 S subunit [59] [60] [61].

\subsection{Chemical Modulation of the Ketone Function in $C 9$}

In order to prevent the formation of the inactive 6,9-hemiketal, and therefore to compensate for the degradation in gastric acid medium of Erythromycin A, its ketone function at $C 9$ has previously been transformed into an $\mathrm{N}$-9-oxime derivative. The latter, serving as a synthesis intermediary, subsequently underwent several chemical variations. This chemical variation at $C 9$ ketone has led to the development of Roxithromycin, Clarithromycin, Erythromycylamine, Dirithromycin and Azithromycin.

The first was an $O$-alkylation reaction of the hydroxyl of the oxime function, thus leading to the production of ether oximes including Roxithromycin, the first hemisynthetic macrolide (Figure 5) [62] [63]. Roxithromycin has better stability in an acid environment and good digestive absorption, hence an increase in its bioavailability by oral route ranging from $72 \%$ to $85 \%$ [64] [65]. In addition, Roxithromycin has a weaker binding to cytochrome P450 associated with an exaltation of the elimination half-life time of the order of 12 hours, resulting in twice-daily administration. On the other hand, its spectrum of antibacterial activity remains equivalent to that of Erythromycin A [66] [67] [68].

The second reaction undertaken on the $N$-9-oxime derivative of Erythromycin A was its reduction to an amine function. This modulation made it possible to obtain Erythromycylamine, which is very active on bacterial germs (Figure 5). Unfortunately, this $N$-9-amine from Erythromycin A has the major drawback of being poorly absorbed orally due to the presence of the protonable amine function, which is therefore difficult to cross the digestive membranes [35] [69] [70]. To improve membrane crossings, Erythromycylamine underwent heterocyclization through its amine functions at $C$, hydroxyl at $C 11$ and under the action of an acetaldehyde. Such heterocyclization led to the formation of a bicycle of Erythromycin A or 1,3-oxazinane of Erythromycin A also called Dirithromycin (Figure 5). Dirithromycin is actually a prodrug, because in an acidic environment, it rapidly transforms into Erythromycylamine [71] [72] [73]. It appears to have a good tissue concentration after oral administration, a low potential for interaction with cytochrome P450 [74] [75], a large volume of distribution (11 - $100 \mathrm{~L} / \mathrm{kg})$ and a half-life of high elimination (20 - 50 hours), resulting in once-daily administrations. However, the antibacterial activity spectrum of Dirithromycin in vitro is similar to that of Erythromycin A with low oral bioavailability (10\%) [74] [75].

The latest reaction to the $N$-9-oxime derivative of Erythromycin A was that of the Beckmann rearrangement. It led to the enlargement of the lactonic macrocycle from 14-membered ring to a new macrocycle with 15-membered ring following the introduction of a nitrogen atom which undergoes methylation in the end. These are the Azalides, the leader of which is Azithromycin (Figure 5) [76] [77]. 


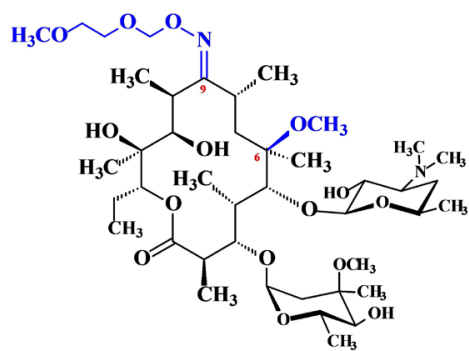

Roxithromycin

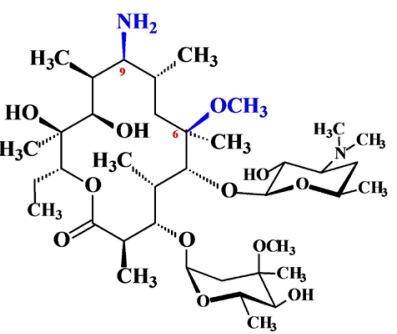

Erythromycylamine

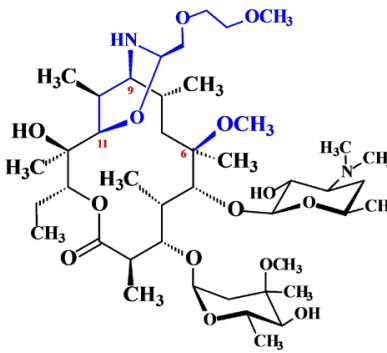

Dirithromycin

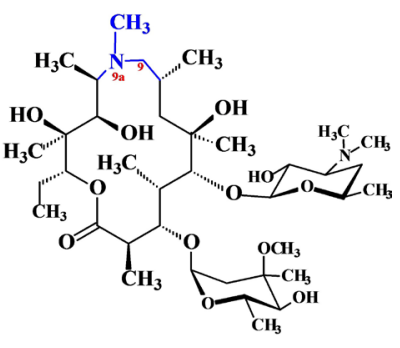

Azithromycin

Figure 5. Chemicals structures of $C 9$-modified neomacrolides.

The addition of this basic nitrogen atom and the suppression of the ketone function at $C 9$, would not only prevent the degradation of the molecule in acid medium, but also would allow the broadening of the spectrum of antibacterial activity towards Gram-negative bacteria, such as Haemophilus influenzae, as well as atypical germs [78] [79]. In addition, this structural alternative has enabled much better tolerability of Azithromycin, an increase in its tissue penetration and its elimination plasma half-life (40 - 68 hours); at the origin of its once-daily administration [78] [79].

With all its benefits, Azithromycin quickly became the antibiotic of choice for the treatment of several Gram-negative and Gram-positive infections. In addition, other properties of Azithromycin mainly linked to its cell accumulation capacity inducing modulations of various cellular functions have been noted. These proprieties have been exploited in new therapeutic indications. These include anti-inflammatory and immunomodulatory activities [80] [81] [82] [83], but also tuberculostatic activities in chronic pneumonia due to Mycobacterium avium [84] [85], antimalarials [86] [87], antivirals [88] [89] and anti-tumor [90] [91].

In the end, Azithromycin or 9-deoxo-9a-aza-9a-methyl-homoerythromycin A has become one of the most effective antibiotics in the world and currently contributes, due to its exceptional therapeutic properties, to the improvement of quality of life globally.

\section{Pharmacochemical Evolution of Erythromycin and Neomacrolides to Ketolides}

\subsection{Ketolide: Definition-Origin}

Ketolides may be considered to be hemisynthesis derivatives of Erythromycin A. They all have in their respective molecules, a macrocycle with 14-membered ring carrying a ketone function at $C 3$, hence their name of ketolide. They are further characterized by the presence of $D$-desosamine at $C 5$, of a heterocycle in $C 11$ and $C 12$ of a nature most often of carbamate or 1,3-oxazolidin-2-one like. Their $C 6$ hydroxyl group, like Clarithromycin, is always alkylated to avoid the formation of hemiketal between the $C 6$ hydroxyl and the $C 3$ and $C 9$ carbonyl groups [92] [93] [94]. In addition, the $C 2$ of ketolides often carries a halogen type $\mathrm{R}_{3}$ atom (Figure 6). 


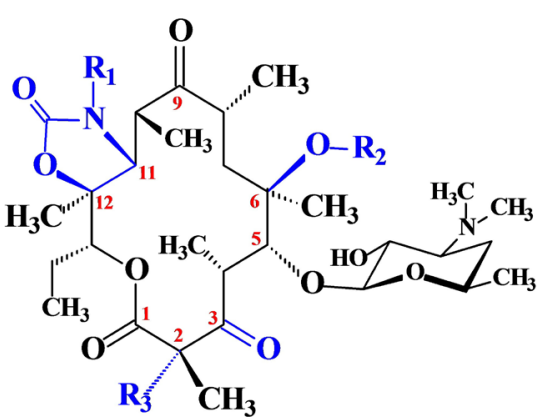

Hemisynthesis ketolides

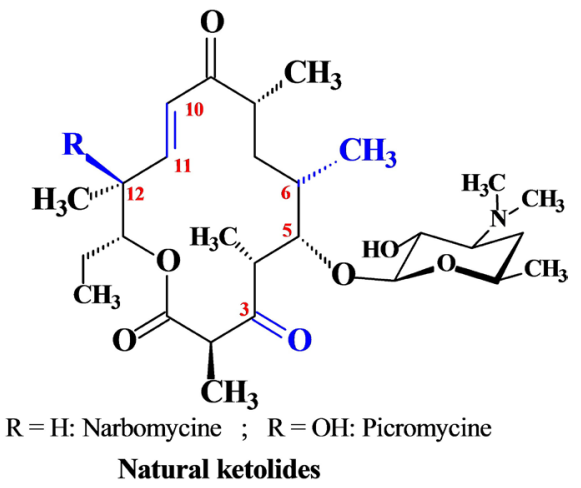

Natural ketolides

Figure 6. General chemical structures of hemisynthesis ketolides and natural ketolides.

The ketolides were also obtained after a pharmacochemical re-examination of the structure of Narbomycin and Picromycin (Figure 6), two natural macrolides whose chemical structure mainly shows the replacement of $L$-cladinose at $C 3$ by a ketone. These natural compounds have the advantage of being active on strains resistant to other macrolides. However, their weak antibacterial activity limited their development [95] [96] [97] [98].

Also, the new pharmacomodulations undertaken around the chemical structure of Erythromycin A, have retained the following sites (see Figure 2): $L$-cladinose at position $C 3$, hydroxyls at position $C 6, C 11$ and $C 12, D$-desosamine at $C 5$, the ketone at $C 9$ and/or the carbon at position $C 2$.

\subsection{Access to the First Ketolides: Telithromycin and Cethromycin}

The first chemical modulation to access the ketolides used in therapy, was to eliminate $L$-cladinose in $C 3$ by a ketone function. Indeed, the presence of this sugar is not necessary to induce a notable antibacterial activity [99]. The suppression of $L$-cladinose has thus made it possible to improve the stability in acid medium of ketolides, to widen their spectrum of antibacterial action towards Gram-positive germs including the strains resistant to other macrolides and to avoid induction MLSB resistance as well as the efflux of the antibiotic [100] [101] [102] [103]. From the 3-keto erythromycin or ketolide derivative obtained, the second chemical modulation consisted in protecting the $C 6$ hydroxyl by $O$-alkylation to prevent spontaneous hemiketalization in gastric acid medium (Figure 7); which prevented the formation of inactive derivatives responsible for digestive disorders. In addition, the alkyl nature of the $C 6$ alkoxyl would play an important role in binding to the bacterial ribosome. Thus, an alkyl or an aryl on the $C 6$ oxygen would make it possible to obtain a conformation of the ketolides favourable to an additional anchoring of the molecule to the domain II of the ribosome in addition to the domain $\mathrm{V}$. This is at the origin of a better affinity of ketolides for the ribosomal target and therefore of an increase in antibacterial activity [104] [105] [106] [107]. Concomitantly, to avoid the formation of spiroketals, the hydroxyls in $C 11$ and $C 12$ were also blocked by a cyclization to lead to heterocycles with functional grouping of carbamate, carbonate or lactone like. 
The creation of this heterocycle in $C 11$ and $C 12$ has led to molecular rigidity, an improvement in stability in an acid medium and above all a broadening of the antibacterial action spectrum of ketolides [108] [109] [110] [111]. The creation of a cyclic carbamate in $C 11$ and $C 12$ to form a heterocycle of 1,3-oxazolidin-2-one nature was carried out from the molecular model of natural ketolides thanks in particular to the reactivity of the ethylenic function in $C 10-C 11$ (Figure 7). The presence of this carbamate has led to an increase in antibacterial activity, including on strains resistant to other macrolides, by the creation of a second anchor point for the antibiotic with the bacterial ribosome. This second anchor is at the origin of an affinity of the ketolides for the 50S ribosomal subunit, 10 times greater than that of Erythromycin A. In addition, the presence of the nitrogen atom of the carbamate creates an additional basicity participating in the improvement of the pharmacokinetic parameters of the molecule [112] [113] [114] [115] [116]. Furthermore, the $N$-alkylation of the cyclic carbamate by a side chain of butyl like of lipophilic nature and of heterocyclic support of imidazolyl-pyridine like. These different chemical modulations led to the production of Telithromycin, the first 11,12-ketolide carbamate used in human medicine (Figure 7). Telithromycin has shown a strong affinity for ribosomal targets, an increase in antibacterial activity against Gram-positive organisms, an improvement in pharmacokinetic performance and a decrease in the impact of efflux resistance [112] [113] [114] [115] [116]. To this, it should be mentioned that this Ketolide has retained the advantages of neomacrolides, namely good digestive tolerance, good oral bioavailability, longer half-life and reduction of drug interactions. In addition, it has the advantage of being more active with an antibacterial spectrum extended to strains resistant to the other macrolides with the exception of methicillin-resistant Staphylococcus aureus. Ketolides are also more effective on $H$. influenzae, a Gram (-) germ that causes serious respiratory infections, compared to Erythromycin A and Clarithromycin. However, this activity is still weak compared to that of Azithromycin on the same pathogenic germ [117] [118] [119] [120].

Unfortunately, some toxicity appeared during the use of Telithromycin. Indeed, additional studies have found that the pyridine nucleus of the $N$-butyl-imidazolyl-pyridinyl side chain of Telithromycin, has been shown to cause undesirable side effects such as severe fulminant hepatitis, worsening of myasthenia and visual disturbances. The mechanism of toxicity is due to the preferential inhibition of the nicotinic receptors $\alpha 3, \beta 4$ and $\alpha 7$ of acetylcholine at the neuromuscular junction, at the level of the ciliary ganglion of the eye as well as at the level of the vague nerve innervating the liver by the imidazolyl-pyridine pair of Telithromycin [121]. This is what justifies the precipitated withdrawal of Telithromycin from the antimicrobial therapeutic arsenal. In addition, the introduction of a sulfur atom with an electronic density higher than that of carbon atoms, in the lateral carbon chain fixed on the nitrogen atom of ketolide carbamates, helped to adjust the nucleophilic and length of the side chain. This 

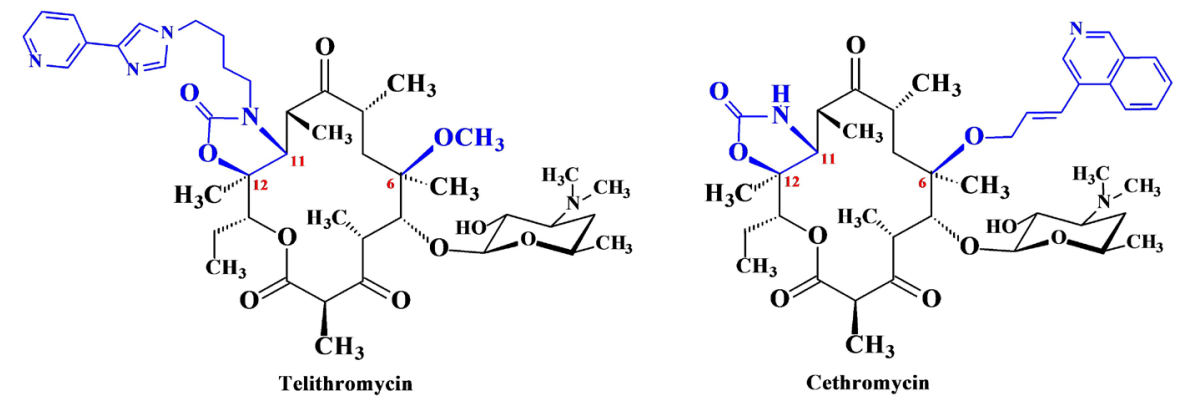

Figure 7. Chemical structure of the first ketolides in infectiology.

enable to reduce the hepatotoxicity of the molecule while improving the pharmacokinetic parameters, and the antibacterial activity. Thus, these compounds have better activity on strains resistant to other macrolides by an inducible and efflux MLSB mechanism [122]. In order to reduce the harmful effects of Telithromycin, Cethromycin (Figure 7), another cyclic 11,12-carbamate derivative, has been developed. It has the advantage of being less hepatotoxic than Telithromycin. This is linked to the displacement on hydroxyl at $C 6$ by $O$-alkylation, of lipophilicity linked to the butyl-imidazolyl-pyridinyl chain fixed on the nitrogen of the oxazolidinone of Telithromycin. In addition, this chain was modified by the introduction of an unsaturation of the allylic group and by the replacement of the imidazole-pyridine couple by a quinoline (Figure 7).

Cethromycin is therefore a non- $N$-alkylated Ketolide. It also presents a spatial conformation favouring the binding of the molecule to the domain II of the ribosome, in addition to the domain V. So that the Cethromycin exhibits a better affinity of the molecule for the ribosomal target doubled by an increase in antibacterial activity [107] [123] [124] [125]. This molecule has good antibacterial activity and is used as an orphan drug in the treatment of pulmonary anthrax [126] [127]. In addition, the presence of the quinoline-like unsaturated side chain resulted in a reduction in cytochrome inhibition. It contributes to the reduction of drug interactions and improves the safety of co-administration of the drug even if it is not yet known how the side chain had an effect on the reduction of inhibition of cytochrome 3A4 [128]. However, at the lowest approved dose of $250 \mathrm{mg}$, Cethromycin has not been shown to be more effective in severe respiratory infections compared to Clarithromycin [129] [130].

\subsection{Pharmacochemical Evolution of Ketolides to Neoketolides}

In order to overcome the drawbacks of using the first 1,3-oxazolidinone ketolides and to have a greater range of new high-performance ketolides, the pharmacomodulations undertaken have targeted new sites for modulating Erythromycin A or 1,3-oxazolidinone ketolides. Indeed, to take into account the performance of Telithromycin, linked above all to the presence of the heterocycle 1,3-oxazolidinone on $C 11$ and $C 12$, various variations have also been undertaken to modify or replace this heterocycle with analogues. Thus, 11,12-carbonate, 11,12-thiocarbamate [131], 11,12-carbazate [132] and 11,12-lactone like hetero- 
cycles have been proposed for new, more effective derivatives. These included considerably reducing the undesirable effects which appeared with Telithromycin and widening the spectrum of action of the derivatives and analogues obtained on the resistant germs of the species $S$. aureus methicillin-resistant. In addition, these new ketolides had to be more effective than Azithromycin, especially on Gram (-) germs like $H$. influenzae. In short, it was a question of optimizing the affinity of the new ketolides for their ribosomal target. These new chemical variations have made it possible to develop a new series of oxazolidinone-ketolide derivatives which could be called "Neoketolides".

\subsubsection{C2-Halogenation of Ketolides: Solithromycin and Fluoroketolides}

To enhance the interaction between ketolides and the ribosome, alpha halogenation on $C 2$ by a fluorine atom has been undertaken in a stereospecific manner. The presence of this fluorine atom in an alpha configuration on $C 2$, would help prevent the enolization of the $\mathrm{C} 3$ ketone found with Telithromycin or other ketolides. This chemical variation, coupled with the replacement of the imidazole-pyridine couple of Telithromycin by a 1,2,3-trizolyl-aniline, led to the development of Solithromycin (Figure 8). Solithromycin or CEM-101 actually presented better chemical stability, better affinity for the 50S subunit of the bacterial ribosome by the creation of a third interaction site [133]-[138]. It does not inhibit nicotinic acetylcholine receptors nAChRs like Telithromycin, so should not have the harmful side effects of Telithromycin [135].

Solithromycin also showed good activity in vivo and in vitro on most respiratory pathogens including strains resistant to other macrolides as well as atypical germs. It has been shown to be 8 to 16 times more effective than Azithromycin both on sensitive germs and on those resistant to Azithromycin [135]-[140]. Furthermore, the interaction of Solithromycin with the third ribosomal site makes it possible to limit the development of bacterial resistance [135]-[141]. Solithromycin also has a broad spectrum of activity against methicillin-resistant Staphylococcus aureus strains, Enterococci and the genus Plasmodium in animal models. It also has a relevant activity on bacteria responsible for urinary tract infections such as Neisseria gonorrhoeae including the multidrug resistant strains Chlamydia, Mycoplasma, Genitalium and Ureaplasma [141]-[146]. For some reasons in particular of insufficient data on hepatotoxicity, the FDA has

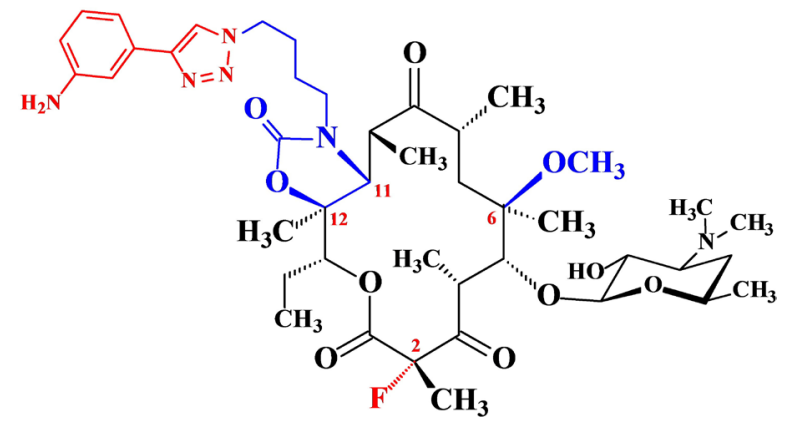

Figure 8. Chemical structure of Solithromycin (CEM-101). 
not approved the marketing authorization for this first fluoroketolide. However, the search for other 2-fluorinated derivatives of Solithromycin was continued. Thus, the variations undertaken were aimed at reducing hepatotoxicity and widening the performance of fluoroketolides. To do this, the first chemical variations used an atypical approach which called on the ribosomes involved in resistance mechanisms and mutations as a platform for developing new, more effective and more selective fluoroketolides [147]. Thus, by this method which also uses a structurally diverse library of alkynes, the aniline of the triazole of Solithromycin has been replaced by various aryls and heteroaryls. Among these new derivatives, those in which the triazole carries a thiophene heterocycle are particularly illustrated by their effectiveness. In fact, two positional isomers of thiophene (4-thiophene isomer and 5-thiophene isomer) (Figure 9) exhibited significant activities against strains of $E$. coli and against standard and resistant strains of $S$. pneumoniae [148]. Other modulations of Solithromycin have focused on the entire structural link of the $C 11-C 12$ cyclic carbamate. This is how the butyl-triazolyl-aniline chain of Solithromycin was replaced by a butenyl-quinoline link (compound 1) or by a propoxyl-quinoline (compound 2) (Figure 9). These compounds have shown in vitro antibacterial activities that can be superimposed or even superior to those of Clarithromycin and Telithromycin against sensitive and resistant macrolide germs. The activity of compound 1 with the butenyl-quinoline chain was also 8 times greater than that of telithromycin against the strain CSMS 12-1 of M. catarrhalis [149].

The butyl-triazolyl-aniline chain on the carbamate of Solithromycin has also been replaced this time by a rigid propargyl-like link carrying the triazole-pyridine couple. Among these new derivatives of Solithromycin, the compounds FSM-100573 and FSM-100563 (Figure 10) have shown antibacterial performances superior to those in particular of Azithromycin, Telithromycin and Solithromycin against some resistant strains extremely difficult such as $S$. pneumoniae and Pseudomonas aeruginosa [150]. Another chemical variation operated is to move the link of the carbamate cycle on the oxygen atom in $C 6$ as in the case of Cethromycin. These new fluoroketolides carry at 06 , a rigid propargyl-like link carrying a terminal heteroaryl-isoxazolyl group [151]. The leading compound in this series or compound 3 (Figure 10) is effective against
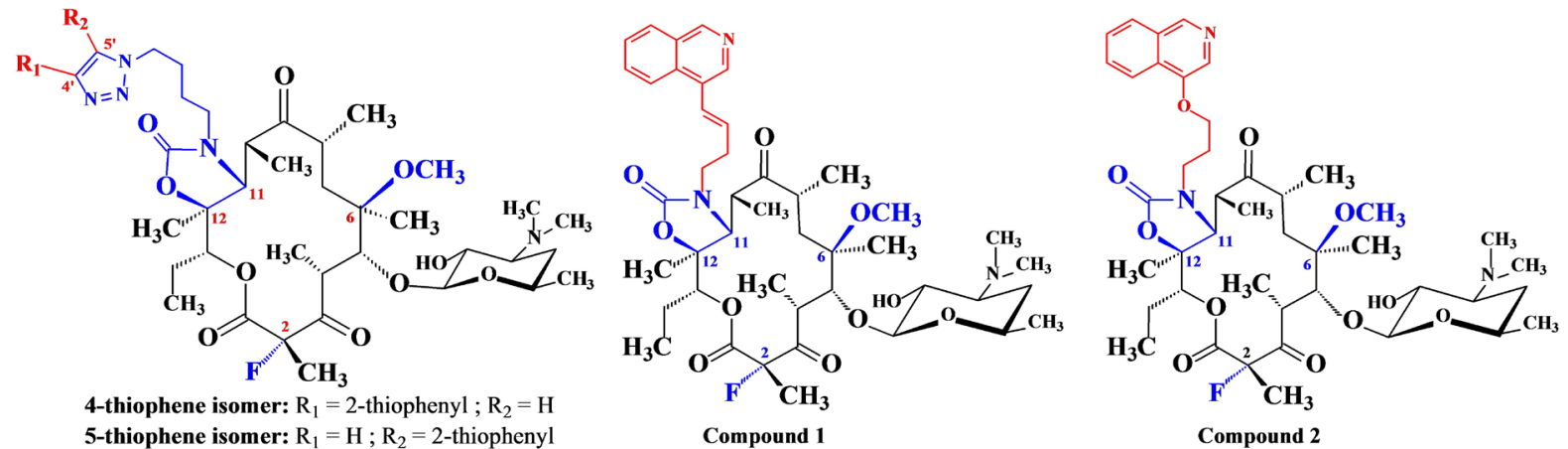

Figure 9. Fluoroketolide derivatives. 

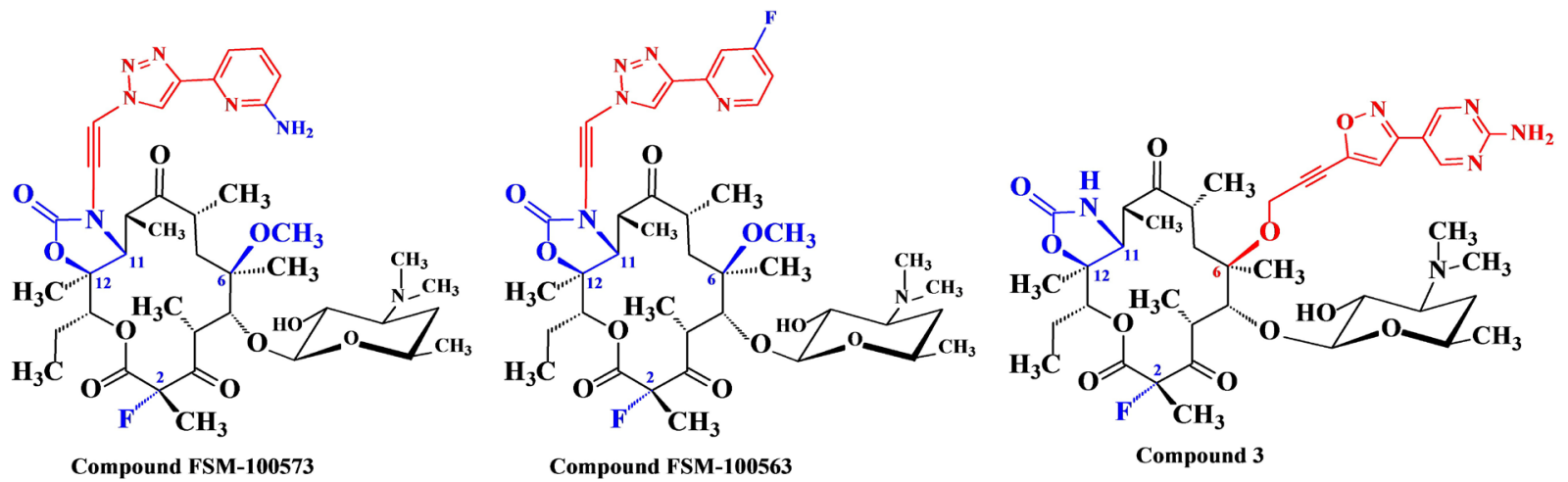

Figure 10. Propargyl-fluoroketolide derivatives.

the strains of $S$. pneumoniae, $S$. pyogenes and $H$. influenzae with an antibacterial properties 10 times that of Clarithromycin against the sensitive strains of $S$. pneumoniae. The same compound is also 100 to 16,000 times more effective against strains of $S$. pneumoniae resistant to Erythromycin [151].

\subsubsection{Azetidinyl Ketolides}

Always looking for new derivatives of Telithromycin that are more effective, in particular with regard to respiratory tract infections of community origin that are sensitive and multidrug-resistant and especially less hepatotoxic, the new chemical variations undertaken using Clarithromycin have made it possible to dot the series of azetidinyl carbamate ketolides [152] [153]. The chemical modulation undertaken essentially concerned the butyl imidazolyl-pyridine group of Telithromycin: the butyl chain was heterocyclized into azetidine, the nitrogen of which carries a methyl diazanaphthalene group of the 1,5- or 1,8-naphthyridine-like substituted (Figure 11). The first derivatives comprising the 1,8-naphthyridine heterocycle (compounds 4 and 5) were found to be favourable for the metabolism induced by human aldehyde oxidase (AO). On the other hand, the 1,5-naphthyridine derivative carrying a hydroxyl group in position 3 has been shown to be poorly metabolizable by AA even if the regioselectivity of the hydroxylation has not been established. Attenuation of the effect of AO appeared not with other polar functional groups but rather with the positional rearrangement of

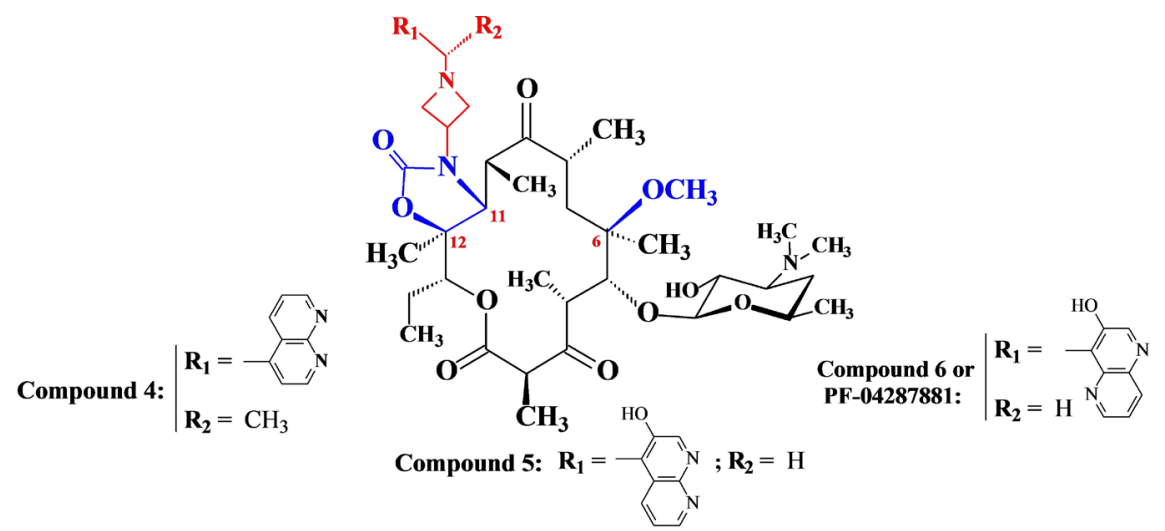

Figure 11. Azetidinyl carbamate ketolide series. 
the nitrogen atoms of naphthyridine. This is how the 1,5-naphthyridine derivative (compound 6 or PF-04287881) (Figure 11) has been shown to be more stable in the human hepatic cytosol. This molecule has a good ability to attenuate hepatotoxicity while minimizing hepatic renewal and inactivation as a function of time of the CYP3A isoforms in the liver [152]. In addition, this azetidinyl ketolide (PF-04287881) has an efficacy and a significant antibacterial activity against the germs responsible for infections of respiratory tracts of community origin that are sensitive or multi-resistant [152]. This is why it was selected for clinical development.

\subsection{3. $C 10$ and $C 12$-Substituted Ketolides}

In order to optimize therapeutic activities against both sensitive and resistant respiratory pathogenic bacteria, another chemical variation consisted in replacing the methyl initially present on the $C 10$ or $C 12$ carbon of ketolides with non-polar groups [147] [154] [155]. The aim of such an option was to keep in ketolides series, the same overall hydrophobic character observed at the level of the underside of the neomacrolide macrocycle [156] [157] [158] [159]; which could lead to new ketolides with an antibacterial spectrum and more effective pharmacokinetic properties. The pharmacomodulation undertaken consisted in replacing methyl in $C 12$ by a vinyl-like group [154] or to introduce in addition on $C 10$, a hydroxyl [147] or also in replacing methyl in $C 10$ by an alkylamine group [155].

\section{1) 12 -vinyl ketolide derivatives}

In the 12 -vinyl ketolides series, two derivatives are particularly illustrated both by their antibacterial activities and by their pharmacokinetic properties [154]. These are Telithromycin derivatives which differ from one another by the presence on the pyridinyl nucleus of the $N$-butyl imidazolyl-pyridine sequence, either of a methyl (compound 7) or of a chlorine atom (compound 8) (Figure 12).

The antibacterial activities of compounds $\mathbf{7}$ and $\mathbf{8}$ were comparable in vitro to those of telithromycin. However, the presence of the vinyl group, doubled by that of methyl or chlorine on pyridine, reinforced the lipotropy of the hydrophobic surface of the macrocycle.

Thus, this contributing to a profound modification of the pharmacokinetic

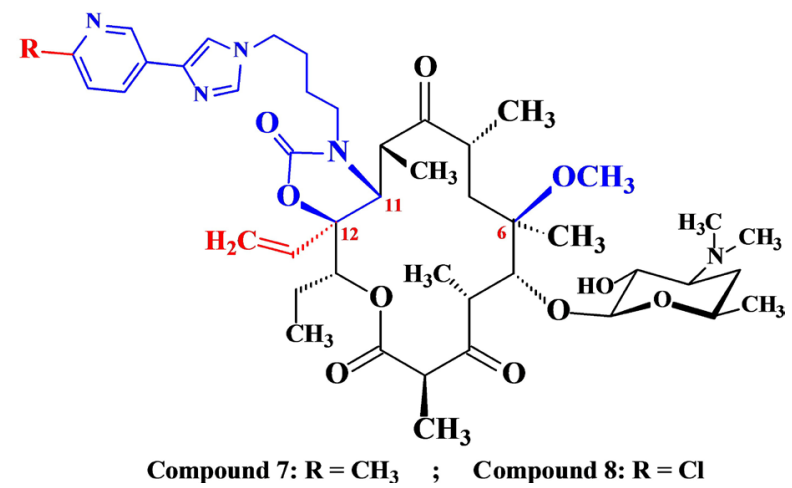

Figure 12. Series of 12-vinyl ketolides. 
and pharmacodynamic aspects of these compounds in vivo in rats. Indeed, vinyl ketolides had larger lung distribution volumes and longer half-life times; so that they had a much better pharmacodynamics by their better activity in vivo against Streptococcus pneumoniae and Haemophilus influenzae compared to Telithromycin [154].

\section{2) C10-substituted ketolide derivatives}

Following the performance of 12-vinyl ketolides [154], other regioselective modifications have been undertaken. They consisted in introducing either alongside the methyl at C10, a hydroxyl group [147], or by substituting this methyl with an aryl group or with an $N$-arylamine function [155]. Thus, three series were obtained: the series of 10-hydroxyl ketolides, that of 10-alkylaryl ketolides and that of 10-alkylamine ketolides and analogues. The objective was also to maintain the structural coherence of the macrolides with their bifacial characteristic. The results of the in vitro antibacterial screening of these new ketolides against a panel of respiratory pathogens and compared to the activities of Telithromycin and Clarithromycin, unfortunately showed that the presence of hydroxyl was not favourable to the expected results. The 10-hydroxyl ketolides (compounds 9, 10,11) and their analogue 10,11-epoxide (compound 12) (Figure 13), were clearly less effective than Telithromycin and Clarithromycin [147]. Such a poor performance could be attributed to a conformational modification induced by the presence of hydroxyl in the prepared ketolides; which undoubtedly changed the tight 10-hydroxyl ketolide binding capabilities with their ribosomal target. In fact, the methyl at $C 10$, initially in the indispensable beta configuration, is this time oriented in alpha with respect to the plane of the macrocycle (Figure 13).

In series of 10-alkylaryl ketolides and 10-alkylamine ketolides (Figure 14), the SAR studies undertaken noted that to induce good antibacterial activity, the nitrogen of ketolide 11,12-carmabate should not be substituted. In addition, only the C10-benzyl (compound 13) and C10-benzylamine (compound 14) derivatives are found to be twice as effective as Clarithromycin against sensitive and resistant strains of $S$. pneumoniae. Replacing the phenyl of benzyl with a basic heterocycle like pyridine does not improve the antibacterial activities [155]. Against certain resistant strains of $S$. aureus (BAA976 M mef and BAA977 iMLS

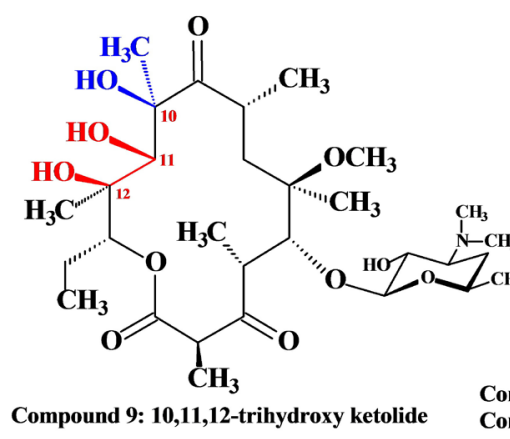

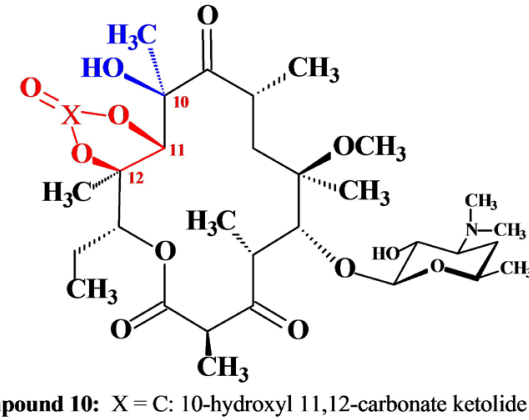

Compound 11: $\mathrm{X}=\mathrm{S}$ : 1,3,2-dioxathiolane 2-oxide ketolide

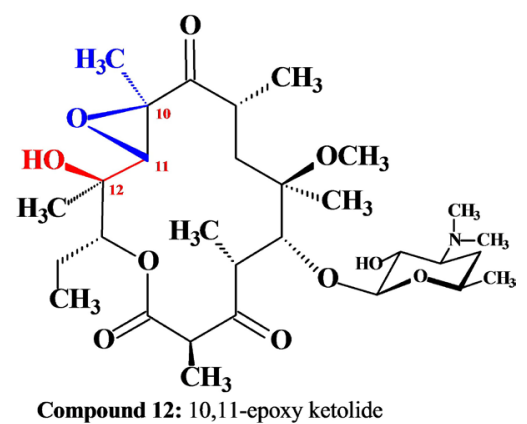

Figure 13. Series of 10-hydroxyl ketolides and analogues. 
erm), the benzylamine derivative (compound 14) was found to be 32 times more active than Clarithromycin [155]. As for the analogue C10-spiro-pyrazole (compound 15) (Figure 14), this one presented against the 3914 MLS strain of $S$. pneumoniae, a moderate activity compared to Clarithromycin. On the other hand, like benzylamine, spiro-pyrazole was also found to be 32 times more effective than Clarithromycin against resistant strains of $S$. aureus [155].

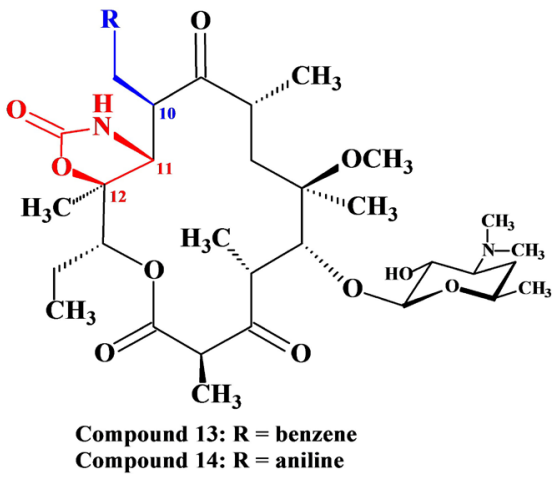

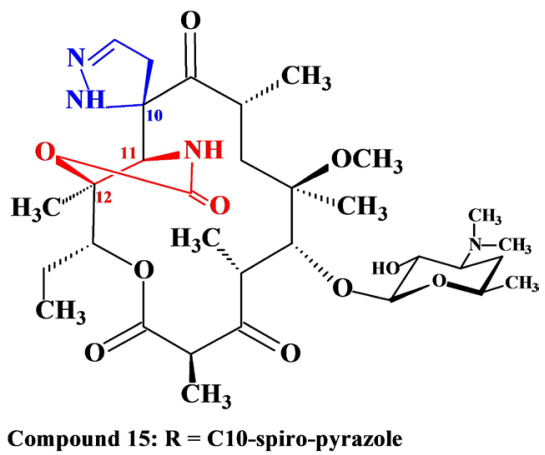

Figure 14. Series of 10-alkylaryl- and 10-alkylamine ketolides and analogues

\subsubsection{Telithromycin Derivatives Modified on Desosamine}

In order to study the structural factors at the origin of resistance to macrolides, the amino sugar $D$-desosamine of Telithromycin undergoes several pharmacomodulations in particular a C2'-deoxygenation (compound 16), a 3'-desmethylation (compound 17) and an $N$-butylation of this desmethylated derivative (compound 18) (Figure 15). All the new derivatives showed moderate antibacterial activities against the sensitive strains ATCC29213 of $S$. aureus. However, they were completely inactive against the constitutive resistance of $S$. aureus. These results could indicate that the steric repulsion between the desmethylated cycle A2058 and the desosamine cycle cannot be considered as a main reason for resistance against the ermA strain ATCC3359 of $S$. aureus [160].

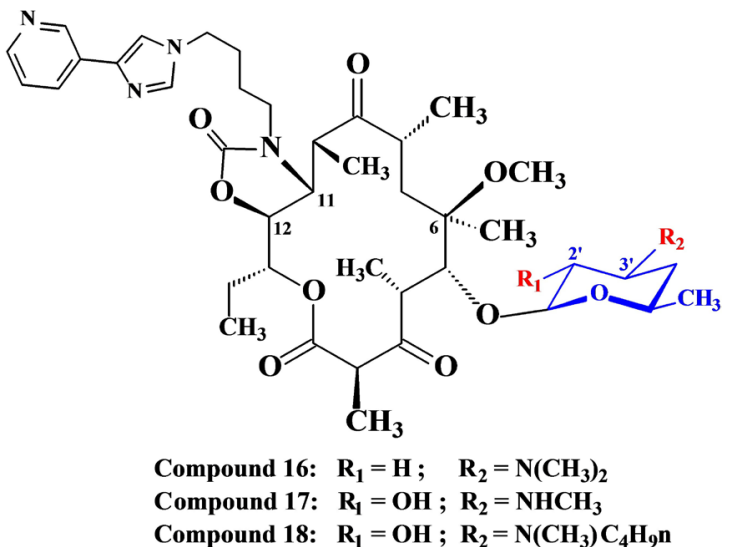

Figure 15. Telithromycin derivatives modified on desosamine.

\subsubsection{1-O-carbamoyl Ketolides: Clarithromycin Analogues}

A series of acyclic carbamate derivatives which can be considered as originating 
from the opening of the oxazolidinone (11,12-carbamate) nucleus of Telithromycin and its rearrangement into 11- $O$ carbamoyl derivatives have been recently proposed [161] [162]. In fact, these derivatives are obtained directly from 3-ceto clarithromycin by 11-O-carbamoylation (Figure 16). Such a chemical variation led to the production of a series of carbamoyl ketolides, two derivatives of which exhibited effective activities compared to that of Clarithromycin. Indeed, the compounds 17 and 18 carrying on the carbamate nitrogen, a propyl chain 1,2,3-triazole variously substituted (Figure 16) have shown in vitro a good activity not only against bacterial germs sensitive to Clarithromycin but also on resistant bacterial strains. These $O$-carbamoyl ketolides are in particular more effective in vitro on strains resistant to Erythromycin, in particular Streptococcus pneumoniae and Streptococcus pyogenes. In terms of sensitive germs, these triazole compounds have shown better activity against the strains of Staphylococcus aureus ATCC25923 and Bacillus Subtilis ATCC9372 [161] [162].

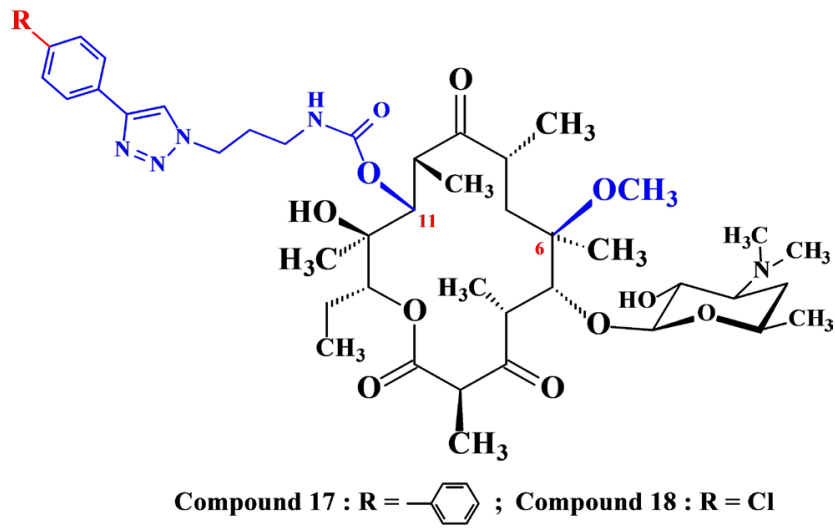

Figure 16. 11-O-carbamoyl ketolide derivatives.

\subsubsection{Carbonate Ketolides and Derivatives}

Carbonate ketolides were designed following the replacement of 1,3-oxazolidinone from Telithromycin by a cyclic carbonate or 1,3-dioxolanone at $C 11$ and $C 12$. In addition, these new ketolides are likely to undergo a second modification in their amino sugar ( $D$-desosamine). Thus, two series of ketolide carbonates have been developed: those without modification of the amino sugar and those which have also undergone a modification at the level of $D$-desosamine. Like 11,12-carbamate ketolides or oxazolidinone ketolides, the creation of a cyclic carbonate or 1,3-dioxolan-2-one in position $C 11$ and $C 12$ would lead to an improvement in the antibacterial performance of the macrolides obtained. In addition, these compounds would have much better stability in an acid medium as well as better pharmacokinetic properties [109] [163] [164] [165] [166]. Among these carbonates, those from Erythromycin (compounds 19) or 3-ceto-Clarithromycin or compound 20 (Figure 17), exhibited antibacterial activities twice that of Erythromycin A [109] [163] [164]. This superior antibacterial performance of 11,12-carbonate derivatives is due to a better affinity of these derivatives for the 50S ribosomal subunit [164]. Thus, these derivatives presented MICs twice lower 
than those of Erythromycin and Clarithromycin against strains of Streptococcus pyogenes resistant to macrolides by a constitutive or inductive MLSB mechanism [165]. In contrast, compound 20 from 3-ceto-Clarithromycin (Figure 17) has induced excellent antistreptococcal activities [164] [166]. However, the 11,12-carbonate derivatives did not experience the same development as their 11,12-carbamate analogues probably due to their high hepatotoxic potential [167].

Another pharmacomodulation has been undertaken on ketolide carbonates. It consisted in introducing on 5- $O$-desosamine, a hydroxyl group in position $C 4$ '. The presence of this group has made it possible to increase the antibacterial activity by increasing the interactions between the molecule and the ribosomal subunit. This is due to the fact that the desosamine sugar binds to the $\mathrm{V}$ domain of the $23 \mathrm{~S}$ rRNA by a hydrogen bond. Thus, the existence of a hydrophilic group of hydroxyl-like on the amino sugar could have created another hydrogen bond with the ribosomal target in particular on the amino acid residues of the binding pocket [168]. On the other hand, when the 4'-hydroxyl group of the desosamine is alkylated by hydrophobic groups of alkyl or aryl like, there is a non-improvement of the antibacterial activities [168]. These different chemical variations on desosamine have made it possible to access new ketolides whose antibacterial activities in vitro against several sensitive or resistant microbial agents have shown relevant activities. Thus the 4'-hydroxylated ketolide carbonate or compound 21 (Figure 17), unlike its 4'-O-alkylated derivative, has shown a potent activity against all pathogens sensitive or resistant to methicillin. Thus, compound 21 would be more active than Clarithromycin for the strains ATCC29213 (MSSA), 09L075 (MSAR), 09M124 (MRSE), 09H071 (ESSP) and 09U070 (ESSPy). Compared to Telithromycin, compound 21 has shown the same potency of activity against all pathogens sensitive or resistant to methicillin [168].
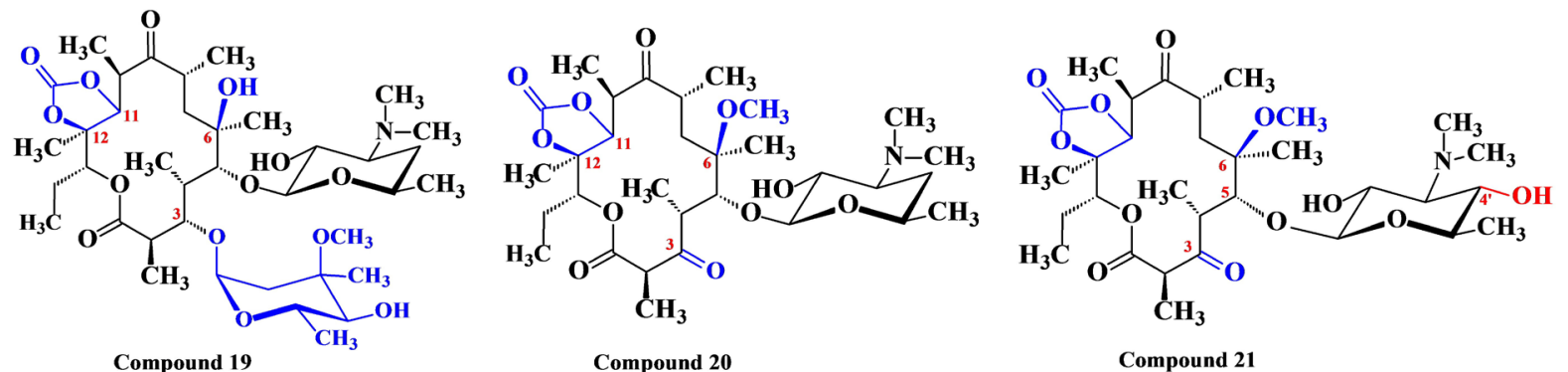

Figure 17. Carbonate ketolides and derivatives.

\subsubsection{Lactone Ketolides and Derivatives}

Another series of neoketolides, in particular those carrying at $C 11$ and $C 12$ a $\gamma$-lactone, have been prepared and evaluated for their activity against respiratory pathogenic bacteria. These are derivatives derived from the replacement of 1,3-oxazolidinone (carbamate) of Telithromycin by a cyclic ester or lactone. In fact, these new ketolides have two lactone groups: that belonging to the macrocyclic aglycone and that carried by the carbons $C 11$ and $C 12$. This $\gamma$-lactone very 
often carries an $\alpha$ function (thiol or amine) thus leading to the class of $\alpha$-thio- $\gamma$-lactone ketolides and to that of $\alpha$-amino- $\gamma$-lactone ketolides.

\section{1) $\gamma$-lactone ketolides derivatives}

Among these compounds, it has been established that only $\mathrm{N}$-alkylated 6-carbamate derivatives with a rigid allyl-aryl link, in this case allyl phenylpyrimidine, are capable of inducing excellent antibacterial activities [169]. Furthermore, the stereochemistry at the $C 10$ methyl level was of paramount importance for antibacterial performance. Indeed compound 22, the most active with an activity superimposable on that of Telithromycin, was that endowed with a type $R$ stereoisomerism at the level of methyl in $C 10$ (Figure 18) [169].

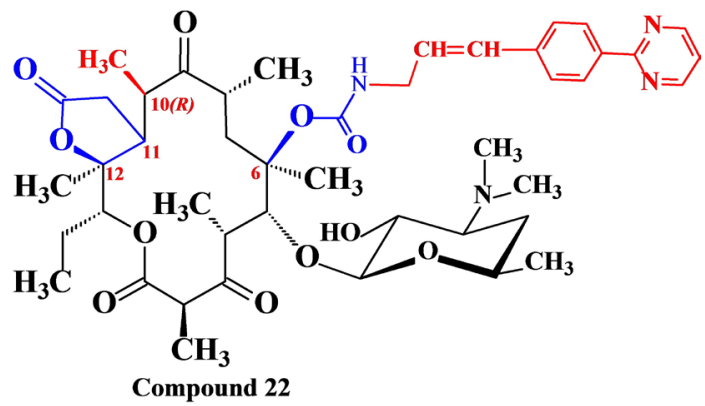

Figure 18. 6- $O$-carbamate-11,12-lactone ketolide derivatives.

\section{2) a-thio- $\gamma$-lactone ketolides derivatives}

Following a Michael intramolecular addition reaction of an aryl alkylthio acetic acid ester enolate to an $\alpha, \beta$-unsaturated ketone, a series of $\gamma$-lactone ketolides were prepared. The new lactones fused in $C 11$ and $C 12$ carried in the alpha position, a thiol function variously substituted by alkyls, alkyl-aryls or by aryls (Figure 19) [170]. Some of these neoketolides have been the subject of an in vitro antibacterial evaluation against sensitive and resistant pathogenic respiratory strains and compared to Telithromycin. Thus, against sensitive germs such as $S$. aureus and $S$. pneumoniae and $H$. influenzae, the best compounds of the diastereoisomer type (compounds 23, 24 and 25) (Figure 19), have shown a similar antibacterial spectrum and an activity comparable to that of Telithromycin. However, such compounds were less active against resistant strains of $S$. pneumoniae and $S$. aureus.

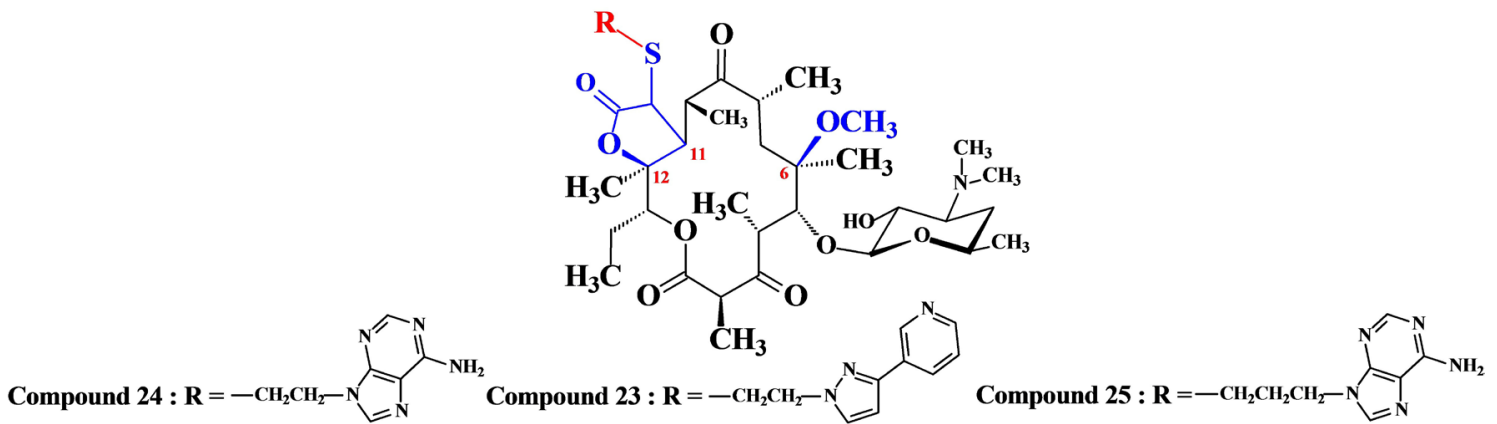

Figure 19. $\alpha$-Thio- $\gamma$-lactone ketolide derivatives. 
The $S$-ethyl adenyl derivative (compound 24), was particularly illustrated by its antibacterial performance against certain Gram-negative germs such as $E$. coli [170]. Compared to Erythromycin and Clarithromycin, this chemical variation led to much better pharmacokinetic characteristic. Thus compound 23 ( $S$-ethyl pyrazolyl-pyridinyl) and compounds 24 and 25 or $S$-alkyl adenyls, have shown in oral mice bioavailability (around 60\%) and significantly higher plasma levels. Furthermore, their plasma half-lives were of the order of 1.1 to 1.2 hours in mice, thus suggesting a once-daily administration in humans [170]. Consequently, an in vivo screening in mice of compounds 23, 24 and 25 was carried out against a sensitive strain of Streptococcus pyogenes. It has been noted that compounds 23 and 25 were slightly less active, but nevertheless in the same performance range as Telithromycin. However, all of these compounds were significantly more effective than Erythromycin [170].

3) a-amino- $\gamma$-lactone derivatives ketolides and analogues: Nafithromycin

The $\alpha$-amino- $\gamma$-lactone ketolides can be considered to be derived from the 11,12-carbazate ketolides or $N$-amino 11,12-carbamate ketolides [132] by removing nitrogen from the carbamate. Indeed, they were proposed following the antibacterial performances of 11,12-carbamate. The aim of such a chemical variation was to modulate, by various substituents, the $\alpha$-amine function of $\gamma$-lactone. The $\alpha$-amino- $\gamma$-lactone ketolides are therefore considered to be versatile intermediates for accessing neoketolides with optimized antibacterial activity and enhanced pharmacokinetic performance. Thus, from the 3-ceto clarithromycin carrying the $\alpha$-amino- $\gamma$-lactone group in $C 11$ and $C 12$, two chemical series were prepared: the chemical series or the $\alpha$-amine function was substituted by various side chains of the type aryl or heteroaryl following an amidation reaction ( $N$-acylamine derivatives) [171], and that or the $\alpha$-amine has been replaced by an amidoxime [172].

In the series of $\alpha$ - $N$-acylamine $\gamma$-lactone ketolides, a derivative is particularly illustrated by its performance. This is compound 26 carrying the $\mathrm{N}$-2-methylthio quinoxaline link (Figure 20). Indeed, this compound is particularly effective in vitro against Gram-positive pathogenic germs sensitive to Erythromycin. In addition, it was effective against strains of $S$. aureus resistant to MLSB, $S$. pneumoniae resistant to efflux and $S$. pneumoniae and $S$. pyogenes resistant to MLSB.
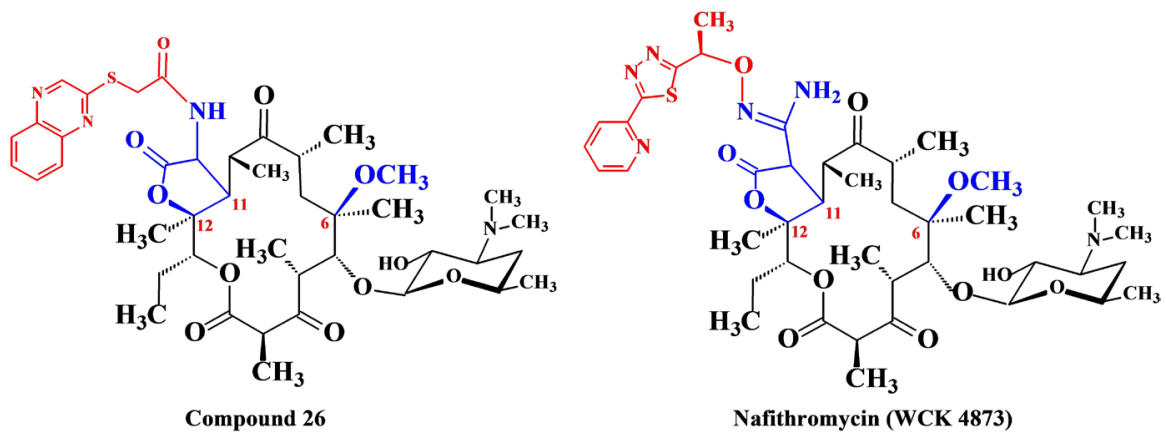

Figure 20. $\alpha$-Amino- $\gamma$-lactone derivatives ketolides and analogues. 
Furthermore, compound 26 was approximately 4 times more effective against BML-resistant $S$. pyogenes and $H$. influenzae than Telithromycin [171]. The presence of the $N$-acylamine chain in $\alpha$ of the $\gamma$-lactone ketolide is therefore important for inducing serial antibacterial performances of the neoketolides.

In series of antibacterial $\alpha$-amidoxime 11,12- $\gamma$-lactone ketolides, derived from amines by replacement of the latter by an amidoxime, only one representative is currently in clinical development. These are WCK 4873 or Nafithromycin developed by the Research Center in Wockhardt, India [172] (Figure 20).

Nafithromycin is structurally presented as a 3-keto Clarithromycin with a $\gamma$-lactonic heterocycle joined to $C 11$ and $C 12$ of the aglycone. The $\gamma$-lactone carries in $\alpha$ an amidoxime whose oxygen atom is alkylated in position 1 by an ethyl group itself fixed in position 2 of a 1,3,4-thiadiazole carrier in position 5 of a 2-pyridinyl. Nafithromycin with this structural characteristic based on the $\alpha$-amidoxime group and a hydrophilic side alkyl chain, would have a much better interaction with the target domain II and the target domain $\mathrm{V}$ including modified, of rRNA. Such an affinity would be at the origin of potent antibacterial activity against strains collected worldwide [173] [174] [175] [176] [177] including against strains resistant to macrolides, in particular Telithromycin and Solithromycin [178] [179] [180]. In terms of pharmacokinetics and tolerance, Nafithromycin has been shown to be generally well tolerated at all doses. No serious or severe side effects have been observed [181] [182]. Unlike most macrolides and ketolides, Nafithromycin has also been shown to be non-inhibitor of all major human CYP isoforms, even at significantly higher concentrations. These results suggest a lower clinical drug interaction potential for Nafithromycin [183].

Thus, the excellent antimicrobial profile, pharmacodynamics, pharmacokinetics and the safety and human tolerability data of Nafithromycin, mean that it is currently in clinical development III in India. Nafithromycin is thus presented as the future broad-spectrum neomacrolide antibiotic for the treatment of bacterial pneumonia of community origin endowed with a notable activity against the typical and atypical respiratory pathogenic germs and the resistant strains [173]-[180].

\subsubsection{Oxime and Ether-Oxime Ketolides}

As previously in the neomacrolide series, chemical modulations of the $C 9$ ketone have also been undertaken in the ketolide series. The objective was the same, namely to prevent the formation of inactive 6,9-hemiketal for better stability of ketolides in gastric acid medium. Furthermore, it is also a question of optimizing the therapeutic and pharmacokinetic performances as well as the tolerability of the neoketolides obtained. In this perspective, the $C 9$ ketone function of kétolides, like that of Roxithromycin, has been transformed into its oxime analogue and $O$-alkyl oxime derivatives.

\section{1) Oxime ketolides}

From the 11,12-carbamate ketolides or from the 11,12-carbonate ketolides a 
C9 oximation reaction was undertaken to give rise to the 9-oxime ketolides. The latter, in particular those of the 11,12-carbonate ketolides series (Figure 21) with compound 27 [184] exhibited better activity both on sensitive and resistant strains than other macrolides including Staphylococcus aureus resistant to Erythromycin by a constitutive MLSB mechanism [184]-[190]. However, the activity although being more stable in gastric acid medium, compound 27 has proved to be ineffective against $S$. pneumoniae resistant to Erythromycin [184]. To improve the activity of these oximes, in particular against $H$. influenzae and $S$. pneumoniae resistant to Erythromycin, two types of chemical modulations have been undertaken: either a chemical variation on the $D$-desosamine of the oxime ketolides, or either $O$-alkylation of these oximes (Ether-oxime ketolides). The first chemical modulation conserved the oxime in $C 9$ but introduced at $C 4$ ' of $D$-desosamine of 11,12 carbonate 3-keto-Clarithromycin, a hydroxyl group or a carbamate group [191]. Such variations are thought to cause damage to the center of peptidyl transferase (CPT) in the exit tunnel and inhibit the formation of peptide bonds thanks to the presence of the 4'-O-carbamate group on desosamine. This activity would be comparable to that identified in 16-membered ring macrolides carrying mycaminosis-mycarose disaccharide in position C5 [191]. Thus, the derivative 11,12-carbonate $C 9$ oxime (compound 28) and its derivative of 5-O-4'-carbamate (compound 29) (Figure 21), presented good antibacterial activities on respiratory pathogens comparable to those of Telithromycin and Clarithromycin [191].
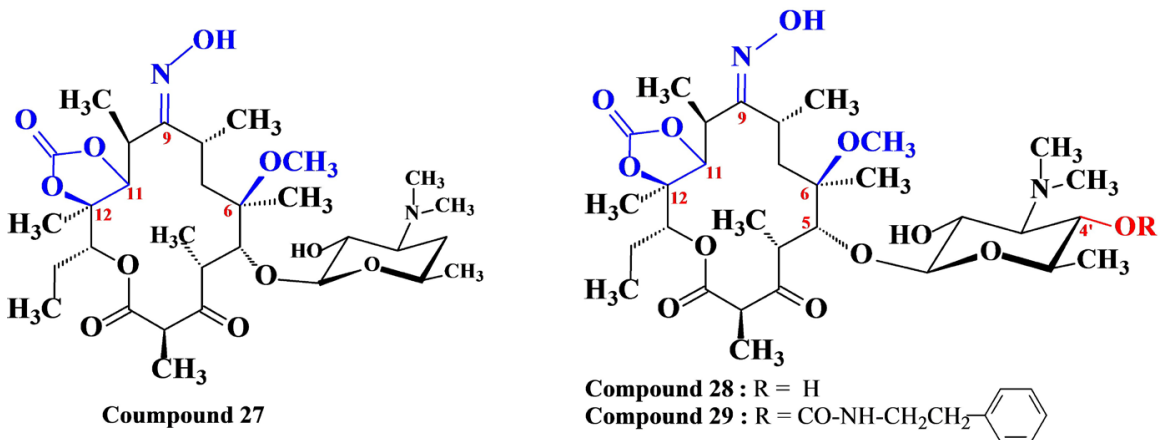

Figure 21. 11,12-Carbonate oxime ketolide derivatives.

\section{2) Ether-oxime ketolides}

The $O$-alkylation of $C 9$ oxime, as in Roxithromycin, constitutes the second chemical variation operated in order to improve the antimicrobial activity of the ether oxime ketolides obtained. Chemical modulations have been undertaken on 11,12-carbamate ketolides and 11,12-carbonate ketolides. Several series of etheroxime ketolides have been developed, four of which are currently under intense investigation. These are methyloxime derivatives, $N$-(aryl-alkyl) acetamidyl oximes, 9- $\mathrm{O}$-arylpropenyl oximes and 9-O-arylpropargyl oximes.

Methyloxime ketolides were accessed from Telithromycin following the replacement of the $C 9$ ketone by a methyloxime and the replacement of the butyl 
group by a propyl chain but still carrying the imidazo-pyridine chain. Furthermore, in order to improve the pharmacokinetic parameters as well as the antibacterial performance of these new derivatives compared to Telithromycin, various chemical variations have also been made, in particular by the introduction at $C 2$ of modulators of hydroxyl, methyl, fluorine like, etc. [188] [189] [190]. Among these, the derivative 2-fluoro-9-oxime (CP-654743) analogue to Solithromycin, demonstrated the best activity both on strains sensitive and resistant to Erythromycin. CP-654743 is slightly more active than the non-fluorinated analogue (CP-605006) (Figure 22), but its activity on the main respiratory pathogens is similar to that of Telithromycin. In animal models, CP-654743 has shown efficacy similar to Telithromycin and superior to the non-fluorinated analogue CP-605006 against Streptococcus pneumoniae. The pharmacokinetic profile of CP-654743 was similar to that of CP-605006 and Telithromycin in middle ear infections [188] [189] [190].

As regards the $N$-(aryl alkyl) acetamidyl oxime ketolides derivatives, these were obtained from the 11,12-carbonate ketolides as a result of the attachment of an $N$-(aryl alkyl) acetamide group to the hydroxyl oxime [185] [186]. Optimization of activity was dependent on the length of the alkyl chain and the nature of the aryl. In fact, it was optimal when it was a propyl chain carrying a heteroaryl of the quinoline or quinoxaline nature (Figure 22). The importance of these heterocycles, in particular quinoline, has also been reported to be an excellent inducer of antibacterial activity in macrolide series [149] like that of the $C 6$ side chain of Cethromycin. In addition, an extensive SAR study has shown that the amide function with its free amine group is of paramount importance for the induction of good activity. Thus, $N$-(arylalkyl) acetamidyl oxime ketolide derivatives have shown potent antibacterial activities against Haemophilus influenzae and Streptococcus pneumoniae including Erythromycin-resistant strains [185] [186].

Despite their excellent in vitro activity, these ketolide acetamide derivatives have unfortunately proved to be ineffective in vivo in animal models, probably due to their poor pharmacokinetic profiles [185] [186]. In order to improve the pharmacokinetic parameters of ether-oximes while optimizing their antibacterial
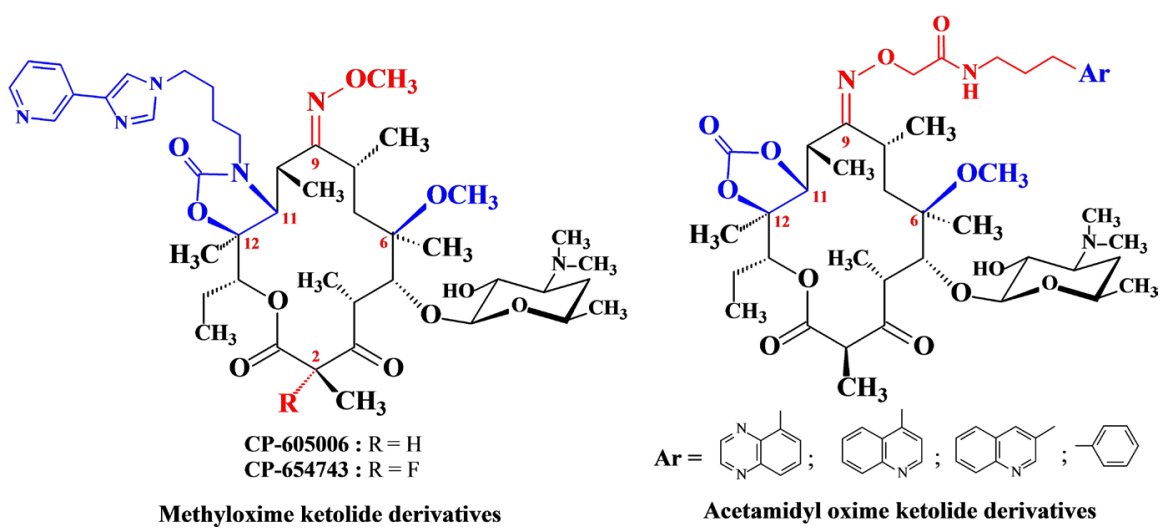

Figure 22. Methyloxime and Acetamidyl oxime ketolide derivatives. 
activities against resistant respiratory pathogenic strains, a new modulation of oxime was operated. This is the introduction of a degree of rigidity in the alkyl linker linking oxime and the aryl. Thus, propenyl and propargyl groups carrying in this case a heterocycle of the quinoline, isoquinoline, pyridine, pyrimidine, thiophene etc. type have been introduced on the oxime of the ketolides to give respectively the series of 9-O-arylpropenyl oxime ketolides and that of 9- $O$-arylpropargyl oxime ketolides.

In series of the 9-O-arylpropenyloxime ketolides carrying diols at $C 11$ and $C 12$, this variation enables to improve the antibacterial activity of these molecules on Gram-positive germs. The activity was linked to the nature of the aryl. It was higher for compounds in which the aryl is quinoline or thiophene like (Figure 23). These compounds had potent activities against sensitive and resistant strains including Staphylococcus aureus, Staphylococcus epidermidis, Streptococcus pneumoniae and Streptococcus pyogenes [192]. In this same series of 9- $O$-arylpropenyloxime ketolides, this time with a cyclic carbonate at $C 11-C 12$, the introduction of a fluorine atom at $C 2$ has the consequence of obtaining analogues of Solithromycin [193] [194]. Among these, compound 30, the oxime of which is alkylated by the propenyl-quinoline chain, has been shown to be particularly effective against the strain ATCC49619 of $S$. pneumoniae sensitive to Erythromycin (Figure 23). With an $\mathrm{IC}_{50}>5 \mathrm{mM}$, compound 30 also had a weak inhibition of CYP3A4 [194]. The fluorine atom was not involved in the interactions of the $\mathrm{H}$ bond with the ribosomal tunnel. Its presence only resulted in an improvement in the lipophilicity of the less hydrophilic side of the aglycone [193] [194].

Still in the 11,12-carbonate ketolide series, the other chemical variation undertaken consisted in replacing the allyl linker by a propargyl also carrying most of the time a nitrogenous heteroaryl. This variation led to the 9- $O$-arylpropargyloxime ketolides derivatives characterized by the formation of a more rigid bond; which turned out to be essential for a suitable conformation for binding with RNA 23S. Molecular docking studies have elucidated the disparity of SAR in this series of propargyls, and have suggested the possibility of this new binding mode different from Telithromycin and Cethromycin [192]. In addition, when propargyl is

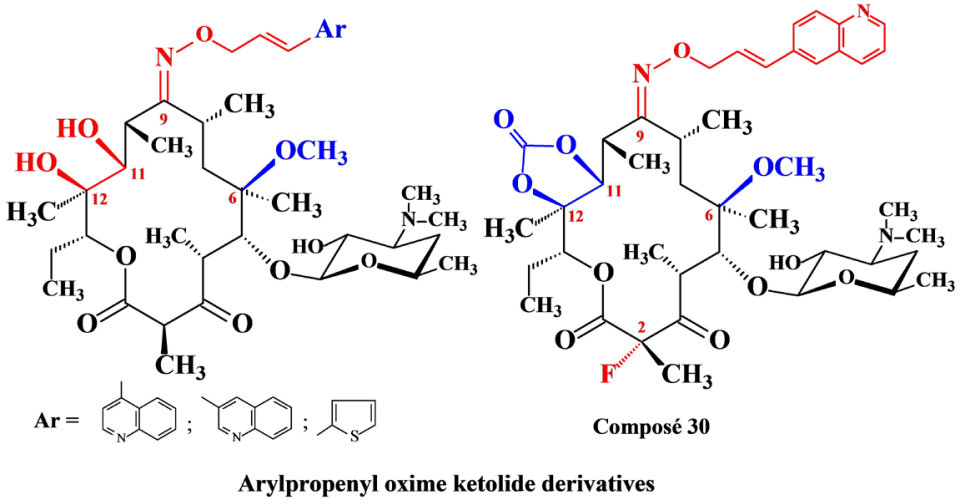

Arylpropenyl oxime ketolide derivatives

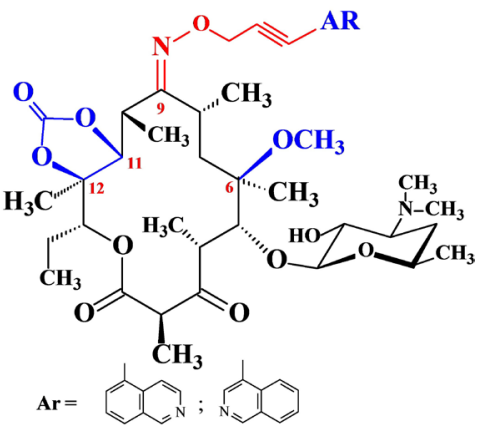

Arylpropargyl oxime ketolide derivatives

Figure 23. Arylpropenyl- and arylpropargyl-oxime ketolide derivatives. 
carried by a nitrogen heterocycle, in this case quinoline, optimal antibacterial activity is obtained. The position of the nitrogen atom in the cycle is essential for the optimal binding of the molecule and its ribosomal target, for example in a 4-isoquinoline heterocycle (Figure 23) [192]. Furthermore, these 4- or 5-isoquinoline derivatives have an interesting antibacterial activity against inducible pathogenic germs resistant to MLSB and resistant to efflux, whatever the phenotypes sensitive to methicillin or resistant to methicillin [192].

\subsubsection{Ketoazalides or Azaketolides}

Faced with the performance of azalides, in particular those of Azithromycin which has a reassuring safety profile, good stability and exceptional pharmacokinetic, pharmacodynamic and therapeutic properties, it was normal for the chemical modulations that led to the development of the Azithromycin are also taken up in series of Ketolides. The "ketoazalides or azaketolides" obtained should be at least as effective against infectious germs as Azithromycin, or even provide better molecular stability in gastric acid medium.

\section{1) 3-keto azithromycin derivatives and their pharmacomodulation sites}

The first ketoazalides were prepared from a 3-keto-9-oxime-erythromycin A. Thus, from this compound, the Beckmann rearrangement reaction was carried out successively, the reduction of the intermediate iminoether obtained, then $\mathrm{N}$-methylation of the nitrogen atom introduced into the macrocycle. The first ketoazalides with 15-membered ring obtained, were all derivatives of 3-keto azithromycin or derivatives 9a-aza homoerythromycin A ketolides (Figure 24). Despite the addition of an additional nitrogen atom which has led azalides in series to an enhancement of antimicrobial performance, at the level of ketoazalides this modification alone is not enough to induce good activities. This poor performance is related to possible instability reactions which would lead to the formation of inactive 3,6-hemiketals, if the $C 6$ hydroxyl group was not previously protected, for example by a methyl [195]. However, even the 6-O-methylated derivative (Figure 24) has been found to be largely ineffective against respiratory pathogens compared to Azithromycin and Telithromycin [116] [196]. To induce the expected antibacterial activity, 6-O-methyl has been replaced by the side chain of Cethromycin. Such a structural variation has led to the production of 6-O-(3-quinolyl) allyl-3-keto-azithromycin (Figure 24) which has effectively

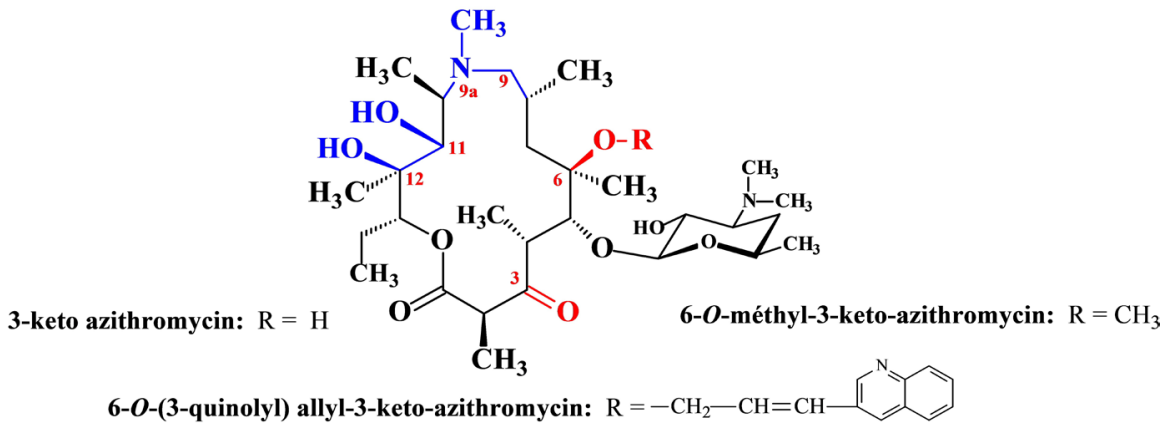

Figure 24. 3-Keto azithromycin derivatives or 9a-aza homoerythromycin A ketolides. 
become active against $S$. aureus, $S$. epidermidis, Escherichia coli and Nocardia asteroides [197].

In the end, in the ketoazalides series, the replacement of $L$-cladinose in $C 3$ by a ketone function doubled or not by 6-O-methylation, are not sufficient in themselves to induce good antibacterial activities. Also, to develop ketoazalides with effective antibacterial activities, use was made of the structural study of Azithromycin adapted to that of 3-keto azithromycin. It has identified functional sites likely to undergo chemical variations beneficial for antibacterial activities [198]. This is particularly to (Figure 25):

- the alkylation by various groups other than methyl, of the $C 6$ hydroxyl function,

- the introduction of $C 11$ or $C 11-C 12$, respectively of an acyclic carbamate and of an cyclic carbamate,

- the halogenation of carbon $C 2$,

- the substitution in $C 4$ 'of $D$-desosamine or of the $O$-alkylation of hydroxyl in position $C 2$, or even of the introduction of ester or amide functions on methyl in C5', $^{\prime}$

- the desmethylation of the nitrogen atom $9 a$ or of its displacement in position 8 a or $11 a$,

- narrowing or widening of the aglycone at 15 -membered ring to new aglycones respectively at 14 - or 16-membered ring,

- the introduction of a lactam function in which the nitrogen atom is either in position $9 a$ or in $8 a$.

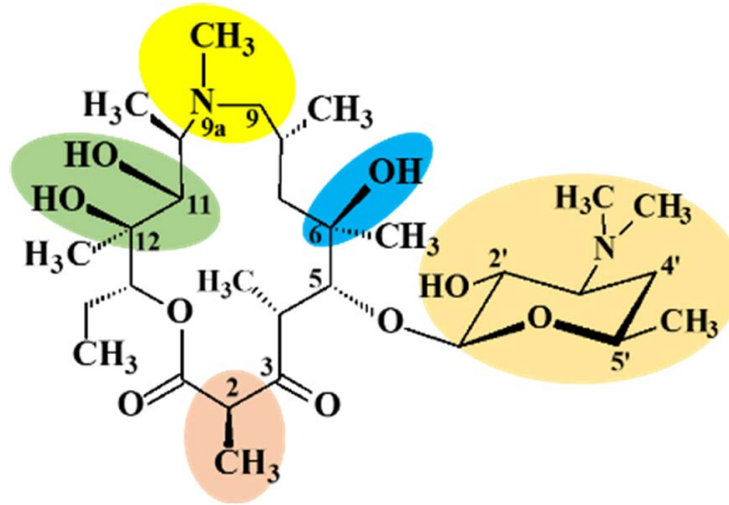

Figure 25. Pharmacomodulation sites for ketoazalides.

\section{2) Carbamate-ketoazalide derivatives with 15 -membered ring}

In order to boost the serial antimicrobial activities of ketoazalides, one of the chemical variations undertaken consisted in introducing an acyclic carbamate function on the $C 11$ hydroxyl. The studies of SAR undertaken, have noted that the open and rigid nature of carbamoyl-ethylamide-like carbamate, is not conducive to the induction of good antimicrobial activities. Indeed, compounds $\mathbf{3 1}$ and 32 (Figure 26) were respectively 8 times and 4 times less active than Clarithromycin and Azithromycin against various bacterial strains, including clinical strains of sensitive $S$. pyogenes [161] [199]. To remedy this poor per- 
formance, the carbamate group was introduced on carbon $C 11$ and $C 12$ in an oxazolidinone-like heterocycle as in the Telithromycin structure. Other chemical modulations have been carried out on these new 11,12-carbamate ketoazalide derivatives. These are in particular the substitution of the nitrogen of the cyclic carbamate by the chain 1-butyl-1,2,3-trizolyl-aniline of Solithromycin and the removal of the methyl previously fixed on the nitrogen in $9 a$ of ketoazalide, 6-O-methylation of hydroxyl or even $C 2$ fluorination like Solithromycin [150] [197] [198].

It appears from these various pharmacomodulations that the presence on ketoazalides of a cyclic carbamate $C 11$ and $C 12$ carrying on its nitrogen atom of the same side chain as Solithromycin, leads to an improvement of the antibacterial activities on strains resistant to Erythromycin A by an inducible and efflux MLSB mechanism [150] [197] [198]. Among these compounds, the derivative not methylated in 9 a but 6- $O$-methylated (compound 33) (Figure 26) was found in vitro on Gram (+) germs in particular on sensitive and resistant $S$. aureus, more effective than Azithromycin. This efficacy was however less good compared to that of Telithromycin and Solithromycin. The same trend was also observed with resistant $S$. pneumoniae and with sensitive $E$ faecalis. Compound 33 had an activity comparable to Azithromycin and Telithromycin but superior to Solithromycin against Gram (-) germs in particular on $H$. influenzae. Furthermore, even if its efficacy remained equivalent to that of Azithromycin on $E$ coli, compound 33 was significantly more effective compared to Telithromycin and Solithromycin [198]. Furthermore, the introduction of a $C 2$ fluorine atom (compound 34) (Figure 26) improves the activity on both Gram (+) and Gram $(-)$ germs. We are indeed witnessing a broadening of the antibacterial spectrum towards the germs of the genus $S$. aureus, $S$. pneumoniae, S. pyogenes, E. faecalis, E. coli, $P$. aeruginosa and $H$. influenzae, including the multiresistant strains [150] [197] [198].

Still in series with 11,12-carbamate Ketoazalide derivatives, another chemical variation consisted in mimicking the structure of Cethromycin, characterized by the presence of an allyl-quinoline link on $C 6$ hydroxyl [150]. Thus, the analogue ketoazalide obtained (compound 35) (Figure 26) has been shown to perform

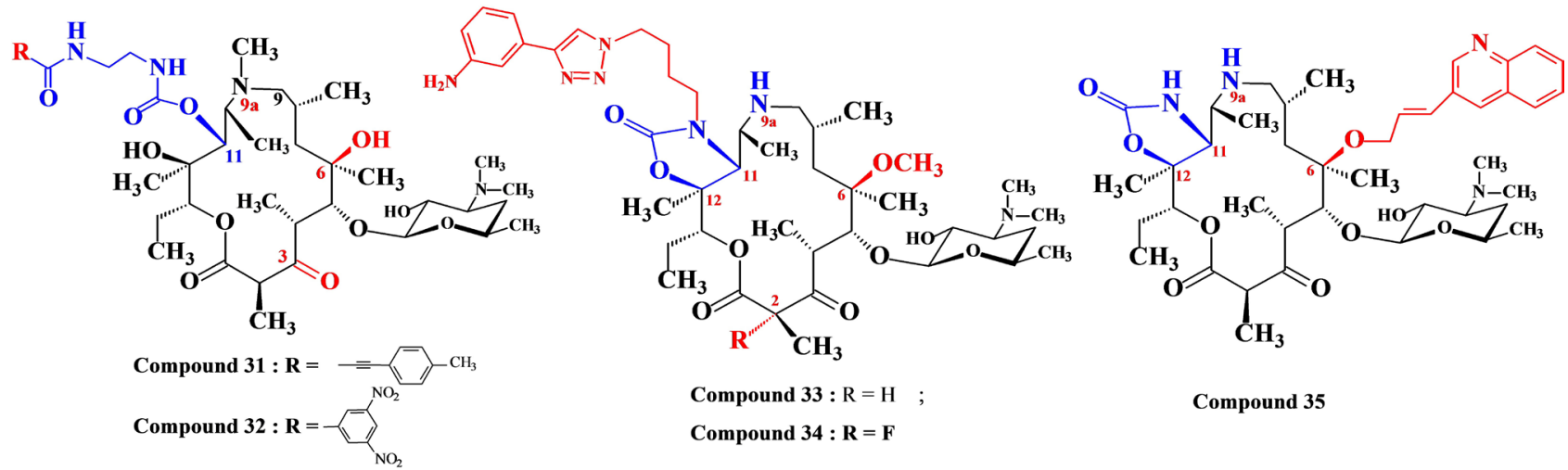

Figure 26. Carbamate ketoazalide derivatives. 
better in vitro than Azithromycin on sensitive and resistant strains of $S$. aureus. However, its efficacy was less good in the same species compared to Telithromycin and Solithromycin. The activity against sensitive and resistant $S$. pneumoniae was also more effective than Azithromycin. However, compared to Telithromycin, compound 35 was less effective on the resistant strain. Against Gram (-) germs, especially $H$. influenzae, the activity of compound 35 was low compared to that of Azithromycin and Telithromycin, but it remained comparable to that of Solithromycin. This ketoazalide analogue of Cethromycin has been shown to be superimposable on the activity of Azithromycin against E. coli and above all superior to Telithromycin and Solithromycin on E. coli [150].

Another site has been modified in the structure of 11,12-carbamate Ketoazalides. These include $D$-desosamine in position $C 5$. The latter was substituted either by an ester function or by an amide group (Figure 27). The non-6-O-methylated derivative, carrying the methylene ester, in particular methylene benzoate and whose carbamate has the same link as Telithromycin (compound 36), has shown a relevant antibacterial activity comparable to that of Azithromycin and Solithromycin against most strains of $S$. pneumoniae and the strain ATCC 19615 of $S$. pyogenes [200] [201]. On the other hand, the derivative carrying an amide group, not methylated in $9 \alpha$ but 6- $O$-methylated (compound 37), has proved to be less effective both on Gram (+) and Gram (-) germ compared to Azithromycin, Telithromycin and Solithromycin [150].
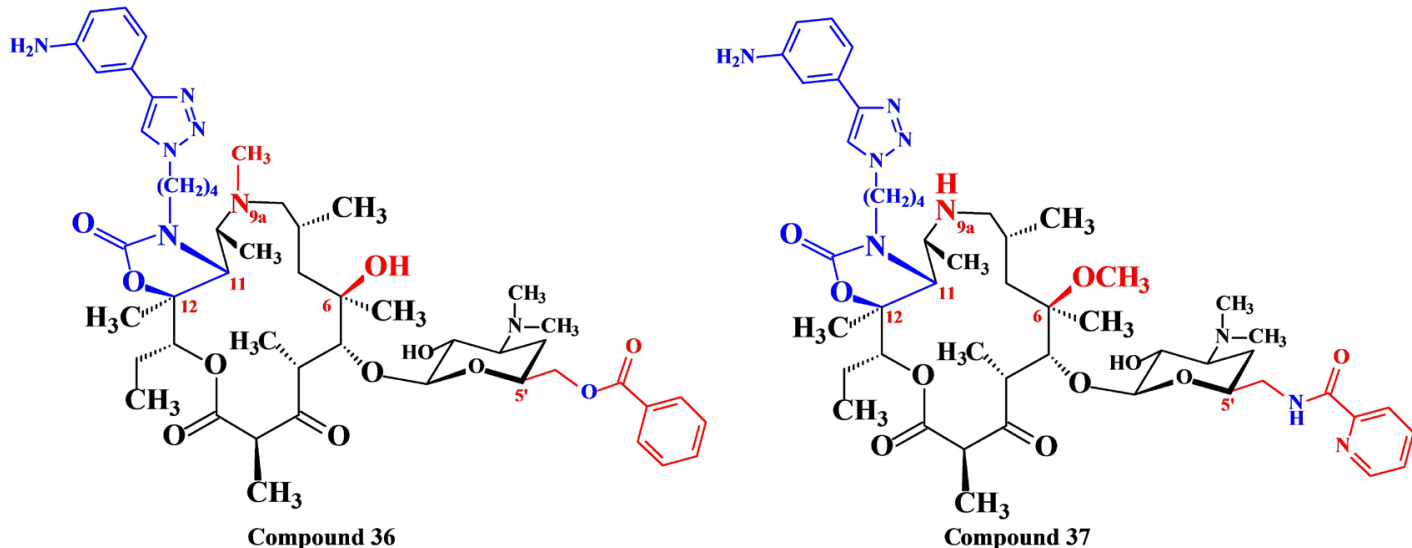

Figure 27. C5' alkyl-ester and C5' alkyl-amide ketoazalide derivatives.

\section{3) 11a-aza ketolide derivatives with 15 -membered ring}

A new ketoazalide 15-membered ring has been developed following the displacement of the nitrogen atom to an atypical position, particularly by the introduction of a methylamine at 11a. Furthermore, the general structure of these ketoazalides undergoes a profound modification characterized by the presence of a $C 9$ hydroxyl and the suppression of diols at $C 11$ and $C 12$ diols. The ethyl group protecting the lactone function of the macrolide was also deleted (Figure 28). Pharmacochemically, the introduction of nitrogen into this unusual position in the aglycone and the profound structural changes in the 
active base motif were not beneficial for the induction of effective antimicrobial activities. Indeed, compound 38 (Figure 28) is found to be ineffective against Gram (+) germs such as sensitive and resistant $S$. pneumoniae with MICs $>128 \mu \mathrm{g} / \mathrm{ml}[202]$.

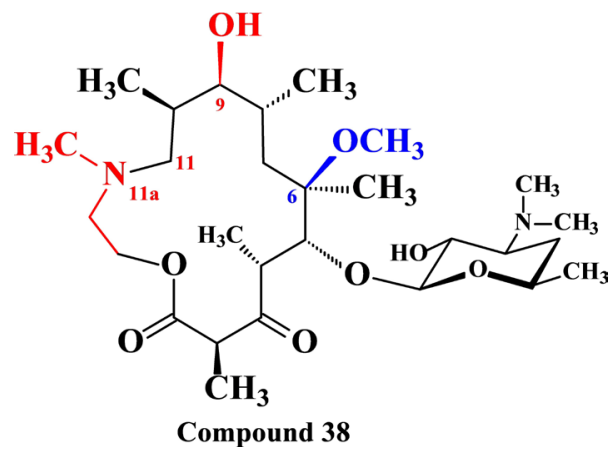

Figure 28. $11 a$-aza Ketolide.

\section{4) 14- and 16-membered ring ketoazalides}

By narrowing the aglycone from 15-membered ring, new 14-membered ring ketoazalides have been fully developed by total synthesis [150]. In summary, this involves replacing the $C 9$ carbonyl group of Solithromycin with an amine function. Among its new ketoazalides, the non-fluorinated compound 39 (Figure 29) proved to be less effective compared to Solithromycin against sensitive and resistant Gram (+) pathogens such as $S$. aureus, $S$ pneumoniae, $S$ pyogenes and $E$. faecalis [203]. On the other hand, the introduction of a $C 2$ fluorine atom like Solithromycin, resulted in an effectiveness and a broadening of the antibacterial spectrum of compound 40 (Figure 29). Indeed, the latter was more effective than Azithromycin both on sensitive and resistant Gram (+) germs, in particular $S$. aureus, $S$ pneumoniae, $S$ pyogenes and $E$. faecalis. On the other hand, on Gram (-) germs the activities of the fluorinated compound are less effective like that of Solithromycin [150].

In contrast to the cycle restriction, the enlargement of the ketoazalides from 15-membered ring to a new aglycone with 16-membered ring consisted in the introduction of a methylene amine group $\left(-\mathrm{CH}_{2}-\mathrm{NH}-\right)$ in place of the carbonyl $\mathrm{C} 9$
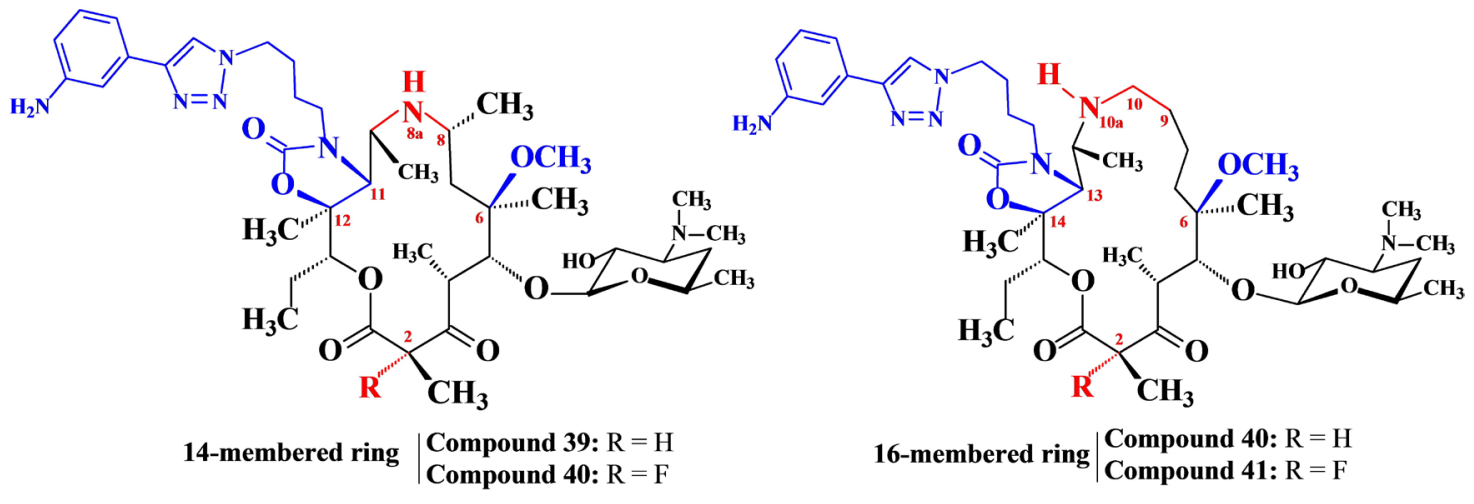

Figure 29. Ketoazalides with 14- and 16-membered ring. 
of Solithromycin. Among its 16-membered ring ketoazalides, non-fluorinated compound 41 (Figure 29) exhibited antibacterial activities on sensitive and resistant Gram (+) germs ( $S$. aureus, $S$. pneumoniae, $S$. pyogenes and E. faecalis) superior to those of Azithromycin. However, the performances of this same compound were less good compared to Telithromycin and Solithromycin against these same germs. Furthermore, the activates of compound 41 were not very effective against Gram (-) germs compared to Azithromycin [150]. The introduction of a fluorine atom in $C 2$ in series of the ketoazalides with 16-membered ring (compound 42) (Figure 29), proved not very favourable to the induction of a good antibacterial activity on Gram $(+)$ germs [203]. In the end, unlike the series of ketoazalides with 14-membered ring or $C 2$-fluoridation improve antimicrobial performance, in series of ketoazalides with 16-membered ring, the presence of this fluorine atom does not induce antibacterial efficacy on Gram (+) germs expected.

\section{5) Ketolactams or derivatives of Aza-homoerythromycin A ketolide}

This new series of ketoazalides is the result of the pharmacomodulation of 3-keto erythromycin A. These ketoazalides were obtained by introducing a nitrogen atom either between the $C 8$ and the carbonyl at $C 9$ or between the $C 10$ and the carbonyl at $C 9$ of 3-keto-erythromycin A, to obtain respectively 9 a-lactams and $8 a$-lactams ketolides (Figure 30). The chemical synthesis of these compounds took place according to key strategic steps including an $E Z$ isomerization followed by an aglycone enlargement reaction of the resulting $9(Z)$-oxime via the Beckmann rearrangement [204] [205]. These are therefore ketoazalides with a lactam function also called Ketolactams, the most prominent of which are those of the $8 a$-aza-8a-homoerythromycin A ketolides series and of the 9a-aza-9a-homoerythromycin A ketolides series (Figure 30). The general structure of Ketolactams is therefore characterized by the presence of an aglycone with 15-membered ring, the creation of a lactam chain from $C 8$ or $C 9$, the presence of the diols $C 12$ and $C 13$ or their cyclization into carbonate, the maintenance of $D$-desosamine at $C 5$ and by the presence of an ether chain functionalized at the level of the hydroxyl in C6. This $O 6$ chain is most often carrying nitrogen heterocycle including quinolines or quinolones to give hybrid compounds (Figure 30).

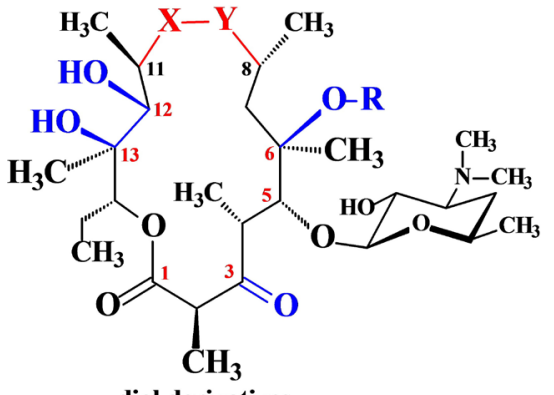

diol derivatives

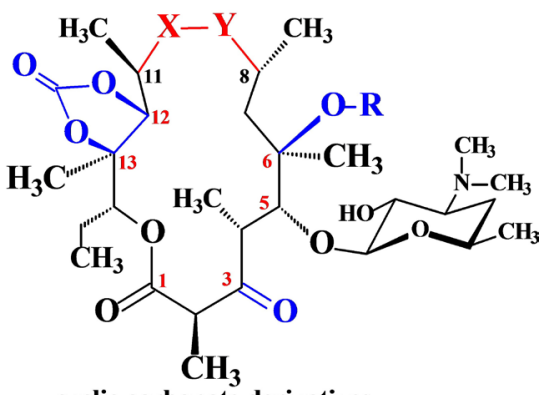

cyclic carbonate derivatives

Retrolactam series $=8 a$-aza- $8 a$-homoerythromycin A ketolide $: \mathrm{X}=\mathrm{CO} ; \mathrm{Y}=\mathrm{NH}$ Lactam series $=9 a$-aza-9 $a$-homoerythromycin A ketolide $: \mathrm{X}=\mathrm{NH} ; \mathrm{Y}=\mathrm{CO}$

Figure 30. General structure of Ketolactams. 
In terms of the impact of these chemical variations on the induction of antibacterial activities, three modulations are to be retained. These are the lactam $(\mathrm{CO}-\mathrm{NH}=9 a-\mathrm{aza})$ or retrolactam $(\mathrm{NH}-\mathrm{CO}=8 a-\mathrm{aza})$ of the 15 -membered ring aglycone, cyclization to carbonate or not of the $C 12$ and $C 13$ diols and of the nature of the ethereal sequence at the $C 6$ level (Figure 30). Whatever the nature of the $C 6$ ether chain, retrolactam-ketolides ( $8 a$-aza) performed better than their lactam-ketolide counterparts (9a-aza). Furthermore, the cyclization of the diols in $C 12$ and $C 13$ into carbonate, does not necessarily induce a higher antibacterial activity unless the presence of the cyclic carbonate is associated with that of an ethereal chain in $C 6$ as effective on the ribosomal target as the chain $C 6$ of Cethromycin [198] [204] [205] [206]. In the end, in series of ketolactams or Aza-homoerythromycin A ketolides, the whole problem of improving their antibacterial activities finally focused on retrolactams ( $8 a$-aza) with the rarely cycled $C 12$ and $C 13$ diols.

The only pharmacomodulation site for improved antimicrobial activity was the nature of the $C 6$ ether chain. Therefore, we will approach this part of the SAR studies, classifying the retrolactams (8a-aza) according to the nature of the ether chain in C6. Thus, three groups are to be distinguished: the group of 6- $O$-alkyl retrolactams, that of 6- $O$-allyl carrying or not heteroaryl and that of 6- $O$-isopropanolyl-aminoheteroaryl. When the $C 6$ hydroxyl is tethered by groups of the methyl, ethyl or allyl like, it is found that the antimicrobial properties, both on sensitive strains and on resistances, decreases from 6- $O$-methyl (compound 42) to 6-O-allyl (compound 44) through 6- $O$-ethyl (compound 43) derivatives (Figure 31) [204] [205]. The 6-O-methylated retrolactam-ketolide (compound 42) has shown better activity against inducible resistant $S$. aureus. It had a significant antibacterial activity not only against strains sensitive to Azithromycin, but also against strains resistant to Gram positive [198] [204] [205]. To improve the induction of antimicrobial activities with ether-allyls, these have been replaced by a quinoline-like heterocycle having a primordial role in the ligand-receptor binding, in particular at domain II of 23S rRNA [125] [128]

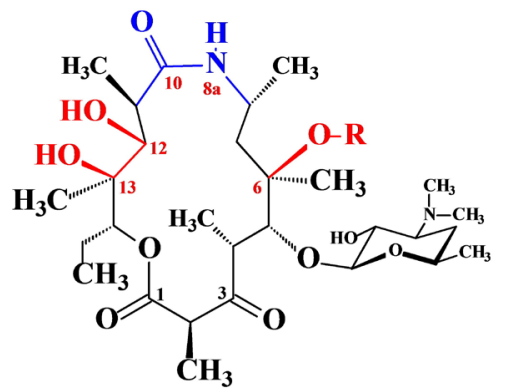

Compound 42: $\mathrm{R}=\mathrm{CH}_{3}$; Compound 43: $\mathrm{R}=\mathrm{C}_{2} \mathrm{H}_{5}$ Compound 44: $\mathrm{R}=-\mathrm{CH}_{2}-\mathrm{CH}=\mathrm{CH}_{2}$ Compound 45: $\mathbf{R}=-\mathrm{CH}_{2}-\mathrm{CH}=\mathrm{CH}_{2}$

Compound 46: $\mathbf{R}=-\mathrm{CH}_{2}-\mathrm{CH}=\mathrm{CH}_{2}$

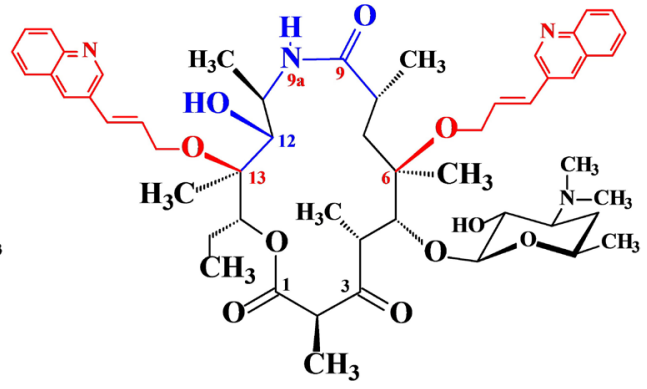

Compound 48

Figure 31. Ketolactam derivatives. 
[149]. The 6-O-allyl-quinoline chain thus obtained is supposed to be an excellent inducer of antibacterial activity in series of ketolides like that of the $C 6$ side chain of Cethromycin. In fact, the retrolactam-ketolide (8a-aza) obtained (compound 45) has shown, as the unsubstituted allyl derivative (compound 44), good activity against pathogens sensitive to Erythromycin (Figure 31). On the other hand, it was much more active than unsubstituted allyl (compound 44) against very resistant strains of $S$. pneumoniae, $S$. pyogenes and $S$. aureus. In particular, the 3-quinolyl compound (compound 45) was more effective against the strains of $S$. pneumoniae and of $S$. pyogenes resistant to MLSB compared to its positional isomer 4-quinolyl (compound 46) (Figure 31). However, this compound was still inactive against the B0330 strain of $S$. aureus, resistant to MLSB [206]. The cyclization of the diols $C 11$ and 12 of compound 45 surprisingly strengthened the activities of the derivative 11,12 cyclic carbonate obtained (compound 47). Compared to its acyclic diol analogue (compound 45), it has a broad antibacterial spectrum extended against BML resistant $S$. aureus, $S$. pyogenes and $H$. influenzae. With the exception of its moderate activity against strains of $S$. pneumoniae resistant to BML, the overall performance of compound 47 was comparable on that of Telithromycin [206] (Figure 31).

Duplication of the same allyl-quinoline ether chain at positions $O 6$ and $O 13$, on the lactam-ketolide analogue (9a-aza) of compound 45 , considerably improved the antibacterial activity of compound $\mathbf{4 8}$ obtained (Figure 31 ). This performance was reflected in the activity against $S$. pneumoniae and $S$. pyogenes, which are resistant to MLSB as well as against Gram-positive bacteria resistant to MLSB. The lactam-ketolide ( $9 a$-aza) or compound 48 was approximately 8 to 16 times more effective against the strains of $\mathcal{S}$. pneumoniae and $S$. pyogenes resistant to BML than its monosubstituted analogue or compound 45 [206].

\subsubsection{Bicyclic and Tricyclic Ketolides: Bicyclonides and Tricyclonides}

\section{1) Acetylimine 6,11-bicyclonides: Modithromycin and derivatives.}

Another approach for obtaining neoketolides capable of avoiding intra-acetalization reactions, consisted in bridging in particular the hydroxyls in $C 6$ and $C 11$ of 3-keto erythromycin A, by means of an acetone oxime chain whose oxygen is alkylated by a methyl-heteroaryl group: $\left[-\mathrm{CH}_{2}-\mathrm{C}\left(\mathrm{NO}-\mathrm{CH}_{2}-\right.\right.$ heteroaryl) $-\mathrm{CH}_{2}-$ ]. This chemical modification led to the formation of a new O6-O11 cycle to give rise to a new chemical series, that of bicyclic ketolides or 6,11-bicyclonides. The best representative of this group is Modithromycin (Figure 32). This bicyclonide is also characterized structurally by the presence of an acetylimine function by replacing the $C 9$ ketone. The heteroaryl of the methyl-heteroaryl chain of the bridged oxime is of the 2-pyrazolyl-3-pydinyl like [207] [208]. Modithromycin has good activity on most respiratory pathogens including strains resistant to Erythromycin by an inducible MLSB mechanism, on atypical germs as well as on methicillin-resistant Staphylococcus with a post-antibiotic effect comparable to that of Telithromycin [209] [210]. Furthermore, its activity on Mycobacterium avium is remarkable [208]. After a single 
oral dose to healthy volunteers, plasma concentrations were $0.2 \mathrm{mg} / \mathrm{L}$ and $1 \mathrm{mg} / \mathrm{L}$ at $100 \mathrm{mg}$ and $1200 \mathrm{mg}$ doses respectively after an average of 3 hours. The apparent elimination half-life was approximately 15 hours. Modithromycin is currently recommended for the treatment of respiratory tract infections [211] [212]. Other 6,11-bicyclonides analogues of Modithromycin (Figure 32) have also been developed [213]. The modifications made consisted in replacing the $C 9$ acetylimine group with the initial carbonyl (compound 49) or else in replacing acetylimine with another of a propionylimine nature (compound 50). At the level of the heteroaryl pyridinyl-pyrazole of Modithromycin, this has also been replaced by other heteroaryl fractions of pyridinyl-aminothiazole nature (compound 49) still thiazolyl-aminopyridine (compound 50) or pyridinyl-isoxazole (compound 51). Furthermore, by analogy with the interesting antibacterial effects stimulated by the presence of fluorine, we are also witnessing such an introduction of fluorine into $C 2$ like Solithromycin (compound 50). All of these new bicyclonides have shown potent activities against $H$. influenzae strains. Compound 50 with a faction of thiazolyl-aminopyridine-like heterocycles, a $C 9$ propionylimine and a $C 2$ fluorine has risen like Modithromycin, active against the methicillin-resistant $S$. aureus [213].

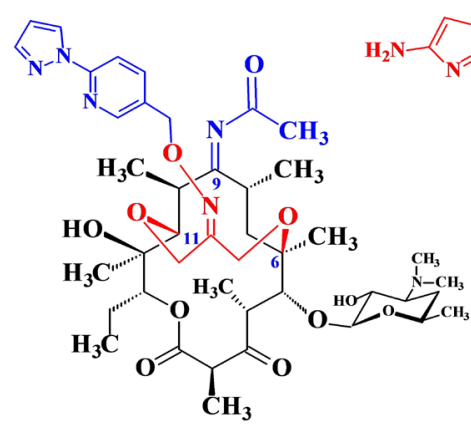

Modithromycin
Compound 49
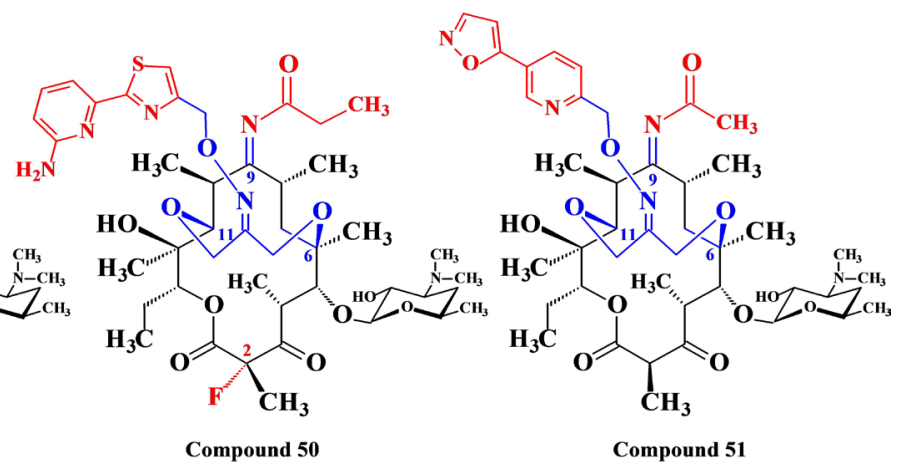

Figure 32. Bicyclonide: structure of modithromycin and its derivatives and analogues.

\section{2) Tricyclic ketolides or Tricyclonides}

In pursuit of the quest for more effective macrolides against pathogenic and resistant respiratory germs, a new series of ketolides characterized by a 6-O-methyltricyclic skeleton bridged with $\mathrm{C} 9-\mathrm{C} 11-\mathrm{C} 12$ has been developed (Figure 33). These ketolides or Tricyclonides were prepared from Clarithromycin intermediates following a series of reactions introducing ethylenediamine, the formation of $C 11$ and $C 12$ carbamate followed by an intramolecular formation of imine and the construction of a 9,11-diazaheptene cycle [214] [215] [216]. The first derivatives of this series differed in the presence or absence of methyl substituents in alpha (C17) of the imine of the 9,11-diazaheptene ring. Thus, four derivatives, namely the compounds TE-802, TE-935, TE-943 and TE-806 were evaluated for their antibacterial activities (Figure 33). These note that these new ketolides are effective in vitro on strains sensitive to Erythromycin, on S. aureus resistant to Erythromycin, on certain Gram (-) bacteria, an- 
aerobic bacteria and Mycoplasma pneumoniae. In particular, the compound not methylated on diazaheptene ring or compound TE-802, has proved to be the most effective and has exhibited activities comparable to or even superior to those of Clarithromycin and Azithromycin against the Gram (+). TE-802 was also effective against certain strains of $S$. pneumoniae resistant to erythromycin. In terms of pharmacokinetics, TE-802 presented in vivo in rats, good stability in gastric acid medium, a long half-life and better tissue penetration. However, all these 6-O-methyltricyclic ketolides did not show any effective activity against $S$. pneumoniae constitutionally resistant to MLSB [214] [215] [216].

Faced with the low activity of TE-802 and its methylated derivatives against Streptococcus pneumoniae resistant to Erythromycin by an MLSB mechanism and on Haemophilus influenzae, two types of chemical variation were operated in order to reinforce the activity antibacterial of new TE-802 derivatives on these bacteria. The first modulation consisted in introducing on the $C 2$ of TE-802 compound, a fluorine atom as in the case of Solithromycin [217]. The analogue 2-fluoro-TE-802 or compound 52 obtained (Figure 33) effectively presented an improved antibacterial and pharmacokinetic profile. Indeed, the presence of fluorine widened the spectrum of action in vivo in the rat of this analogue of TE-802 to $H$. influenzae. Furthermore, the other analogues C2-substituted by hydroxyl or alkyl groups or even chlorine or bromine atoms, showed no improvement in the expected activities [217]. The second modification consisted to introducing alkoxy-aryl substituents in alpha position (C17) or in beta position (C16) of the imine of 9,11-diazaheptene ring of TE-802 compound (Figure 33). In general, the derivatives resulting from this modification of TE-802 have shown improved antibacterial activities, in particular on Streptococci resistant by an MLSB mechanism and on Haemophilus influenzae [218]. In addition, SAR studies show that the spatial and isomeric arrangements of alkoxy-aryls on the diazaheptene ring influence activity. Derivatives with $C 16$ substitution carrying a quinoline have better in vitro activity against MLSB resistant Streptococci and $H$. influenzae. Conversely, the compounds resulting from the substitution for $\mathrm{Cl} 7$ would have better in vivo efficacy. These are indeed 2 to 3 times more effective

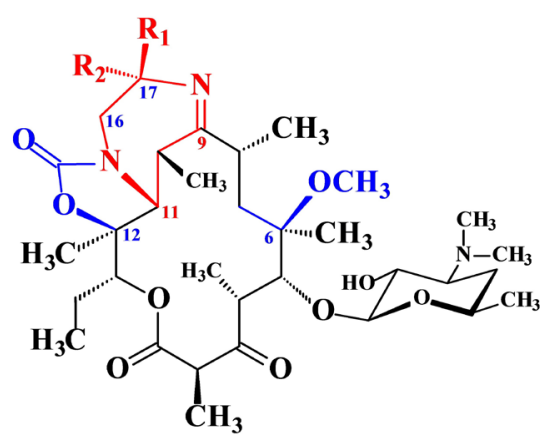

TE-802: $\mathrm{R}_{1}=\mathrm{R}_{2}=\mathrm{H} \quad$ TE-935: $\mathrm{R}_{1}=\mathrm{CH}_{3} ; \mathrm{R}_{2}=\mathrm{H}$ TE-806: $\mathrm{R}_{1}=\mathrm{R}_{2}=\mathrm{CH}_{3}$ TE-943: $\mathrm{R}_{1}=\mathrm{H} ; \mathrm{R}_{2}=\mathrm{CH}_{3}$

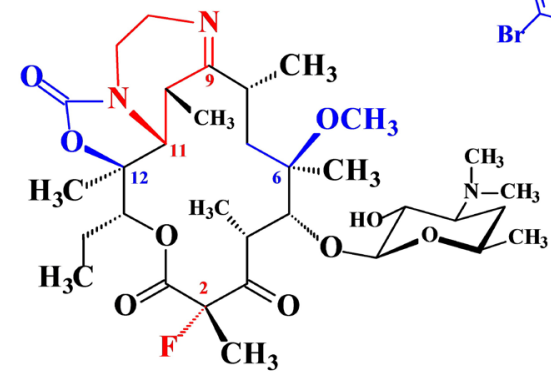

Compound 52

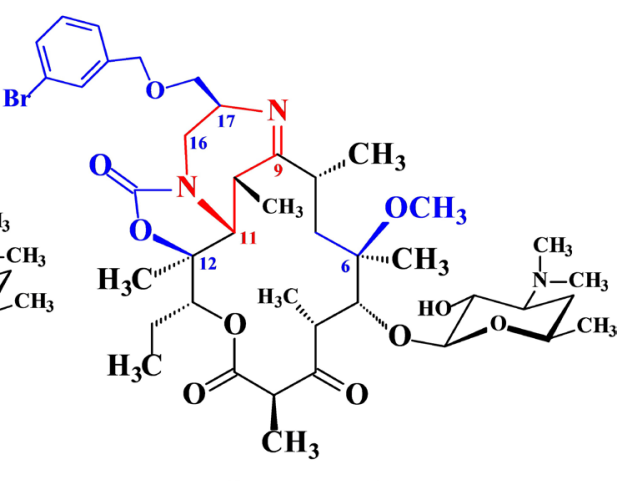

Compound 53

Figure 33. Tricyclic ketolides: TE-802 and its derivatives and analogues. 
than Clarithromycin even if they have a performance comparable to that of TE-802. Among these substituted $C 17 \mathrm{~s}$, the bromobenzyloxy-methyl analogue (compound 53) was found to be the most effective (Figure 33). Substituted C17 derivatives or alpha derivatives of imine appear to preserve the antibacterial properties of TE-802 [218] [219].

\section{Structure-Activity Correlations and Serial Molecular Docking of Ketolides and Neoketolide Derivatives}

At the end of this review of the literature relating to the pharmacochemical evolution of Erythromycin towards ketolides and its neoketolide derivatives, structure-activity relationships can be established as well as a molecular docking study, that can be used as pharmacochemical tools for the development of news effective and less toxic ketolides and neoketolides. Indeed, SAR studies have established the importance of modulators for optimizing bacterial activities as well as pharmacodynamic and pharmacokinetic properties (Figure 34). For molecular docking studies using ligand and receptor overlays, these have explored the binding patterns of ketolides and neoketolides at the ribosomal target of the bacterial germ [113]. Thus, as shown in Figure 34.

The 6-O-alkylation of the hydroxyl by a linker carrying heterocyclic groups would be beneficial to improve the antibacterial activities if the linker is a hydrogen bond donor and if the heterocyclic part is of a nature to constitute a privileged region for the hydrogen bonds acceptor groups. Furthermore, this 6- $O$-alkylation would strongly contribute to molecular stability. The replacement of the ketone in position $C 9$ by an oxime group would prevent degradation reactions in an acid medium and would therefore be beneficial for the maintenance of antibacterial activities. This activity would be optimal with minor, hydrophobic and electron donor bonds. The creation of carbamate, carbonate or

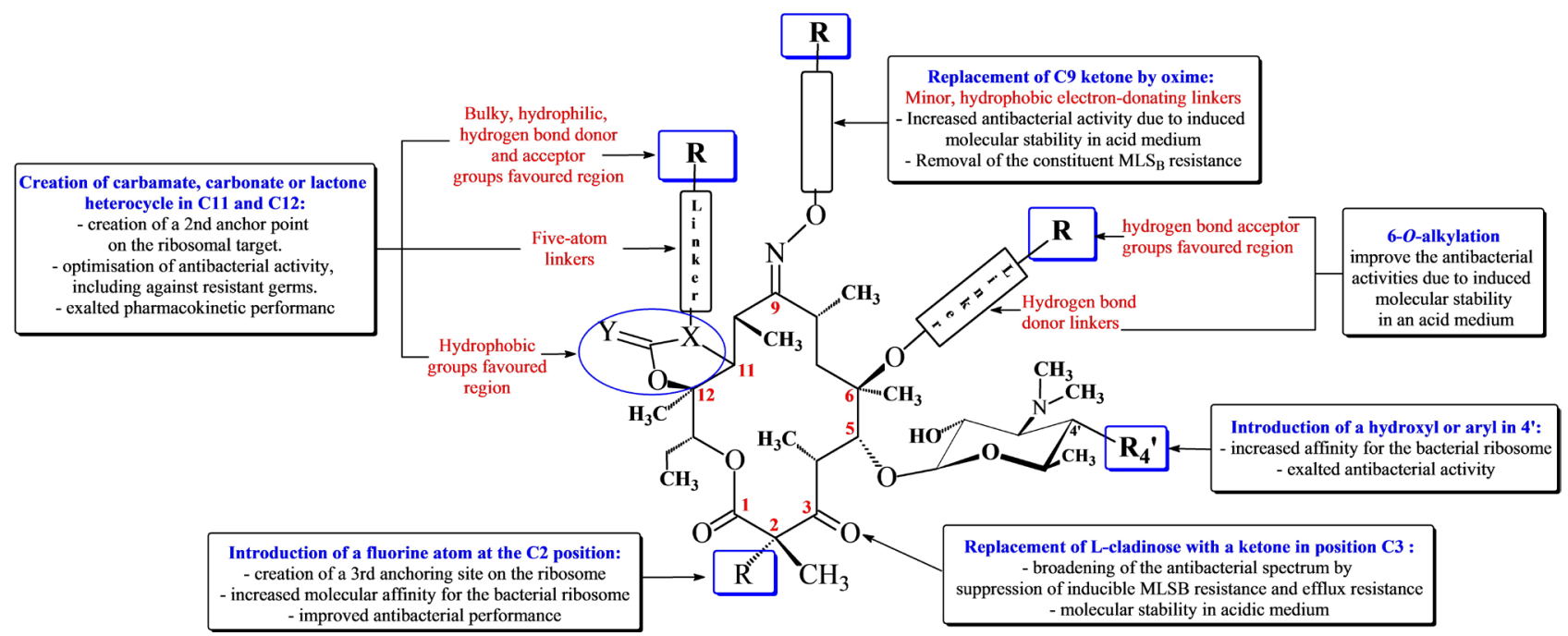

Figure 34. SAR and serial molecular docking of ketolides. 
lactone heterocycle in $C 11$ and $C 12$ would generate a second anchoring point on the ribosomal target and would optimize the antibacterial activity including against resistant germs. This region must be hydrophobic. Furthermore, when this cycle in $C 11$ and $C 12$ is substituted by a side chain, it must be equivalent in length to 5-atoms and carry a region capable of promoting the anchoring of bulky, hydrophilic or hydrogen bond donor and acceptor groups.

\section{Conclusions}

Almost seventy years. They have therapeutic potential beyond their usual antibacterial properties that should be explored. Currently, with the development of total synthesis methods, they represent a real opportunity for pharmacochemists to design new and even more effective macrolide derivatives and analogues for the revival of effective antibiotic therapy. Indeed, taking into account the structural elements essential to the antibacterial activity of macrolides, several chemical variations have been undertaken on Erythromycin A, their lead molecule, in order to overcome its limits of use. The SAR studies undertaken on the structure of Erythromycin A have led to the development of neomacrolides (Clarithromycin, Roxithromycin, Azithromycin etc.). However, some respiratory pathogens remained resistant to neomacrolides. Thus, new chemical variations were undertaken to enhance the interaction between macrolides and their ribosomal bacterial target by creating new anchoring sites. This led to the development of ketolides. The latter is characterized by the presence of a ketone at position $C 3$, a carbamate, carbonate or cyclic lactone in position $C 11$ and $C 12$. These heterocycles are substituted or not by an alkyl-aryl type side chain. It should be noted that all ketolides are O6-alkylated. These modulations have made it possible to improve stability in gastric acid medium, but above all to broaden the spectrum of antibacterial action towards Gram-positive germs, including strains resistant to other macrolides. The three main representatives of ketolides that are Telithromycin, Cethromycin and Solithromycin are more or less well tolerated. However, these ketolides were less effective against methicillin-resistant Staphylococcus aureus and Haemophilus influenzae. Therefore, new ketolide or neoketolide derivatives, active on Gram-positive germs including resistant strains inducing MLSB resistance as well as antibiotic efflux have been developed. These neoketolides have been designed with the same pharmacochemical concepts used in the development of neomacrolides. To this should be added variations of the $C 2$-fluorination type, the introduction of alkyl-amine groups (ketoazalide) or an amide (ketolactam) in the aglycone of the neoketolides, the creation of bridged bonds to form bicyclic and tricyclic neoketolides (bicyclonide and tricyclonide).

These different pharmacomodulations show prospects for the development of new ketolides that are even more powerful against the most resistant germs, atypical germs and against certain Gram-negative germs. Among these neoketolides that are the most advanced or in clinical phase are the azetidinyl-carbamate 
ketolide PF-04287881, Nafithromycin, Modithromycin, the compound CP-654743 an ether-oxime derivative, certain compounds of the ketoazalide series, and even tricyclic derivatives of the diazaheptene type such as the compound TE-802 and its derivatives.

\section{Acknowledgments}

The authors thank Professor Aissata Diakité for the corrections made to the English translation.

\section{Conflicts of Interest}

The authors declare no conflicts of interest regarding the publication of this paper.

\section{References}

[1] Bryskier, A. (2005) Antimicrobial Agents: Antibacterials and Antifungals. ASM Press, Washington. https://doi.org/10.1128/9781555815929

[2] Schönfeld, W. and Kirst, H.A. (2002) Macrolide Antibiotics. Springer Science \& Business Media, Berlin. https://doi.org/10.1007/978-3-0348-8105-0

[3] Sabath, L.D., Laverdiere, M., Wheeler, N., Blazevic, D. and Wilkinson, B. (1977) A New Type of Penicillin Resistance of Staphylococcus Aureus. The Lancet, 309, 443-447. https://doi.org/10.1016/S0140-6736(77)91941-9

[4] Zuckerman, J.M. (2004) Macrolides and Ketolides: Azithromycin, Clarithromycin, Telithromycin. Infectious Disease Clinics of North America, 18, 621-649. https://doi.org/10.1016/j.idc.2004.04.010

[5] Anderson, R., Groundwater, P.W., Todd, A. and Worsley, A. (2012) Antibacterial Agents: Chemistry, Mode of Action, Mechanisms of Resistance and Clinical Applications. John Wiley \& Sons, Ltd., Hoboken. https://doi.org/10.1002/9781118325421

[6] Gaudy, C., Buxeraud, J. and Mereghetti, L. (2005) Antibiotiques (Pharmacologie et Thérapeutique). Collection Pharma.

[7] Labro, M.T. (2006) Immunomodulation médiée par les agents antibactériens. Réanimation, 15, 259-264. https://doi.org/10.1016/j.reaurg.2006.06.004

[8] Langelot, M., Cellerin, L. and Germaud, P. (2006) Effets anti-inflammatoires des macrolides: Applications en Pneumologie. Revue de Pneumologie Clinique, 62, 215-222. https://doi.org/10.1016/S0761-8417(06)75444-X

[9] Canu, A. and Leclercq, R. (2002) Les macrolides: une diversité de mécanismes de résistance. Medecine et maladies infectieuses, 32, 32-44. https://doi.org/10.1016/S0399-077X(02)80005-1

[10] Leclercq, R. (2002) Mechanisms of Resistance to Macrolides and Lincosamides: Nature of the Resistance Elements and Their Clinical Implications. Clinical Infectious Diseases, 34, 482-492. https://doi.org/10.1086/324626

[11] Driggers, E.M., Hale, S.P., Lee, J. and Terrett, N.K. (2008) The Exploration of Macrocycles for Drug Discovery-An Underexploited Structural Class. Nature Reviews Drug Discovery, 7, 608-624. https://doi.org/10.1038/nrd2590

[12] Mallinson, J. and Collins, I. (2012) Macrocycles in New Drug Discovery. Future Medicinal Chemistry, 4, 1409-1438. https://doi.org/10.4155/fmc.12.93 
[13] Marsault, E. and Peterson, M.L. (2011) Macrocycles are Great Cycles: Applications, Opportunities, and Challenges of Synthetic Macrocycles in Drug Discovery. Journal of Medicinal Chemistry, 54, 1961-2004. https://doi.org/10.1021/jm1012374

[14] Adam, Y., Boudet-Dalbin, R., Brion, J.D., Buxeraud, J. and Castel, J. (1992) Traité de chimie thérapeutique 2: Médicaments antibiotiques. Editions: Médicales Internationales.

[15] Zhang, H., Wang, Y., Wu, J., Skalina, K. and Pfeifer, B.A. (2010) Complete Biosynthesis of Erythromycin A and Designed Analogs Using E. coli as a Heterologous Host. Chemistry \& Biology, 17, 1232-1240. https://doi.org/10.1016/j.chembiol.2010.09.013

[16] Egan, R.S., Perun, T.J., Martin, J.R. and Mitscher, L.A. (1973) The Conformation of Erythronolide, the 14-Membered Aglycone Ring of the Erythromycin Antibiotics. Tetrahedron, 29, 2525-2538. https://doi.org/10.1016/0040-4020(73)80169-3

[17] Everett, J.R. and Tyler, J.W. (1987) The Conformational Analysis of Erythromycin A. Journal of the Chemical Society, Perkin Transactions, 2, 1659-1667. https://doi.org/10.1039/p29870001659

[18] Masamune, S., Bates, G.S. and Corcoran, J.W. (1977) Macrolides. Recent Progress in Chemistry and Biochemistry. Angewandte Chemie International Edition in English, 16, 585-607. https://doi.org/10.1002/anie.197705851

[19] Xiong, L., Shah, S., Mauvais, P. and Mankin, A.S. (2002) A Ketolide Resistance Mutation in Domain II of 23S rRNA Reveals the Proximity of Hairpin 35 to the Peptidyl Transferase Centre. Molecular Microbiology, 31, 633-639. https://doi.org/10.1046/j.1365-2958.1999.01203.x

[20] Hansen, L.H., Mauvais, P. and Douthwaite, S. (2002) The Macrolide-Ketolide Antibiotic Binding Site is Formed by Structures in Domains II and V of $23 \mathrm{~S}$ Ribosomal RNA. Molecular Microbiology, 31, 623-631. https://doi.org/10.1046/j.1365-2958.1999.01202.x

[21] Weisblum B. (1995) Erythromycin Resistance by Ribosome Modification. Antimicrobial Agents and Chemotherapy, 39, 577-585. https://doi.org/10.1128/AAC.39.3.577

[22] Menninger, J.R. and Otto, D.P. (1982) Erythromycin, Carbomycin, and Spiramycin Inhibit Protein Synthesis by Stimulating the Dissociation of Peptidyl-tRNA from Ribosomes. Antimicrobial Agents and Chemotherapy, 21, 811-818. https://doi.org/10.1128/AAC.21.5.811

[23] Vázquez-Laslop, N. and Mankin, A.S. (2018) How Macrolide Antibiotics Work. Trends in Biochemical Sciences, 43, 668-684. https://doi.org/10.1016/j.tibs.2018.06.011

[24] Chittum, H.S. and Champney, W.S. (1995) Erythromycin Inhibits the Assembly of the Large Ribosomal Subunit in Growing Escherichia coli Cells. Current Microbiology, 30, 273-279. https://doi.org/10.1007/BF00295501

[25] Kataja, J., Seppälä, H., Skurnik, M., Sarkkinen, H. and Huovinen, P. (1998) Different Erythromycin Resistance Mechanisms in Group C and Group G Streptococci. Antimicrobial Agents and Chemotherapy, 42, 1493-1494. https://doi.org/10.1128/AAC.42.6.1493

[26] Sutcliffe, J.A. and Leclercq, R. (2002) Mechanisms of Resistance to Macrolides, Lincosamides, and Ketolides. Mechanisms of resistance to macrolides, lincosamides, and ketolides. In: Schönfeld, W. and Kirst, H.A., Eds., Macrolide Antibiotics. Milestones in Drug Therapy MDT, Birkhäuser, Basel, 281-317.

https://doi.org/10.1007/978-3-0348-8105-0_17 
[27] Lina, G., Quaglia, A., Reverdy, M.E., Leclercq, R., Vandenesch, F. and Etienne, J. (1999) Distribution of Genes Encoding Resistance to Macrolides, Lincosamides, and Streptogramins among Staphylococci. Antimicrobial Agents and Chemotherapy, 43, 1062-1066. https://doi.org/10.1128/AAC.43.5.1062

[28] Roberts, M.C., Sutcliffe, J., Courvalin, P., Jensen, L.B., Rood, J. and Seppala, H. (1999) Nomenclature for Macrolide and Macrolide-Lincosamide-Streptogramin B Resistance Determinants. Antimicrobial Agents and Chemotherapy, 43, 2823-2830. https://doi.org/10.1128/AAC.43.12.2823

[29] Kirst H.A. (1993) Semi-Synthetic Derivatives of Erythromycin. Progress in Medicinal Chemistry, 30, 57-88. https://doi.org/10.1016/S0079-6468(08)70375-8

[30] Kurath, P., Jones, P.H., Egan, R.S. and Perun, T.J. (1971) Acid Degradation of Erythromycin A and Erythromycin B. Experientia, 27, 362.

https://doi.org/10.1007/BF02137246

[31] Itoh, Z., Nakaya, M., Suzuki, T., Arai, H. and Wakabayashi, K. (1984) Erythromycin Mimics Exogenous Motilin in Gastrointestinal Contractile Activity in the Dog. The American Journal of Physiology, 247, G688-G694. https://doi.org/10.1152/ajpgi.1984.247.6.G688

[32] Bensoussan, C., Delaforge, M. and Mansuy, D. (1995) Particular Ability of Cytochromes P450 3A to Form Inhibitory P450-Iron-Metabolite Complexes Upon Metabolic Oxidation of Aminodrugs. Biochemical Pharmacology, 49, 591-602. https://doi.org/10.1016/0006-2952(94)00477-4

[33] Shafiee, A. and Hutchinson, C.R. (1988) Purification and Reconstitution of the Electron Transport Components for 6-Deoxyerythronolide B Hydroxylase, a Cytochrome P-450 Enzyme of Macrolide Antibiotic (Erythromycin) Biosynthesis. Journal of Bacteriology, 170, 1548-1553. https://doi.org/10.1128/JB.170.4.1548-1553.1988

[34] Weber, J.M., Leung, J.O., Swanson, S.J., Idler, K.B. and McAlpine, J.B. (1991) An Erythromycin Derivative Produced by Targeted Gene Disruption in Saccharopolyspora Erythraea. Science, 252, 114-117. https://doi.org/10.1126/science.2011746

[35] Ōmura, S., Ed. (2002) Macrolide Antibiotics: Chemistry, Biology, and Practice. Elsevier.

[36] Douthwaite, S. (2001) Structure-Activity Relationships of Ketolides vs. Macrolides. Clinical Microbiology and Infection, 7, 11-17. https://doi.org/10.1046/j.1469-0691.2001.0070s3011.x

[37] Mabe, S., Eller, J. and Champney, W. (2004) Structure-Activity Relationships for Three Macrolide Antibiotics in Haemophilus influenzae. Current Microbiology, 49, 248-254. https://doi.org/10.1007/s00284-004-4312-9

[38] Jones, P.H., Perun, T.J., Rowley, E.K. and Baker, E.J. (1972) Chemical Modifications of Erythromycin Antibiotics. 3. Synthesis of 4" and 11 Esters of Erythromycin A and B. Journal of Medicinal Chemistry, 15, 631-634. https://doi.org/10.1021/jm00276a017

[39] Asaka, T., Manaka, A. and Sugiyama, H. (2003) Recent Developments in Macrolide Antimicrobial Research. Current Topics in Medicinal Chemistry, 3, 961-989. https://doi.org/10.2174/1568026033452140

[40] Kirst, H.A. (1998) Recent Developments with Macrolide Antibiotics. Expert Opinion on Therapeutic Patents, 8, 111-120.

https://doi.org/10.1517/13543776.8.2.111 
[41] Van Bambeke, F., Verhaegen, J., Tyteca, D., Auckenthaler, R. and Tulkens, P.M. (2001) Erythromycin and Current Neomacrolides: Clinical Uses and Perspectives. Médecine et Hygiène, 59, 2316-2323.

[42] Tardrew, P.L., Mao, J.C. and Kenney, D. (1969) Antibacterial Activity of 2'-Esters of Erythromycin. Applied Microbiology, 18, 159-165.

https://doi.org/10.1128/AEM.18.2.159-165.1969

[43] Welling P.G. (1979) The Esters of Erythromycin. The Journal of Antimicrobial Chemotherapy, 5, 633-634. https://doi.org/10.1093/jac/5.6.633

[44] Booth, R.E., Dale, J.K. and Murray, M.F. (1958) Erythromycin Esters. US Patent No. 2862921.

[45] Stephens, V.C., Conine, J.W. and Murphy, H.W. (1959) Esters of Erythromycin. IV. Alkyl Sulfate Salts. Journal of the American Pharmaceutical Association, 48, 620-622. https://doi.org/10.1002/jps.3030481104

[46] Welling, P.G. and Craig, W.A. (1978) Pharmacokinetics of Intravenous Erythromycin. Journal of Pharmaceutical Sciences, 67, 1057-1059.

https://doi.org/10.1002/jps.2600670809

[47] Patamasucon, P., Kaojarern, S., Kusmiesz, H. and Nelson, J.D. (1981) Pharmacokinetics of Erythromycin Ethylsuccinate and Estolate in Infants under 4 Months of Age. Antimicrobial Agents and Chemotherapy, 19, 736-739. https://doi.org/10.1128/AAC.19.5.736

[48] Chun, A.H.C. and Seitz, J.A. (1977) Pharmacokinetics and Biological Availability of Erythromycin. Infection, 5, 14-22.

[49] Mather, L.E., Austin, K.L., Philpot, C.R. and McDonald, P.J. (1981) Absorption and Bioavailability of Oral Erythromycin. British Journal of Clinical Pharmacology, 12, 131-140. https://doi.org/10.1111/j.1365-2125.1981.tb01191.x

[50] Bahal, N. and Nahata, M.C. (1992) The New Macrolide Antibiotics: Azithromycin, Clarithromycin, Dirithromycin, and Roxithromycin. The Annals of Pharmacotherapy, 26, 46-55. https://doi.org/10.1177/106002809202600112

[51] Peters, D.H. and Clissold, S.P. (1992) Clarithromycin. A Review of Its Antimicrobial Activity, Pharmacokinetic Properties and Therapeutic Potential. Drugs, 44, 117-164. https://doi.org/10.2165/00003495-199244010-00009

[52] Langtry, H.D. and Brogden, R.N. (1997) Clarithromycin. A Review of Its Efficacy in the Treatment of Respiratory Tract Infections in Immunocompetent Patients. Drugs, 53, 973-1004. https://doi.org/10.2165/00003495-199753060-00006

[53] Watanabe, Y., Morimoto, S., Goi, M., Mitsukuchi, M., Adachi, T., Nakagami, J. and Sota, K. (1987) Method for Selective Methylation of Erythromycin a Derivatives. US Patent No. 4672109.

[54] Fraschini, F., Scaglione, F. and Demartini, G. (1993) Clarithromycin Clinical Pharmacokinetics. Clinical Pharmacokinetics, 25, 189-204.

https://doi.org/10.2165/00003088-199325030-00003

[55] Sturgill, M.G. and Rapp, R.P. (1992) Clarithromycin: Review of a New Macrolide Antibiotic with Improved Microbiologic Spectrum and Favorable Pharmacokinetic and Adverse Effect Profiles. The Annals of Pharmacotherapy, 26, 1099-1108. https://doi.org/10.1177/106002809202600912

[56] Davidson R.J. (2019) In Vitro Activity and Pharmacodynamic/Pharmacokinetic Parameters of Clarithromycin and Azithromycin: Why They Matter in the Treatment of Respiratory Tract Infections. Infection and Drug Resistance, 12, 585-596. https://doi.org/10.2147/IDR.S187226 
[57] Saverino, D., Debbia, E.A., Pesce, A., Lepore, A.M. and Schito, G.C. (1992) Antibacterial Profile of Flurithromycin, a New Macrolide. The Journal of Antimicrobial Chemotherapy, 30, 261-272.

[58] Villa, P., Corti, F., Guaitani, A., Bartosek, I., Casacci, F., De Marchi, F. and Pacei, E. (1986) Effects of a New Fluorinated Macrolide (P-0501A) and Other Erythromycins on Drug Metabolizing Enzymes in Rat Liver. The Journal of antibiotics, 39, 463-468. https://doi.org/10.7164/antibiotics.39.463

[59] Benoni, G., Cuzzolin, L., Leone, R., Consolo, U., Ferronato, G., Bertrand, C., Puchetti, V. and Fracasso, M.E. (1988) Pharmacokinetics and Human Tissue Penetration of Flurithromycin. Antimicrobial Agents and Chemotherapy, 32, 1875-1878. https://doi.org/10.1128/AAC.32.12.1875

[60] Galioto, G.B., Mevio, E., Galioto, P., Zanuso, G. and Lepore, A.M. (1989) Concentrations of Flurithromycin in Serum and Tonsils. International Journal of Clinical Pharmacology, Therapy, and Toxicology, 27, 126-128.

[61] Furneri, P.M., Bisignano, G., Cerniglia, G., Tempera, G. and Nicoletti, G. (1995) In-Vitro Antimycoplasmal Activity of Flurithromycin. The Journal of Antimicrobial Chemotherapy, 35, 161-165. https://doi.org/10.1093/jac/35.1.161

[62] Gasc, J.C., D’Ambrieres, S.G., Lutz, A. and Chantot, J.F. (1991) New Ether Oxime Derivatives of Erythromycin A. A Structure-Activity Relationship Study. The Journal of Antibiotics, 44, 313-330.

[63] Gentry, L.O. (1987) Roxithromycin, a new Macrolide Antibiotic, in the Treatment of Infections in the Lower Respiratory Tract: An Overview. The Journal of Antimicrobial Chemotherapy, 20, 145-152. https://doi.org/10.1093/jac/20.suppl_B.145

[64] Lassman, H.B., Puri, S.K., Ho, I., Sabo, R. and Mezzino, M.J. (1988) Pharmacokinetics of Roxithromycin (RU 965). Journal of Clinical Pharmacology, 28, 141-152. https://doi.org/10.1002/j.1552-4604.1988.tb05738.x

[65] Puri, S.K. and Lassman, H.B. (1987) Roxithromycin: A Pharmacokinetic Review of a Macrolide. The Journal of Antimicrobial Chemotherapy, 20, 89-100. https://doi.org/10.1093/jac/20.suppl_B.89

[66] Pechère J.C. (1992) Clinical Evaluation of Roxithromycin 300 mg Once Daily as an Alternative to $150 \mathrm{mg}$ Twice Daily. Diagnostic Microbiology and Infectious Disease, 15, 111S-117S. https://doi.org/10.1016/0732-8893(92)90137-I

[67] Herron J.M. (1987) Roxithromycin in the Therapy of Streptococcus Pyogenes Throat Infections. The Journal of Antimicrobial Chemotherapy, 20, 139-144. https://doi.org/10.1093/jac/20.suppl_B.139

[68] De Campora, E., Camaioni, A., Leonardi, M., Fardella, P. and Fiaoni, M. (1992) Comparative Efficacy and Safety of Roxithromycin and Clarithromycin in Upper respiratory Tract Infections. Diagnostic Microbiology and Infectious Disease, 15, 119S-122S. https://doi.org/10.1016/0732-8893(92)90138-J

[69] Massey, E.H., Kitchell, B.S., Martin, L.D. and Gerzon, K. (1974) Antibacterial Activity of 9(S)-Erythromycylamine-Aldehyde Condensation Products. Journal of $\mathrm{Me}$ dicinal Chemistry, 17, 105-107. https://doi.org/10.1021/jm00247a018

[70] Massey, E.H., Kitchell, B., Martin, L.D., Gerzon, K. and Murphy, H.W. (1970) Erythromycylamine. Tetrahedron Letters, 157-160. https://doi.org/10.1016/S0040-4039(01)97664-6

[71] Mtairag, E.M., Abdelghaffar, H. and Labro, M.T. (1994) Investigation of Dirithromycin and Erythromycylamine Uptake by Human Neutrophils in Vitro. The Journal of Antimicrobial Chemotherapy, 33, 523-536. 
https://doi.org/10.1093/jac/33.3.523

[72] Wintermeyer, S.M., Abdel-Rahman, S.M. and Nahata, M.C. (1996) Dirithromycin: A New Macrolide. The Annals of Pharmacotherapy, 30, 1141-1149. https://doi.org/10.1177/106002809603001014

[73] Counter, F.T., Ensminger, P.W., Preston, D.A., Wu, C.Y., Greene, J.M., FeltyDuckworth, A.M., Paschal, J.W. and Kirst, H.A. (1991) Synthesis and Antimicrobial Evaluation of Dirithromycin (AS-E 136; LY237216), A New Macrolide Antibiotic Derived from Erythromycin. Antimicrobial Agents and Chemotherapy, 35, 1116-1126. https://doi.org/10.1128/AAC.35.6.1116

[74] Brogden, R.N. and Peters, D.H. (1994) Dirithromycin. A Review of Its Antimicrobial Activity, Pharmacokinetic Properties and Therapeutic Efficacy. Drugs, 48, 599-616. https://doi.org/10.2165/00003495-199448040-00008

[75] Sides, G.D., Cerimele, B.J., Black, H.R., Busch, U. and DeSante, K.A. (1993) Pharmacokinetics of Dirithromycin. The Journal of Antimicrobial Chemotherapy, 31, 65-75. https://doi.org/10.1093/jac/31.suppl_C.65

[76] Peters, D.H., Friedel, H.A. and McTavish, D. (1992) Azithromycin. A Review of Its Antimicrobial Activity, Pharmacokinetic Properties and Clinical Efficacy. Drugs, 44, 750-799. https://doi.org/10.2165/00003495-199244050-00007

[77] Schönfeld, W. and Mutak, S. (2002) Azithromycin and Novel Azalides. In: Schönfeld, W. and Kirst, H.A., Eds., Macrolide Antibiotics. Milestones in Drug Therapy MDT, Birkhäuser, Basel, 73-95. https://doi.org/10.1007/978-3-0348-8105-0_6

[78] Roblin, P.M. and Hammerschlag, M.R. (1998) Microbiologic Efficacy of Azithromycin and Susceptibilities to Azithromycin of Isolates of Chlamydia Pneumoniae from Adults and Children with Community-Acquired Pneumonia. Antimicrobial Agents and Chemotherapy, 42, 194-196. https://doi.org/10.1128/AAC.42.1.194

[79] Lode, H., Borner, K., Koeppe, P. and Schaberg, T. (1996) Azithromycin-Review of Key Chemical, Pharmacokinetic and Microbiological Features. The Journal of Antimicrobial Chemotherapy, 37, 1-8. https://doi.org/10.1093/jac/37.suppl_C.1

[80] Labro, M.T. (1998) Anti-Inflammatory Activity of Macrolides: A New Therapeutic Potential? The Journal of Antimicrobial Chemotherapy, 41, 37-46.

https://doi.org/10.1093/jac/41.suppl_2.37

Labro, M.T. (2004) Macrolide Antibiotics: Current and Future Uses. Expert Opinion on Pharmacotherapy, 5, 541-550.

https://doi.org/10.1093/jac/41.suppl_2.37

[81] Ianaro, A., Ialenti, A., Maffia, P., Sautebin, L., Rombolà, L., Carnuccio, R., Iuvone, T., D'Acquisto, F. and Di Rosa, M. (2000) Anti-Inflammatory Activity of Macrolide Antibiotics. The Journal of Pharmacology and Experimental Therapeutics, 292, 156-163.

[82] Culić, O., Eraković, V. and Parnham, M.J. (2001) Anti-Inflammatory Effects of Macrolide Antibiotics. European Journal of Pharmacology, 429, 209-229. https://doi.org/10.1016/S0014-2999(01)01321-8

[83] Amsden G.W. (2005) Anti-Inflammatory Effects of Macrolides-An Underappreciated benefit in the Treatment of Community-Acquired Respiratory Tract Infections and Chronic Inflammatory Pulmonary Conditions? The Journal of Antimicrobial Chemotherapy, 55, 10-21. https://doi.org/10.1093/jac/dkh519

[84] Deshpande, D., Pasipanodya, J.G. and Gumbo, T. (2016) Azithromycin Dose To Maximize Efficacy and Suppress Acquired Drug Resistance in Pulmonary Myco- 
bacterium avium Disease. Antimicrobial Agents and Chemotherapy, 60, 2157-2163. https://doi.org/10.1128/AAC.02854-15

[85] Alffenaar, J.C. and Van Ingen, J. (2017) Treatment of Mycobacterium aviumIntracellulare Complex: A Great Leap Forward. The Journal of Antimicrobial Chemotherapy, 72, i1-i2. https://doi.org/10.1093/jac/dkx310

[86] Van Eijk, A.M. and Terlouw, D.J. (2011) Azithromycin for Treating Uncomplicated Malaria. The Cochrane Database of Systematic Reviews, No. 2, Article No. CD006688. https://doi.org/10.1002/14651858.CD006688.pub2

[87] Rosenthal P.J. (2016) Azithromycin for Malaria? The American Journal of Tropical Medicine and Hygiene, 95, 2-4. https://doi.org/10.4269/ajtmh.16-0332

[88] Gielen, V., Johnston, S.L. and Edwards, M.R. (2010) Azithromycin Induces Anti-Viral Responses in Bronchial Epithelial Cells. The European Respiratory Journal, 36, 646-654. https://doi.org/10.1183/09031936.00095809

[89] Min, J.Y. and Jang, Y.J. (2012) Macrolide Therapy in Respiratory Viral Infections. Mediators of Inflammation, 2012, Article ID: 649570. https://doi.org/10.1155/2012/649570

[90] Zhou, X., Zhang, Y., Li, Y., Hao, X., Liu, X. and Wang, Y. (2012) Azithromycin Synergistically Enhances Anti-Proliferative Activity of Vincristine in Cervical and Gastric Cancer Cells. Cancers, 4, 1318-1332. https://doi.org/10.3390/cancers4041318

[91] Qiao, X., Wang, X., Shang, Y., Li, Y. and Chen, S.Z. (2018) Azithromycin Enhances Anticancer Activity of TRAIL by Inhibiting Autophagy and Up-Regulating the Protein Levels of DR4/5 in Colon Cancer Cells in Vitro and in Vivo. Cancer Communications (London, England), 38, 1-13. https://doi.org/10.1186/s40880-018-0309-9

[92] Viget, N., Legout, L. and Alfandari, S. (2005) Kétolides. EMC-Maladies Infectieuses, 2, 33-41. https://doi.org/10.1016/j.emcmi.2004.09.001

[93] Ma, Z. and Nemoto, P.A. (2002) Discovery and Development of Ketolides as a New Generation of Macrolide Antimicrobial Agents. Current Medicinal Chemistry-Anti-Infective Agents, 1, 15-34. https://doi.org/10.2174/1568012023355027

[94] Zhanel, G.G., Walters, M., Noreddin, A., Vercaigne, L.M., Wierzbowski, A., Embil, J.M., Gin, A.S., Douthwaite, S. and Hoban, D.J. (2002) The Ketolides: A Critical Review. Drugs, 62, 1771-1804. https://doi.org/10.2165/00003495-200262120-00006

[95] Schlünzen, F., Harms, J.M., Franceschi, F., Hansen, H.A., Bartels, H., Zarivach, R. and Yonath, A. (2003) Structural Basis for the Antibiotic Activity of Ketolides and Azalides. Structure, 11, 329-338. https://doi.org/10.1016/S0969-2126(03)00022-4

[96] Rickards, R.W., Smith, R.M. and Majer, J. (1968) The Structure of the Macrolide Antibiotic Picromycin. Chemical Communications (London), 17, 1049-1050. https://doi.org/10.1039/c19680001049

[97] Almutairi, M.M., Svetlov, M.S., Hansen, D.A., Khabibullina, N.F., Klepacki, D., Kang, H.Y., Sherman, D.H., Vázquez-Laslop, N., Polikanov, Y.S. and Mankin, A.S. (2017) Co-Produced Natural Ketolides Methymycin and Pikromycin Inhibit Bacterial Growth by Preventing Synthesis of a Limited Number of Proteins. Nucleic Acids Research, 45, 9573-9582. https://doi.org/10.1093/nar/gkx673

[98] Almutairi, M.M. (2015) The Natural Ketolides Methymycin and Pikromycin: Binding Sites, Modes of Action, Mechanisms of Resistance. Doctoral Dissertation, University of Illinois at Chicago, Chicago.

[99] Arsic, B., Novak, P., Kragol, G., Barber, J., Rimoli, M.G. and Sodano, F. (2018) 
Macrolides: Properties, Synthesis and Applications. De Gruyter, Berlin. https://doi.org/10.1515/9783110515756

[100] Bryskier, A. (1999) New Research in Macrolides and Ketolides since 1997. Expert Opinion on Investigational Drugs, 8, 1171-1194.

https://doi.org/10.1517/13543784.8.8.1171

[101] Resek, J.E., Wang, X.C. and Bhatia, A.V. (2000) Highlights of Recent Research on the Synthesis of Ketolide Antibiotics. Current Opinion in Drug Discovery \& Development, 3, 807-817.

[102] Bhatia, A.V. (2004) Strategies Leading to the Synthesis of a Novel Ketolide Antibiotic. Strategies and Tactics in Organic Synthesis, 5, 133-152. https://doi.org/10.1016/S1874-6004(04)80028-5

[103] Wei, X. and You, Q. (2006) A Facile and Scaleable Synthesis of 3-O-Decladinose-6Methyl-10,11-Dehydrate-Erythromycin-3-One-2'-Acetate, an Important Intermediate for Ketolide Synthesis. Organic Process Research \& Development, 10, 446-449. https://doi.org/10.1021/op060001x

[104] Bulkley, D., Innis, C.A., Blaha, G. and Steitz, T.A. (2010) Revisiting the Structures of Several Antibiotics Bound to the Bacterial Ribosome. Proceedings of the National Academy of Sciences of the United States of America, 107, 17158-17163. https://doi.org/10.1073/pnas.1008685107

[105] Or, Y.S., Clark, R.F., Wang, S., Chu, D.T., Nilius, A.M., Flamm, R.K., Mitten, M., Ewing, P., Alder, J. and Ma, Z. (2000) Design, Synthesis, and Antimicrobial Activity of 6-O-Substituted Ketolides Active against Resistant Respiratory Tract Pathogens. Journal of Medicinal Chemistry, 43, 1045-1049. https://doi.org/10.1021/jm990618n

[106] Ma, Z., Clark, R.F., Brazzale, A., Wang, S., Rupp, M.J., Li, L., Griesgraber, G., Zhang, S., Yong, H., Phan, L.T., Nemoto, P.A., Chu, D.T., Plattner, J.J., Zhang, X., Zhong, P., Cao, Z., Nilius, A.M., Shortridge, V.D., Flamm, R., Mitten, M., Or, Y.S. (2001) Novel Erythromycin Derivatives with Aryl Groups Tethered to the C-6 Position are Potent Protein Synthesis Inhibitors and Active Against Multidrug-Resistant Respiratory Pathogens. Journal of Medicinal Chemistry, 44, 4137-4156. https://doi.org/10.1021/jm0102349

[107] Plata, D.J., Leanna, M.R., Rasmussen, M., McLaughlin, M.A., Condon, S.L., Kerdesky, F.A. and Wittenberger, S.J. (2004) The Synthesis of Ketolide Antibiotic ABT-773 (Cethromycin). Tetrahedron, 60, 10171-10180. https://doi.org/10.1016/j.tet.2004.09.027

[108] Baker, W.R. and Clark, J.D. (1988) Semisynthetic Erythromycin Antibiotics. US Patent No. 4742049.

[109] Slawinski, W., Bojarska-Dahlig, H., Glabski, T., Dziegielewska, I., Biedrzycki, M. and Naperty, S. (1975) The Structure of Erythromycin a Cyclic Carbonate. Recueil des Travaux Chimiques des Pays-Bas, 94, 236-238.

https://doi.org/10.1002/recl.19750941104

[110] Bryskier, A. (2000) Ketolides-Telithromycin, an Example of New Class of Antibacterial Agents. Clinical Microbiology and Infection, 6, 661-669. https://doi.org/10.1046/j.1469-0691.2000.00185.x

[111] Hunt, E., Knowles, D.J., Shillingford, C. and Zomaya, I.I. (1988) Erythromycin a 11,12-Methylene Acetal. The Journal of Antibiotics, 41, 1644-1648. https://doi.org/10.7164/antibiotics.41.1644

[112] Baker, W.R., Clark, J. D., Stephens, R.L. and Kim, K.H. (1988) Modification of Macrolide Antibiotics. Synthesis of 11-Deoxy-11-(Carboxyamino)-6-O-Methylerythromycin A 11, 
12-(Cyclic Esters) via an Intramolecular Michael Reaction of O-Carbamates with an $\alpha, \beta$-Unsaturated Ketone. The Journal of Organic Chemistry, 53, 2340-2345. https://doi.org/10.1021/jo00245a038

[113] Ruan, Z.X., Huangfu, D.S., Xu, X.J., Sun, P.H. and Chen, W.M. (2013) 3D-QSAR and Molecular Docking for the Discovery of Ketolide Derivatives. Expert Opinion on Drug Discovery, 8, 427-444. https://doi.org/10.1517/17460441.2013.774369

[114] Elliott, R.L., Pireh, D., Griesgraber, G., Nilius, A.M., Ewing, P.J., Bui, M.H., Raney, P.M., Flamm, R.K., Kim, K., Henry, R.F., Chu, D.T., Plattner, J.J. and Or, Y.S. (1998) Anhydrolide macrolides. 1. Synthesis and Antibacterial Activity of 2, 3-Anhydro-6-O-Methyl 11, 12-Carbamate Erythromycin A Analogues. Journal of Medicinal Chemistry, 41, 1651-1659. https://doi.org/10.1021/jm970547x

[115] Allen, M.S., Premchandran, R.H., Chang, S.J., Condon, S., Demattei, J.A., King, S.A. and Patel, S.R. (2003) Preparation of Quinoline-Substituted Carbonate and Carbamate Derivatives. US Patent No. 6579986.

[116] Denis, A., Agouridas, C., Auger, J.M., Benedetti, Y., Bonnefoy, A., Bretin, F., Chantot, J. F., Dussarat, A., Fromentin, C., D’Ambrières, S. G., Lachaud, S., Laurin, P., Le Martret, O., Loyau, V., Tessot, N., Pejac, J.M. and Perron, S. (1999) Synthesis and Antibacterial Activity of HMR 3647 a New Ketolide Highly Potent against Erythromycin-Resistant and Susceptible Pathogens. Bioorganic \& Medicinal Chemistry Letters, 9, 3075-3080. https://doi.org/10.1016/S0960-894X(99)00534-X

[117] Brook, I. and Hausfeld, J.N. (2006) Effect of Telithromycin and Azithromycin on Nasopharyngeal Bacterial Flora in Patients with Acute Maxillary Sinusitis. Archives of Otolaryngology_Head \& Neck Surgery, 132, 442-445. https://doi.org/10.1001/archotol.132.4.442

[118] Wellington, K. and Noble, S. (2004) Telithromycin. Drugs, 64, 1683-1696. https://doi.org/10.2165/00003495-200464150-00006

[119] Giovanetti, E., Montanari, M.P., Marchetti, F. and Varaldo, P.E. (2000) In Vitro Activity of Ketolides Telithromycin and HMR 3004 against Italian Isolates of streptococcus Pyogenes and Streptococcus Pneumoniae with Different Erythromycin Susceptibility. The Journal of Antimicrobial Chemotherapy, 46, 905-908. https://doi.org/10.1093/jac/46.6.905

[120] Shi, J., Montay, G. and Bhargava, V.O. (2005) Clinical Pharmacokinetics of Telithromycin, the First Ketolide Antibacterial. Clinical Pharmacokinetics, 44, 915-934. https://doi.org/10.2165/00003088-200544090-00003

[121] Bertrand, D., Bertrand, S., Neveu, E. and Fernandes, P. (2010) Molecular Characterization of Off-Target Activities of Telithromycin: A Potential Role for Nicotinic Acetylcholine Receptors. Antimicrobial Agents and Chemotherapy, 54, 5399-5402. https://doi.org/10.1128/AAC.00840-10

[122] Chen, X.Z., Xu, P., Liu, L., Zheng, D. and Lei, P.S. (2011) Synthesis and Antibacterial Activity of Novel Ketolides with 11,12-Sulfur Contained Aryl Alkyl Side Chains. European Journal of Medicinal Chemistry, 46, 208-217. https://doi.org/10.1016/j.ejmech.2010.11.004

[123] Mansour, H., Chahine, E. B., Karaoui, L.R. and El-Lababidi, R.M. (2013) Cethromycin: A New Ketolide Antibiotic. The Annals of Pharmacotherapy, 47, 368-379. https://doi.org/10.1345/aph.1R435

[124] Beebe, X., Yang, F., Bui, M.H., Mitten, M.J., Ma, Z., Nilius, A.M. and Djuric, S.W. (2004) Synthesis and Antibacterial Activity of 6-O-Arylpropargyl-9-Oxime-11,12Carbamate Ketolides. Bioorganic \& Medicinal Chemistry Letters, 14, 2417-2421. https://doi.org/10.1016/j.bmcl.2004.03.020 
[125] Yong, H., Gu, Y.G., Clark, R.F., Marron, T., Ma, Z., Soni, N., Stone, G.G., Nilius, A. M., Marsh, K. and Djuric, S.W. (2005) Design, Synthesis and Structure-Activity Relationships of 6-O-Arylpropargyl Diazalides with Potent Activity against Multidrug-Resistant Streptococcus Pneumoniae. Bioorganic \& Medicinal Chemistry Letters, 15, 2653-2658. https://doi.org/10.1016/j.bmcl.2005.03.011

[126] Conte, J.E., Jr. Golden, J.A., Kipps, J. and Zurlinden, E. (2004) Steady-State Plasma and Intrapulmonary Pharmacokinetics and Pharmacodynamics of Cethromycin. Antimicrobial Agents and Chemotherapy, 48, 3508-3515.

https://doi.org/10.1128/AAC.48.9.3508-3515.2004

[127] Rafie, S., MacDougall, C. and James, C.L. (2010) Cethromycin: A Promising New Ketolide Antibiotic for Respiratory Infections. Pharmacotherapy, 30, 290-303. https://doi.org/10.1592/phco.30.3.290

[128] Liang J.H. (2015) Introduction of a Nitrogen-Containing Side Chain Appended on $C-10$ of Cethromycin Leads to Reduced CYP3A4 Inhibition (WO2014049356A1) Expert Opinion on Therapeutic Patents, 25, 119-123. https://doi.org/10.1517/13543776.2014.971754

[129] FDA (2009) Cethromycin Briefing Document for the Anti-Infective Drugs Advisory Committee.

http://www.fda.gov/downloads/AdvisoryCommittees/CommitteesMeetingMaterials /Drugs/Anti-InfectiveDrugsAdvisoryCommittee/UCM161850.pdf

[130] English, M.L., Fredericks, C.E., Milanesio, N.A., Rohowsky, N., Xu, Z.Q., Jenta, T.R., Flavin, M.T. and Eiznhamer, D.A. (2012) Cethromycin versus Clarithromycin for Community-Acquired Pneumonia: Comparative Efficacy and Safety Outcomes from Two Double-Blinded, Randomized, Parallel-Group, Multicenter, Multinational Noninferiority Studies. Antimicrobial Agents and Chemotherapy, 56, 2037-2047. https://doi.org/10.1128/AAC.05596-11

[131] Zhu, B., Marinelli, B.A., Abbanat, D., Foleno, B.D., Bush, K. and Macielag, M.J. (2007) Synthesis and Antibacterial Activity of 3-Keto-6-O-Carbamoyl-11,12-cyclic Thiocarbamate Erythromycin A Derivatives. Bioorganic \& Medicinal Chemistry letters, 17, 3900-3904. https://doi.org/10.1016/j.bmcl.2007.04.104

[132] Griesgraber, G., Or, Y.S., Chu, D.T., Nilius, A.M., Johnson, P.M., Flamm, R.K., Henry, R.F. and Plattner, J.J. (1996) 3-Keto-11,12-Carbazate Derivatives of 6-O-Methylerythromycin A Synthesis and in Vitro Activity. The Journal of Antibiotics, 49, 465-477.

[133] Rodgers, W., Frazier, A.D. and Champney, W.S. (2013) Solithromycin Inhibition of Protein Synthesis and Ribosome Biogenesis in Staphylococcus Aureus, Streptococcus Pneumoniae, and Haemophilus Influenzae. Antimicrobial Agents and Chemotherapy, 57, 1632-1637. https://doi.org/10.1128/AAC.02316-12

[134] Xu, X., Henninger, T., Abbanat, D., Bush, K., Foleno, B., Hilliard, J. and Macielag, M. (2005) Synthesis and Antibacterial Activity of C2-Fluoro, C6-Carbamate Ketolides, and Their C9-Oximes. Bioorganic \& Medicinal Chemistry Letters, 15, 883-887. https://doi.org/10.1016/j.bmcl.2004.12.067

[135] Fernandes, P., Martens, E., Bertrand, D. and Pereira, D. (2016) The solithromycin journey-It is all in the chemistry. Bioorganic \& Medicinal Chemistry, 24, 6420-6428. https://doi.org/10.1016/j.bmc.2016.08.035

[136] McGhee, P., Clark, C., Kosowska-Shick, K.M., Nagai, K., Dewasse, B., Beachel, L. and Appelbaum, P.C. (2010) In Vitro Activity of Golparian, against Streptococcus Pneumoniae and Streptococcus Pyogenes with Defined Macrolide Resistance Mechanisms. Antimicrobial Agents and Chemotherapy, 54, 230-238. 
https://doi.org/10.1128/AAC.01123-09

[137] Putnam, S.D., Sader, H.S., Farrell, D.J., Biedenbach, D.J. and Castanheira, M. (2011) Antimicrobial Characterisation of Solithromycin (CEM-101), a Novel Fluoroketolide: Activity against Staphylococci and Enterococci. International Journal of Antimicrobial Agents, 37, 39-45. https://doi.org/10.1016/j.ijantimicag.2010.08.021

[138] Wittlin, S., Ekland, E., Craft, J.C., Lotharius, J., Bathurst, I., Fidock, D.A. and Fernandes, P. (2012) In Vitro and in Vivo Activity Of Solithromycin (CEM-101) against Plasmodium Species. Antimicrobial Agents and Chemotherapy, 56, 703-707. https://doi.org/10.1128/AAC.05039-11

[139] Golparian, D., Fernandes, P., Ohnishi, M., Jensen, J.S. and Unemo, M. (2012) In Vitro Activity of the New Fluoroketolide Solithromycin (CEM-101) against a Large Collection of Clinical Neisseria Gonorrhoeae Isolates and International Reference Strains, Including Those with High-Level Antimicrobial Resistance: Potential Treatment Option for Gonorrhea? Antimicrobial Agents and Chemotherapy, 56, 2739-2742. https://doi.org/10.1128/AAC.00036-12

[140] Mallegol, J., Fernandes, P., Seah, C., Guyard, C. and Melano, R.G. (2013) Determination of in Vitro Activities of Solithromycin at Different pHs and Its Intracellular Activity against Clinical Isolates of Neisseria Gonorrhoeae from a Laboratory Collection. Antimicrobial Agents and Chemotherapy, 57, 4322-4328. https://doi.org/10.1128/AAC.00564-13

[141] Still, J.G., Schranz, J., Degenhardt, T.P., Scott, D., Fernandes, P., Gutierrez, M.J. and Clark, K. (2011) Pharmacokinetics of Solithromycin (CEM-101) after Single or Multiple Oral Doses and Effects of Food on Single-Dose Bioavailability in Healthy Adult Subjects. Antimicrobial Agents and Chemotherapy, 55, 1997-2003. https://doi.org/10.1128/AAC.01429-10

[142] Jensen, J.S., Fernandes, P. and Unemo, M. (2014) In Vitro Activity of the New Fluoroketolide Solithromycin (CEM-101) against Macrolide-Resistant and -Susceptible Mycoplasma Genitalium Strains. Antimicrobial Agents and Chemotherapy, 58, 3151-3156. https://doi.org/10.1128/AAC.02411-14

[143] Kobayashi, Y., Wada, H., Rossios, C., Takagi, D., Higaki, M., Mikura, S., Goto, H., Barnes, P.J. and Ito, K. (2013) A Novel Macrolide Solithromycin Exerts Superior Anti-Inflammatory Effect via NF- $\kappa \mathrm{B}$ Inhibition. The Journal of Pharmacology and Experimental Therapeutics, 345, 76-84. https://doi.org/10.1124/jpet.112.200733

[144] Keelan, J.A., Kemp, M.W., Payne, M.S., Johnson, D., Stock, S.J., Saito, M., Fernandes, P. and Newnham, J.P. (2014) Maternal Administration of Solithromycin, a New, Potent, Broad-Spectrum Fluoroketolide Antibiotic, Achieves Fetal and Intra-Amniotic Antimicrobial Protection in a Pregnant Sheep Model. Antimicrobial Agents and Chemotherapy, 58, 447-454. https://doi.org/10.1128/AAC.01743-13

[145] Rodvold, K.A., Gotfried, M.H., Still, J.G., Clark, K. and Fernandes, P. (2012) Comparison of Plasma, Epithelial Lining Fluid, and Alveolar Macrophage CONCENTRATIONS of Solithromycin (CEM-101) in Healthy Adult Subjects. Antimicrobial Agents and Chemotherapy, 56, 5076-5081. https://doi.org/10.1128/AAC.00766-12

[146] Oldach, D., Clark, K., Schranz, J., Das, A., Craft, J.C., Scott, D., Jamieson, B.D. and Fernandes, P. (2013) Randomized, Double-Blind, Multicenter Phase 2 Study Comparing the Efficacy and Safety of Oral Solithromycin (CEM-101) to Those of Oral Levofloxacin in the Treatment of Patients with Community-Acquired Bacterial Pneumonia. Antimicrobial Agents and Chemotherapy, 57, 2526-2534. https://doi.org/10.1128/AAC.00197-13

[147] Jiang, J.W., Sun, Y., Nie, Y., Zhi, H.J., Zhang, X.J., Li, X., Sun, H.P. and You, Q.D. 
(2013) Synthesis and Antibacterial Evaluation of a Novel Series of 10-Hydroxyl Ketolide Derivatives. Bioorganic \& Medicinal Chemistry Letters, 23, 3452-3457. https://doi.org/10.1016/j.bmcl.2013.03.057

[148] Glassford, I., Teijaro, C.N., Daher, S.S., Weil, A., Small, M.C., Redhu, S.K., Colussi, D.J., Jacobson, M.A., Childers, W.E., Buttaro, B., Nicholson, A.W., MacKerell, A.D., Jr, Cooperman, B.S. and Andrade, R.B. (2016) Ribosome-Templated Azide-Alkyne Cycloadditions: Synthesis of Potent Macrolide Antibiotics by in Situ Click Chemistry. Journal of the American Chemical Society, 138, 3136-3144.

https://doi.org/10.1021/jacs.5b13008

[149] Zhao, Z.H., Zhang, X.X., Jin, L.L., Yang, S. and Lei, P.S. (2018) Synthesis and Antibacterial Activity of Novel Ketolides with 11,12-Quinoylalkyl Side Chains. Bioorganic \& Medicinal Chemistry Letters, 28, 2358-2363. https://doi.org/10.1016/j.bmcl.2018.06.039

[150] Seiple, I.B., Zhang, Z., Jakubec, P., Langlois-Mercier, A., Wright, P.M., Hog, D.T., Yabu, K., Allu, S.R., Fukuzaki, T., Carlsen, P.N., Kitamura, Y., Zhou, X., Condakes, M.L., Szczypiński, F.T., Green, W.D. and Myers, A.G. (2016) A Platform for the Discovery of New Macrolide Antibiotics. Nature, 533, 338-345. https://doi.org/10.1038/nature17967

[151] Sugimoto, T., Shimazaki, Y., Manaka, A., Tanikawa, T., Suzuki, K., Nanaumi, K., Kaneda, Y., Yamasaki, Y. and Sugiyama, H. (2012) Synthesis and Antibacterial Activity of 6-O-(Heteroaryl-Isoxazolyl) Propynyl 2-Fluoro Ketolides. Bioorganic \& Medicinal Chemistry Letters, 22, 5739-5743. https://doi.org/10.1016/j.bmcl.2012.06.092

[152] Magee, T.V., Ripp, S.L., Li, B., Buzon, R.A., Chupak, L., Dougherty, T.J., Finegan, S.M., Girard, D., Hagen, A.E., Falcone, M.J., Farley, K.A., Granskog, K., Hardink, J. R., Huband, M.D., Kamicker, B.J., Kaneko, T., Knickerbocker, M.J., Liras, J.L., Marra, A., Medina, I. and Flanagan, M.E. (2009) Discovery of Azetidinyl Ketolides for the Treatment of Susceptible and Multidrug Resistant Community-Acquired Respiratory Tract Infections. Journal of Medicinal Chemistry, 52, 7446-7457. https://doi.org/10.1021/jm900729s

[153] Li, B., Magee, T.V., Buzon, R.A., Widlicka, D.W., Bill, D.R., Brandt, T. and Flanagan, M.E. (2012) Process Development of a Novel Azetidinyl Ketolide Antibiotic. Organic Process Research \& Development, 16, 788-797.

https://doi.org/10.1021/op300064b

[154] Burger, M.T., Lin, X., Chu, D.T., Hiebert, C., Rico, A.C., Seid, M., Carroll, G.L., Barker, L., Huh, K., Langhorne, M., Shawar, R., Kidney, J., Young, K., Anderson, S., Desai, M.C. and Plattner, J.J. (2006) Synthesis and Antibacterial Activity of Novel C12 Vinyl Ketolides. Journal of Medicinal Chemistry, 49, 1730-1743. https://doi.org/10.1021/jm051157a

[155] Anwar, H.F., Andrei, M. and Undheim, K. (2017) Synthesis of Clarithromycin Ketolides Chemically Modified at the Unreactive C10-Methyl Group. Bioorganic \& Medicinal Chemistry, 25, 2313-2326. https://doi.org/10.1016/j.bmc.2017.02.041

[156] Awan, A., Brennan, R.J., Regan, A.C. and Barber, J. (1995) Conformational Analysis of the Erythromycin Analogues Azithromycin and Clarithromycin in Aqueous Solution and Bound to Bacterial Ribosomes. Journal of the Chemical Society, Chemical Communications, No. 16, 1653-1654. https://doi.org/10.1039/c39950001653 Awan, A., Brennan, R.J., Regan, A.C. and Barber, J. (2000) The Conformations of the Macrolide Antibiotics Erythromycin A, Azithromycin and Clarithromycin in Aqueous Solution: A ${ }^{1} \mathrm{H}$ NMR Study. Journal of the Chemical Society, Perkin Transaction 2, 1645-1652. https://doi.org/10.1039/b003000g 
[157] Bertho, G., Gharbi-Benarous, J., Delaforge, M. and Girault, J.P. (1998) Transferred Nuclear Overhauser Effect Study of Macrolide-Ribosome Interactions: Correlation between Antibiotic Activities and Bound Conformations. Bioorganic \& Medicinal Chemistry, 6, 209-221. https://doi.org/10.1016/S0968-0896(97)10028-1

[158] Bertho, G., Gharbi-Benarous, J., Delaforge, M., Lang, C., Parent, A. and Girault, J.P. (1998) Conformational Analysis of Ketolide, Conformations of RU 004 in Solution and Bound to Bacterial Ribosomes. Journal of Medicinal Chemistry, 41, 3373-3386. https://doi.org/10.1021/jm970852i

[159] Evrard-Todeschi, N., Gharbi-Benarous, J., Gaillet, C., Verdier, L., Bertho, G., Lang, C., Parent, A. and Girault, J.P. (2000) Conformations in Solution and Bound to Bacterial Ribosomes of Ketolides, HMR 3647 (Telithromycin) and RU 72366: A New Class of Highly Potent Antibacterials. Bioorganic \& Medicinal Chemistry, 8, 1579-1597. https://doi.org/10.1016/S0968-0896(00)00091-2

[160] LeTourneau, N., Vimal, P., Klepacki, D., Mankin, A. and Melman, A. (2012) SYNTHESIS and Antibacterial Activity of Desosamine-Modified Macrolide Derivatives. Bioorganic \& Medicinal Chemistry Letters, 22, 4575-4578. https://doi.org/10.1016/j.bmcl.2012.05.110

[161] Jia, L., Yan, M., Shen, Y., Qin, Y., Qiang, S. and Ma, S. (2017) Synthesis and Antibacterial Evaluation of Novel 11-O-Carbamoyl Clarithromycin Ketolides. Bioorganic \& Medicinal Chemistry Letters, 27, 3693-3697. https://doi.org/10.1016/j.bmcl.2017.07.017

[162] Teng, Y., Qin, Y., Song, D., Liu, X., Ma, Y., Zhang, P. and Ma, S. (2020) A Novel Series of 11-O-Carbamoyl-3-O-Descladinosyl Clarithromycin Derivatives Bearing 1,2,3Triazole Group: Design, Synthesis and Antibacterial Evaluation. Bioorganic \& Medicinal Chemistry Letters, 30, Article ID: 126850. https://doi.org/10.1016/j.bmcl.2019.126850

[163] Kolwas, J. (1981) Erythromycin A Carbonate. Drugs Today, 17, 26-27

[164] Champney, W.S. and Tober, C.L. (1999) Superiority of 11,12 Carbonate Macrolide Antibiotics as Inhibitors of Translation and 50S Ribosomal Subunit Formation in Staphylococcus Aureus Cells. Current Microbiology, 38, 342-348. https://doi.org/10.1007/PL00006814

[165] Fernandes, P.B., Baker, W.R., Freiberg, L.A., Hardy, D.J. and McDonald, E.J. (1989) New Macrolides Active against Streptococcus Pyogenes with Inducible or Constitutive Type of Macrolide-Lincosamide-Streptogramin B Resistance. Antimicrobial Agents and Chemotherapy, 33, 78-81. https://doi.org/10.1128/AAC.33.1.78

[166] Anderson, M., Bergeron, J., Masamune, H., Norcia, M., Retsema, J. and Sutcliffe, J. (1995) Activity of CP-227,182, a Des-Cladinose 3 Keto Clarithromycin Derivative, in Cell Free Peptide Synthesis and Ribosome Binding Studies. In Abstracts Frontiers in Translation Conference, 145.

[167] Bojarska-Dahlig H. (1990) Hepatotoxicity of Macrolide Antibiotics. The Journal of Antimicrobial Chemotherapy, 25, 475-477. https://doi.org/10.1093/jac/25.3.475

[168] Chen, X., Xu, P., Xu, Y., Liu, L., Liu, Y., Zhu, D. and Lei, P. (2012) Synthesis and Antibacterial Activity of Novel Modified 5-O-Desosamine Ketolides. Bioorganic \& Medicinal Chemistry Letters, 22, 7402-7405. https://doi.org/10.1016/j.bmcl.2012.10.064

[169] Grant, E.B., Guiadeen, D., Abbanat, D., Foleno, B.D., Bush, K. and Macielag, M.J. (2006) Synthesis and Antibacterial Activity of 6-O-Heteroarylcarbamoyl-11,12Lactoketolides. Bioorganic \& Medicinal Chemistry Letters, 16, 1929-1933. https://doi.org/10.1016/j.bmcl.2005.12.097 
[170] Hunziker, D., Wyss, P.C., Angehrn, P., Mueller, A., Marty, H.P., Halm, R., Kellenberger, L., Bitsch, V., Biringer, G., Arnold, W., Stämpfli, A., Schmitt-Hoffmann, A. and Cousot, D. (2004) Novel Ketolide Antibiotics with a Fused Five-Membered Lactone Ring-Synthesis, Physicochemical and Antimicrobial Properties. Bioorganic \& $\mathrm{Me}$ dicinal Chemistry, 12, 3503-3519. https://doi.org/10.1016/j.bmc.2004.04.039

[171] Pavlović, D., Mutak, S., Andreotti, D., Biondi, S., Cardullo, F., Paio, A., Piga, E., Donati, D. and Lociuro, S. (2014) Synthesis and Structure-Activity Relationships of $\alpha$-Amino- $\gamma$-Lactone Ketolides: A Novel Class of Macrolide Antibiotics. ACS Medicinal Chemistry Letters, 5, 1133-1137. https://doi.org/10.1021/ml500279k

[172] Trivedi, B., Deshpande, P., Tadiparthi, R., Gupta, S., Diwakar, S., Pawar, S. and Mishra, A. (2015) Ketolide Compounds. US Patent No. 9175031.

[173] Satav, J.S., Takalkar, S.S., Kulkarni, A.M., Bhagwat, S.S. and Patel, M.V. (2016) WCK 4873 (Nafithromycin): In Vitro and in Vivo Activity of Novel Lactone-Ketolide, against Clinically Relevant S. Pneumoniae (SPN) Resistotypes and Methicillin-Sensitive S. Aureus (MSSA), abstr Saturday-456. Abstr ASM Microbe.

[174] Farrell, D.J., Sader, H.S., Rhomberg, P.R., Flamm, R.K. and Jones, R.N. (2016) In Vitro Activity of WCK 4873 (Nafithromycin) against Resistant Subsets of Streptococcus Pneumoniae from a Global Surveillance Program (2014), abstr Saturday-455. Abstr ASM Microbe, Boston, MA, American Society for Microbiology, Washington DC.

Flamm, R.K., Rhomberg, P.R. and Sader, H.S. (2017) In Vitro Activity of the Novel Lactone Ketolide Nafithromycin (WCK 4873) against Contemporary Clinical Bacteria from a Global Surveillance Program. Antimicrobial Agents and Chemotherapy, 61, e01230-17. https://doi.org/10.1128/AAC.01230-17

[175] Dubois, J., Dubois, M. and Martel, J.F. In Vitro Activity of a Novel Lactone Ketolide WCK 4873 against Resistant Legionella Pneumophila, abstr Sunday-477. Abstr ASM Microbe, Boston, MA. American Society for Microbiology, Washington DC. Dubois, J., Dubois, M. and Martel, J.F. In Vitro Activity of a Novel Lactone ketolide WCK 4873 against Resistant Streptococcus Pneumoniae and Haemophilus Influenzae, abstr Sunday-475. Abstr ASM Microbe, Boston, MA. American Society for Microbiology, Washington DC.

Dubois, J., Dubois, M. and Martel, J.F. In Vitro Intracellular Activity of a novel lactone ketolide WCK 4873 against Resistant Legionella Pneumophila, abstr Sunday-479. Abstr ASM Microbe, Boston, MA. American Society for Microbiology, Washington DC.

[176] Waites, K.B., Crabb, D.M. and Duffy, L.B. (2016) In Vitro Activities of Investigational Ketolide WCK 4873 (Nafithromycin) and Other Antimicrobial agents against Human Mycoplasmas and Ureaplasmas, abstr Sunday-480. Abstr ASM Microbe, Boston, MA, USA. American Society for Microbiology, Washington DC, USA.

[177] Kohlhoff, S.A. and Hammerschlag, M.R. In Vitro Activities of WCK 4873, a Second Generation Ketolide, against Chlamydia Pneumoniae, abstr Monday-012. Abstr ASM Microbe, Boston, MA. American Society for Microbiology, Washington DC.

[178] Bhagwat, S.S., Takalkar, S.S., Satav, J.S., Kulkarni, A.M., Udaykar, A.P. and Patel, M. V. (2016) WCK 4873 (Nafithromycin): In Vivo Lung Infection Studies against Macrolide-Resistant (MR) and Telithromycin-Non-Susceptible (TEL-NS) Pneumococci. Abstr ASM Microbe.

[179] Hackel, M.A., Karlowsky, J.A., Dressel, D. and Sahm, D.F. (2017) Determination of Disk Diffusion and MIC Quality Control Ranges for Nafithromycin (WCK 4873), a New Lactone-Ketolide. Journal of Clinical Microbiology, 55, 3021-3027. https://doi.org/10.1128/JCM.00972-17 
[180] Deshpande, P., Tadiparthi, R. and Bhavsar, S. (2016) WCK 4873 (INN: Nafithromycin): Structure-Activity Relationship (SAR) Identifying a Lactone Ketolide with Activity against Telithromycin-Resistant (Tel-R) Pneumococci (SPN) and S. Pyogenes (SPY) Abstract: Saturday, 464, ASM Microbe, Boston, MA, USA.

[181] Rodvold, K.A., Gotfried, M.H., Chugh, R., Gupta, M., Friedland, H.D. and Bhatia, A. (2017) Comparison of Plasma and Intrapulmonary Concentrations of Nafithromycin (WCK 4873) in Healthy Adult Subjects. Antimicrobial Agents and Chemotherapy, 61, e01096-17. https://doi.org/10.1128/AAC.01096-17

[182] Iwanowski, P., Bhatia, A., Gupta, M., Patel, A., Chavan, R., Yeole, R. and Friedland, D. (2019) Safety, tolerability and Pharmacokinetics of Oral Nafithromycin (WCK4873) after Single or Multiple Doses and Effects of Food on Single-Dose Bioavailability in Healthy Adult Subjects. Antimicrobial Agents and Chemotherapy, 63, e01253-19. https://doi.org/10.1128/AAC.01253-19

[183] Chavan, R., Zope, V.S., Yeole, R.D. and Patel, M.V. (2016) WCK 4873 (Nafithromycin): Assessment of in Vitro Human CYP Inhibitory Potential of a Novel Lactone-Ketolide. Open Forum Infectious Diseases, 3, 1808. https://doi.org/10.1093/ofid/ofw172.1356

[184] Nomura, T., Yasukata, T., Narukawa, Y. and Uotani, K. (2005) 9-Oxime-3-Ketolides: Modification at the C-11,12-Diol Moiety and Antibacterial Activities against Key Respiratory Pathogens. Bioorganic \& Medicinal Chemistry, 13, 6054-6063. https://doi.org/10.1016/j.bmc.2005.06.003

[185] Nomura, T., Iwaki, T., Yasukata, T., Nishi, K., Narukawa, Y., Uotani, K., Hori, T. and Miwa, H. (2005) A New Type of Ketolides Bearing an N-Aryl-Alkyl Acetamide Moiety at the C-9 Iminoether Synthesis and Structure-Activity Relationships. Bioorganic \& Medicinal Chemistry, 13, 6615-6628. https://doi.org/10.1016/j.bmc.2005.07.041

[186] Nomura, T., Iwaki, T., Narukawa, Y., Uotani, K., Hori, T. and Miwa, H. (2006) A New Type of Ketolide Bearing an N-Aryl-Alkyl Acetamide Moiety at the C-9 Iminoether: Synthesis and Structure-Activity Relationships (2) Bioorganic \& Medicinal Chemistry, 14, 3697-3711. https://doi.org/10.1016/j.bmc.2006.01.036

[187] Nam, G., Kim, Y.S. and Choi, K.I. (2010) Synthesis and Antibacterial Activity of New 9-O-Arylpropenyloxime Ketolides. Bioorganic \& Medicinal Chemistry Letters, 20, 2671-2674. https://doi.org/10.1016/j.bmcl.2010.01.153

[188] Kaneko, T., Mcmillen, W., Sutcliffe, J., Duignan, J. and Petitpas, J. (2000) Synthesis and in Vitro Activity of C2-Substituted C9-Oxime Ketolides. 40th Interscience Conference on Antimicrobial Agents \& Chemotherapy, Toronto, Canada.

[189] Girard, D., Mathieu, H.W., Finegan, S.M., Cimchowski, C.R., Kaneko, T.K. and Mcmillen, W. (2000) In Vivo Antibacterial Activity of CP-654, 743, a New C2-Fluoroketolide against Macrolide-Resistant Pneumococci and Haemophilus Influenzae. 40 th Interscience Conference on Antimicrobial Agents \& Chemotherapy, Toronto, Canada.

[190] Girard, D., Mathieu, H.W., Shepard, R.M., Yee, S., Kaneko, T.K. and Mcmillen, W. (2000) Pharmacokinetics of CP-654,743, a New C2-Fluoro Ketolide Active against Macrolide Resistant Respiratory Pathogens, in Preclinical Species. 40 th Interscience Conference on Antimicrobial Agents \& Chemotherapy, Toronto, Canada.

[191] Xu, Y., Chen, X., Zhu, D., Liu, Y., Zhao, Z., Jin, L., Liu, C. and Lei, P. (2013) Synthesis and Antibacterial Activity of Novel Modified 5-O-Mycaminose 14-Membered Ketolides. European Journal of Medicinal Chemistry, 69, 174-181. https://doi.org/10.1016/j.ejmech.2013.08.023 
[192] Liang, J.H., An, K., Lv, W., Cushman, M., Wang, H. and Xu, Y.C. (2013) Synthesis, Antibacterial Activity and Docking of 14-Membered 9-O-(3-Arylalkyl) Oxime 1 11,12-Cyclic Carbonate Ketolides. European Journal of Medicinal Chemistry, 59, 54-63. https://doi.org/10.1016/j.ejmech.2012.10.054

[193] Tian, J.C., Han, X., Lv, W., Li, Y.X., Wang, H., Fan, B.Z., Cushman, M. and Liang, J.H. (2017) Design, Synthesis and Structure-Bactericidal Activity Relationships of Novel 9-Oxime Ketolides and Reductive Epimers of Acylides. Bioorganic \& Medicinal Chemistry Letters, 27, 1513-1524. https://doi.org/10.1016/j.bmcl.2017.02.041

[194] Ma, C.X., Lv, W., Li, Y.X., Fan, B.Z., Han, X., Kong, F.S., Tian, J.C., Cushman, M. and Liang, J.H. (2019) Design, Synthesis and Structure-Activity Relationships of Novel Macrolones: Hybrids of 2-Fluoro 9-Oxime Ketolides and Carbamoyl Quinolones with Highly Improved Activity against Resistant Pathogens. European Journal of Medicinal Chemistry, 169, 1-20. https://doi.org/10.1016/j.ejmech.2019.02.073

[195] Kobrehel, G., Lazarevski, G. and Vinkovic, M. (PLIVA) (1999) Novel 3,6-Hemiketals from the Class of 9a-Azalides. WO-09920639.

[196] Denis, A. and Agouridas, C. (1998) Synthesis of 6-O-Methyl-Azithromycin and Its Ketolide Analogue via Beckmann Rearrangement of 9(E)-6-O-Methyl-Erythromycin Oxime. Bioorganic \& Medicinal Chemistry Letters, 8, 2427-2432. https://doi.org/10.1016/S0960-894X(98)00402-8

[197] Or, Y.S., Keyes, R.F. and Ma, Z. (2004) 9a-Azalides with Antibacterial Activity. US Patent No. 6764996.

[198] Mutak, S. (2007) Azalides from Azithromycin to New Azalide Derivatives. The Journal of Antibiotics, 60, 85-122. https://doi.org/10.1038/ja.2007.10

[199] Jia, L., Wang, Y., Wang, Y., Qin, Y., Hu, C., Sheng, J. and Ma, S. (2018) Synthesis and Antibacterial Evaluation of Novel 11-O-Aralkylcarbamoyl-3-ODescladinosylclarithromycin Derivatives. Bioorganic \& Medicinal Chemistry Letters, 28, 2471-2476. https://doi.org/10.1016/j.bmcl.2018.06.006

[200] Myers, A.G., Seiple, I.B. and Zhang, Z. (2018) Macrolides with Modified Desosamine Sugars and Uses Thereof. US Patent No. 20180066008A1.

[201] Janas, A. and Przybylski, P. (2019) 14- and 15-Membered Lactone Macrolides and Their Analogues and Hybrids: Structure, Molecular Mechanism of Action and Biological Activity. European Journal of Medicinal Chemistry, 182, ArticleID: 111662. https://doi.org/10.1016/j.ejmech.2019.111662

[202] Sugimoto, T., Tanikawa, T., Suzuki, K. and Yamasaki, Y. (2012) Synthesis and Structure-Activity Relationship of a Novel Class of 15-Membered Macrolide Antibiotics Known as “11a-Azalides". Bioorganic \& Medicinal Chemistry, 20, 5787-5801. https://doi.org/10.1016/j.bmc.2012.08.007

[203] Rossiter, S.E., Fletcher, M.H. and Wuest, W.M. (2017) Natural Products as Platforms to Overcome Antibiotic Resistance. Chemical Reviews, 117, 12415-12474. https://doi.org/10.1021/acs.chemrev.7b00283

[204] Lazarevski, G., Kobrehel, G. and Kelneric, Z. (PLIVA) (1994) 15-Membered Lactams Ketolides with Antibacterial Activity. WO 99/51616.

[205] Alihodzic, S., Fajdetic, A., Kobrehel, G., Lazarevski, G., Mutak, S., Pavlovic, D., Stimac, V., Cipcic, H., Kramaric, M. D., Erakovic, V., Hasenöhrl, A., Marsic, N. and Schoenfeld, W. (2006) Synthesis and Antibacterial Activity of Isomeric 15-Membered Azalides. The Journal of Antibiotics, 59, 753-769. https://doi.org/10.1038/ja.2006.100

[206] Pavlović, D. and Mutak, S. (2010) Synthesis and Structure-Activity Relationships of Novel 8a-Aza-8a-Homoerythromycin A Ketolides. Journal of Medicinal Chemistry, 
53, 5868-5880. https://doi.org/10.1021/jm100711p

Pavlović, D., Fajdetić, A. and Mutak, S. (2010) Novel Hybrids of 15-Membered 8aand 9a-Azahomoerythromycin A Ketolides and Quinolones as Potent Antibacterials. Bioorganic \& Medicinal Chemistry, 18, 8566-8582.

https://doi.org/10.1016/j.bmc.2010.10.024

[207] Xu, G., Tang, D., Gai, Y., Wang, G., Kim, H., Chen, Z. and Wang, Z. (2010) An Efficient Large-Scale Synthesis of EDP-420, a First-in-Class Bridged Bicyclic Macrolide (BBM) Antibiotic Drug Candidate. Organic Process Research \& Development 2010, 14 504-510. https://doi.org/10.1021/op900228u

[208] Bermudez, L.E., Motamedi, N., Chee, C., Baimukanova, G., Kolonoski, P., Inderlied, C., Aralar, P., Wang, G., Phan, L.T. and Young, L.S. (2007) EDP-420, a Bicyclolide (Bridged Bicyclic Macrolide), Is Active against Mycobacterium avium. Antimicrobial Agents and Chemotherapy, 51, 1666-1670.

https://doi.org/10.1128/AAC.01303-06

[209] Sato, T., Tateda, K., Kimura, S., Iwata, M., Ishii, Y. and Yamaguchi, K. (2011) In Vitro Antibacterial Activity of Modithromycin, a Novel 6,11-Bridged Bicyclolide, Against Respiratory Pathogens, Including Macrolide-Resistant Gram-Positive Cocci. Antimicrobial Agents and Chemotherapy, 55, 1588-1593.

https://doi.org/10.1128/AAC.01469-10

[210] Jacobsson, S., Golparian, D., Phan, L.T., Ohnishi, M., Fredlund, H., Or, Y.S. and Unemo, M. (2015) In Vitro Activities of the Novel Bicyclolides Modithromycin (EDP-420, EP-013420, S-013420) and EDP-322 against MDR Clinical Neisseria Gonorrhoeae Isolates and International Reference Strains. The Journal of Antimicrobial Chemotherapy, 70, 173-177. https://doi.org/10.1093/jac/dku344

[211] Jiang, L.J., Wang, M. and Or, Y.S. (2009) Pharmacokinetics of EDP-420 after Ascending Single Oral Doses in Healthy Adult Volunteers. Antimicrobial Agents and Chemotherapy, 53, 1786-1792. https://doi.org/10.1128/AAC.01270-08

[212] Maglio, D., Sun, H.K., Patel, T., Banevicius, M.A., Nightingale, C.H., Arya, A., Wang, G., Chen, Z., Phan, L.T. and Nicolau, D.P. (2014) Pharmacodynamic Profiling of Modithromycin: Assessment in a Pneumococcal Murine Pneumonia Model. International Journal of Antimicrobial Agents, 43, 540-546. https://doi.org/10.1016/j.ijantimicag.2014.01.029

[213] Kim, I.J., Liu, T., Qiu, Y.L., Phan, L.T. and Or, Y.S. (2009) 6,11-Bicyclolides: Bridged Biaryl Macrolide Derivatives. US Patent No. 20090075915A1

[214] Kashimura, M., Asaka, T., Misawa, Y., Matsumoto, K. and Morimoto, S. (2001) Synthesis and Antibacterial Activity of the Tricyclic Ketolides TE-802 and Its Analogs. The Journal of Antibiotics, 54, 664-678.

[215] Kashimura, M., Matsumoto, K. and Asaka, T. (2004) Conformational Analysis of Tricyclic Ketolide TE-802 and Its Analogues. Heterocycles, 63, 2057-2070. https://doi.org/10.3987/COM-04-10161

[216] Ono, T., Kashimura, M., Suzuki, K., Oyauchi, R., Miyachi, J., Ikuta, H., Kawauchi, H., Akashi, T., Asaka, T. and Morimoto, S. (2004) In Vitro and in Vivo Antibacterial Activities of the Tricyclic Ketolide TE-802 and Its Analogs. The Journal of Antibiotics, 57, 518-527.

[217] Phan, L.T., Or, Y.S., Chen, Y., Chu, D.T.W., Ewing, P., Nilius, A.M., Bui, M.H., Raney, P.M., Hensey-Rudloff, D., Mitten, M., Henry, R.F. and Plattner, J.J. (1998) 2-Substituted Tricyclic Ketolides, New Antibacterial Macrolides. 38th Interscience Conference on Antimicrobial Agents and Chemotherapy, San Diego, CA.

[218] Phan, L.T., Or, Y.S., Spina, K.P., Chen, Y., Tufano, M., Chu, D.T.W., Nilius, A.M., 
Bui, M.H. and Plattner, J.J. (1996) Tetracyclic Ketolides: New Antibacterial Macrolides. Synthesis and In Vitro Antibacterial Activity. 36 th Interscience Conference on Antimicrobial Agents and Chemotherapy, Toronto.

[219] Or, Y.S., Phan, L.T., Chu, D.T., Spina, K.P., Hallas, R., Elliott, R.L. and Tufano, M. (2001) Tricyclic Erythromycin Derivatives. US. Patent No. 6274715B1. 